Florida International University FIU Digital Commons

6-27-2013

\title{
The Role of Teleost Grazers in a Relatively Pristine Seagrass Ecosystem
}

Cindy Bessey

Florida International University, cbessey@fiu.edu

DOI: $10.25148 /$ etd.FI13080527

Follow this and additional works at: https:// digitalcommons.fiu.edu/etd

Part of the Behavior and Ethology Commons, and the Biology Commons

\section{Recommended Citation}

Bessey, Cindy, "The Role of Teleost Grazers in a Relatively Pristine Seagrass Ecosystem" (2013). FIU Electronic Theses and Dissertations. 911.

https://digitalcommons.fiu.edu/etd/911

This work is brought to you for free and open access by the University Graduate School at FIU Digital Commons. It has been accepted for inclusion in FIU Electronic Theses and Dissertations by an authorized administrator of FIU Digital Commons. For more information, please contact dcc@fiu.edu. 


\section{FLORIDA INTERNATIONAL UNIVERSITY}

Miami, Florida

\section{THE ROLE OF TELEOST GRAZERS IN A RELATIVELY PRISTINE SEAGRASS ECOSYSTEM}

A dissertation submitted in partial fulfillment of the

requirements for the degree of

DOCTOR OF PHILOSOPHY

in

BIOLOGY

by

Cindy Bessey

2013 
To: Dean Kenneth G. Furton

College of Arts and Sciences

This dissertation, written by Cindy Bessey, and entitled The Role of Teleost Grazers in a Relatively Pristine Seagrass Ecosystem, having been approved in respect to style and intellectual content, is referred to you for judgment. We have read this dissertation and recommend that it be approved.

William T. Anderson

Deron E. Burkepile

James W. Fourqurean

Date of Defense: June 27, 2013

Michael R. Heithaus, Major Professor

The dissertation of Cindy Bessey is approved.

Dean Kenneth G. Furton

College of Arts and Sciences

Dean Lakshmi N. Reddi

University Graduate School

Florida International University, 2013 
(C) Copyright 2013 by Cindy Bessey

All rights reserved. 


\section{ACKNOWLEDGMENTS}

I would like to thank the numerous professors, assistants, colleagues, collaborators, businesses, and agencies in both the United States and Australia that have provided support, guidance, opportunities, and stimulating scientific discussions. It would be desirable to acknowledge each and every one by name, but to do so may lead to omissions that I would regret. However, I would like to specifically thank my major professor, Dr. Michael R. Heithaus. He provided me with not only the opportunity to accomplish a goal that I had pondered for over a decade, but also the support, guidance and funding to successfully complete that goal. The professional and personal outcomes that have resulted from this opportunity have been among the most rewarding of all my experiences. 


\title{
ABSTRACT OF THE DISSERTATION \\ THE ROLE OF TELEOST GRAZERS IN A RELATIVELY PRISTINE SEAGRASS \\ ECOSYSTEM
}

\author{
by
}

Cindy Bessey

Florida International University, 2013

Miami, Florida

\section{Professor Michael R. Heithaus, Major Professor}

Trophic downgrading of ecosystems necessitates a functional understanding of trophic cascades. Identifying the presence of cascades, and the mechanisms through which they occur, is particularly important for seagrass meadows, which are among the most threatened ecosystems on Earth. Shark Bay, Western Australia provides a model system to investigate the potential importance of top-down effects in a relatively pristine seagrass ecosystem. The role of megagrazers in the Shark Bay system has been previously investigated, but the role of macrograzers (i.e., teleosts), and their importance relative to megagrazers, remains unknown. The objective of my dissertation was to elucidate the importance of teleost macrograzers in transmitting top-down effects in seagrass ecosystems. Seagrasses and macroalgae were the main food of the abundant teleost Pelates octolineatus, but stable isotopic values suggested that algae may contribute a larger portion of assimilated food than suggested by gut contents. Pelates octolineatus is at risk from numerous predators, with pied cormorants (Phalacrocorax varius) taking the majority of tethered P. octolineatus. Using a combination of fish trapping and unbaited underwater video surveillance, I found that the relative abundance of $P$. octolineatus was 
greater in interior areas of seagrass banks during the cold season, and that the mean length of $P$. octolineatus was greater in these areas compared to along edges of banks. Finally, I used seagrass transplants and exclosure experiments to determine the relative effect of megagrazers and macrograzers on the establishment and persistence of three species of seagrasses in interior microhabitats. Teleost grazing had the largest impact on seagrass species with the highest nutrient content, and these impacts were primarily observed during the warm season. My findings are consistent with predictions of a behaviorally-mediated trophic cascade initiated by tiger sharks (Galeocerdo cuvier) and transmitted through herbivorous fishes and their predators. 


\section{TABLE OF CONTENTS}

CHAPTER

PAGE

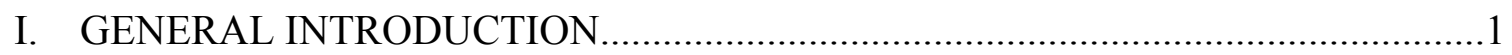

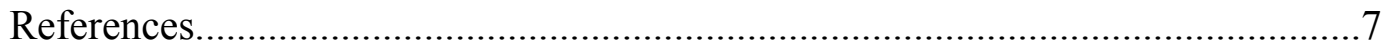

II. FEEDING ECOLOGY OF AN ABUNDANT TELEOST HERBIVORE IN A

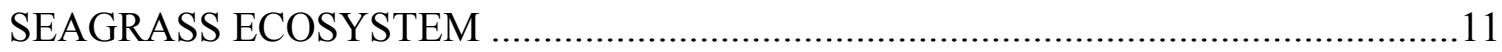

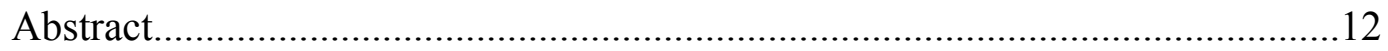

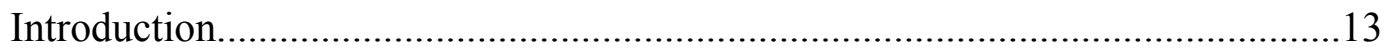

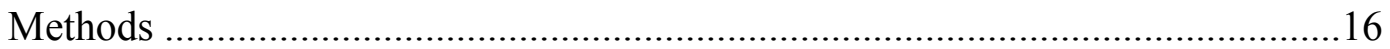

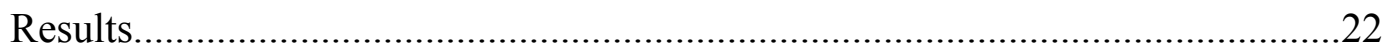

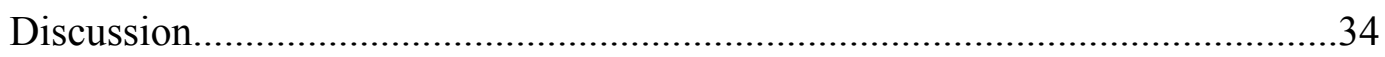

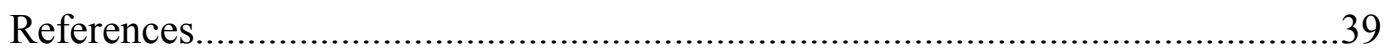

III. ALARM CALL PRODUCTION AND TEMPORAL VARIATION IN PREDATOR ENCOUNTER RATES FOR A FACULTATIVE TELEOST GRAZER IN A

RELATIVELY PRISTINE SEAGRASS ECOSYSTEM..................................................46

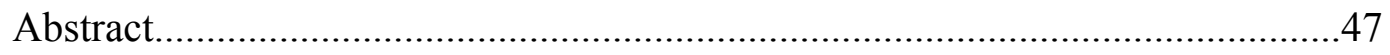

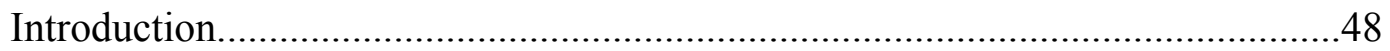

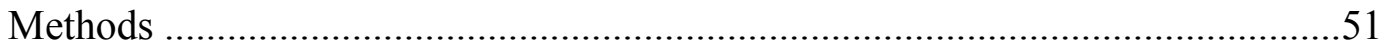

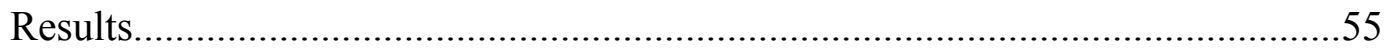

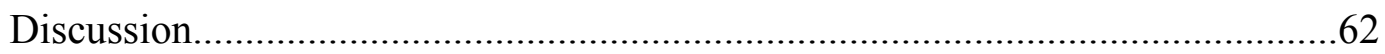

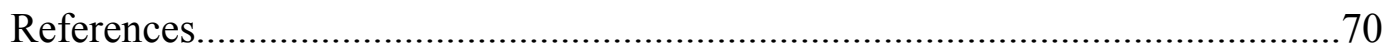

IV. SPATIAL AND TEMPORAL VARIATION IN THE ABUNDANCE OF THREE

DOMINANT TELEOSTS WITHIN A SEAGRASS ECOSYSTEM................................75

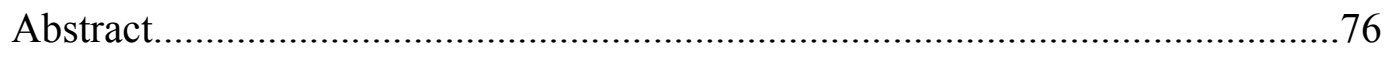

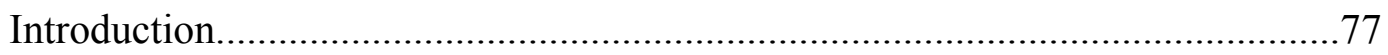

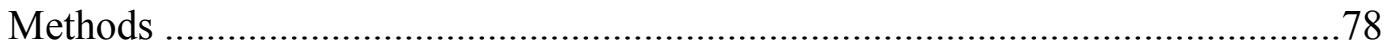

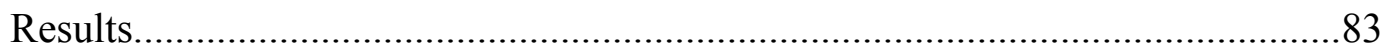

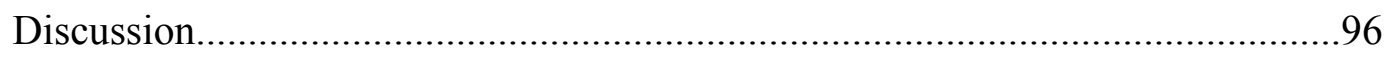

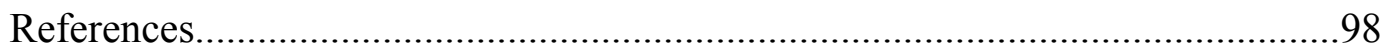

V. GUILD-DEPENDENT IMPACTS OF MARINE HERBIVORES ON AN INTACT

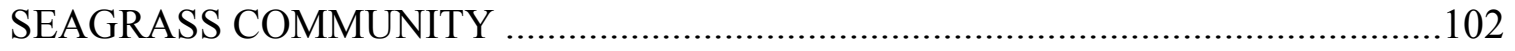

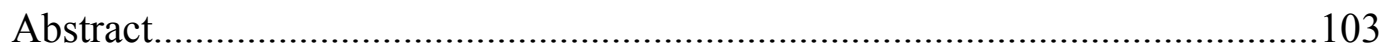

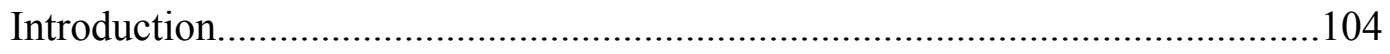

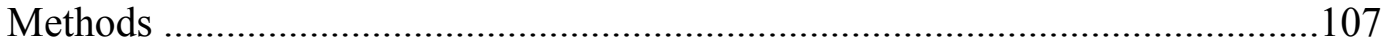

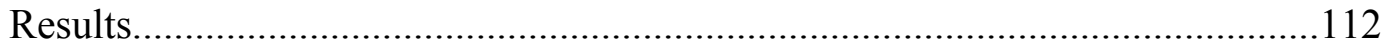

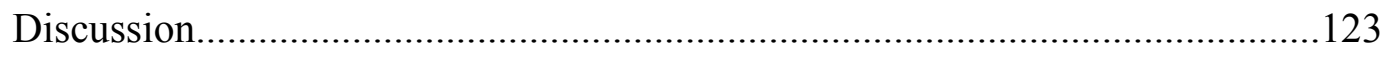

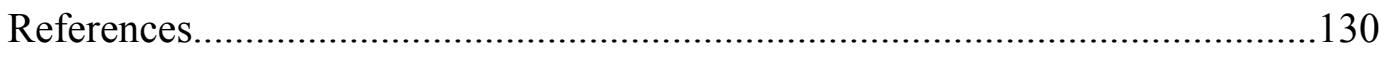


VI. GENERAL CONCLUSIONS.

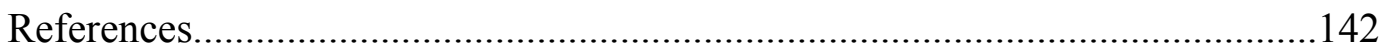

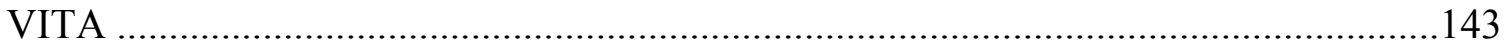




\section{LIST OF TABLES}

TABLES

PAGE

2.1 Quantitative analysis of gut and stomach content for P. octolineatus caught in less

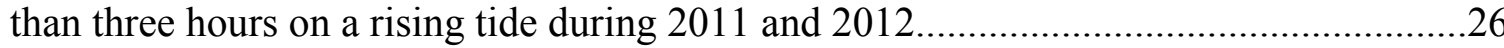

2.2. Primary producer $\delta^{15} \mathrm{~N}$ and $\delta^{13} \mathrm{C}$ stable isotope values (mean and standard deviation).

2.3 Pelates octolineatus stable isotope values did not vary with season, microhabitat, or their interaction.

3.1 Logistic regression results of parameters affecting the probability of western striped trumpeter predation events during tether trials. .56

3.2 Number of western striped trumpeters preyed upon by each identified predator during both the cold and warm period. .58

3.3: Number of trials where a predator was observed but did not successfully attack the tethered fish during 40 analyzed trials (10/depth/period) . .60

4.1 Composition and number of species caught in traps by season and microhabitat.......84

4.2 Zero-inflated model results of parameters affecting $P$. octolineatus catch per trap deployment.

4.3 Zero-inflated model results of parameters affecting $M$. chinensis catch per trap deployment

4.4 Table 4.4: Zero-inflated model results of parameters affecting P.vitta catch per trap deployment.

4.5 Zero-inflated model results for the effect of microhabitat on P. octolineatus sightings during URUVS in the cold season. .89

4.6 Zero-inflated model results for the effect of microhabitat on $M$. chinensis sightings during URUVS in the cold season.

4.7 Zero-inflated model results for the effect of microhabitat on $P$. vitta sightings during

URUVS in the cold season. .91

4.8 ANOVA results for possible predictors of fish length .93 
5.1 Repeated measures nested ANOVA results for subplot Open of the 4-month (September 2009 - January 2010) exclosure study where three different tropical seagrass species were transplanted into different grazer treatment plots and monitored during the warm season. Analysis was conducted to determine differences in open subplots where plot levels are a) full control; no exclusions, b) megagrazers not excluded, and c) megagrazers excluded.

5.2 Repeated measures nested ANOVA results for the 4-month exclosure study where three different seagrass species were transplanted into different grazer treatment plots and monitored during the warm season (September 2009 - January 2010). Plot levels are megagrazers not excluded and megagrazers excluded, and subplot levels are macrograzers not excluded (Open), cage control (CC), and cages (ME - excludes fish grazing)

5.3 Repeated measures nested ANOVA results for the short-term exclosure study where three different tropical seagrass species were transplanted into different grazer treatment plots and monitored over 18 days during both the warm (April 2011) and cold (July 2011) season. Plot levels are megagrazers not excluded and megagrazers excluded, and subplot levels are macrograzers excluded (Open), cage control, (CC), and cages (ME excludes fish grazing) 


\section{TABLE OF FIGURES}

FIGURES

PAGE

2.1 Mean percent cover of seagrass and algae species at sites in edge $(n=19)$ and interior $(n=30)$ microhabitats. Error bars are \pm SE.

2.2 Frequency of occurrence of individual primary producer taxa in Pelates octolineatus diets (edge; $\mathrm{n}=53$, interior; $\mathrm{n}=69$ ).

2.3 Inter-annual variation in the relationship between length and A) gut content to body mass and B) stomach content to body mass ratios.

2.4 Number of individuals consuming different proportions of primary producers and animal matter. Insert picture displays a fish containing 100\% seagrass in gut (entire petri dish) and stomach contents (bottom half of petri dish).

2.5 Isotopic values of Pelates octolineatus, potential prey items, and Chelonia mydas within the study site. Closed symbols are data from 2010-2012. Open symbols represent data from 2005-2009 (Heithaus unpublished data; C. mydas data from Burkholder et al. 2011).

2.6 Effects of total length on A) $\delta^{15} \mathrm{~N}$, B) $\delta^{13} \mathrm{C}$ and C) proportion of seagrass in stomach contents of Pelates octolineatus.

2.7 Convex hulls for dietary habits of Pelates octolineatus and Chelonia mydas with mean and standard deviation in $\delta^{15} \mathrm{~N}$ and $\delta^{13} \mathrm{C}$ for seagrasses (dark green), red algae (red), brown algae (brown) and green algae (light green).........................................................35

3.1 Video screen shots identifying predators of tethered western striped trumpeters

3.2 A) Cormorant density (birds $/ \mathrm{km}^{2}$ ) per period corresponding with timing of tether trials, and B) activity rate (mean time fish spent swimming versus stationary - $\mathrm{s} / \mathrm{min}$ ) of tethered fish by period. Letters represent differences between groups (A: Student t-test, $\mathrm{t}=-4.08, \mathrm{p}=0.01$; B: Mann-Whitney Test, $\mathrm{W}=681, \mathrm{p}=0.03$ ).

3.3 Vocalization occurrence of western striped trumpeter per minute at random intervals compared to at attack. Letters represent differences between groups based on a Mann-

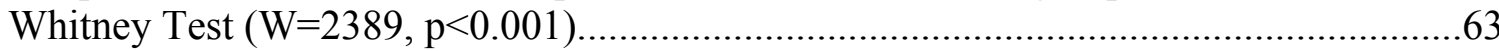

4.1 Size (fork length) distributions of three common teleosts..........................................92

4.2 Spatial and temporal patterns of fork length of $P$. octlineatus...................................94

4.3 Seasonal variation in the sizes of M. chinensis and P. vitta ......................................95 
5.1 Diagram of the experimental design showing replicate sites (1-3) within one interior seagrass bed, where each site contains megagrazer treatment plots that A) are full controls; no exclusions, B) megagrazers no excluded, and C) megagrazers excluded. Each plot was $2.6 \times 3.0 \mathrm{~m}$, which consisted of nine $30 \mathrm{~cm} \times 30 \mathrm{~cm}$ macrograzer treatment subplots, spaced $50 \mathrm{~cm}$ apart. Macrograzers exclusion cage (ME) subplots contain 30 x 30 $\mathrm{x} 20 \mathrm{~cm}$ tall cages made of $\sim 1 \mathrm{~cm}$ wire mesh. Cage controls $(\mathrm{CC})$ are the same as macrograzer cages but have open ends enabling fish to access the subplot and still encounter the presence of a cage, and open subplots (Open) have no cage.

5.2 a) Surface view of a megagrazers excluded plot $(2.6 \times 3.0 \mathrm{~m})$ containing nine subplots $(30 \mathrm{~cm} \times 30 \mathrm{~cm})$. b) Side view of transplanted seagrass species under a cage control (CC) within a megagrazers excluded plot. c) Side view of a cage control subplot (CC) in a megagrazers not excluded plot, and d) Side view of an open control (Open) subplot surrounded by a macrograzer exclusion cage subplot (ME) and cage controls (CC) within a megagrazers not excluded plot. 110

5.3 Mean seagrass shoot counts for both megagrazer and macrograzer treatments during the 4-month exclosure study (Sept.2009-Jan.2010). Error bars are \pm SE.

5.4 Removal rates of seagrasses exposed to grazing after four months of macrograzer exclusion. Error bars are $\pm \mathrm{SE}$

5.5 Mean seagrass shoot counts for both megagrazer and macrograzer treatments during the short-term exclosure study in the warm season (April 2011). Error bars are \pm SE...121

5.6 Mean seagrass shoot counts for both megagrazer and macrograzer treatments during the short-term exclosure study in the cold season (July 2011). Error bars are \pm SE.......122

5.7 Proportional change of seagrass shoot counts during a) the 4-month exclosure study ending in the warm season, $b$ ) the short-term exclosure study in the warm season, and c) the short-term exclosure study in the cold season. Error bars are \pm SE. Bars with the same letters are not significantly different based on post-hoc Tukey's test 
CHAPTER I:

GENERAL INTRODUCTION 
Trophic cascades can be critical in structuring communities, but the ultimate mechanisms driving cascades and variation in their strength and prevalence continue to be debated (Schmitz et al. 2004, Shurin et al. 2006, Heithaus et al. 2008a, Terborgh and Estes 2010). The indirect effects of top predators on plants, transmitted through herbivores, are a result of both consumptive and non-consumptive effects of top predators, and their interaction. Although many studies assume that density changes in plant populations in response to variation in top predator abundance are the result of predator-inflicted mortality on herbivores (Hairston et al. 1960, Carpenter et al. 1985, Bascompte et al. 2005), it is now understood that these changes are the result of both consumptive and non-consumptive effects of predators, and many "classic" examples of consumptive effects may actually be a consequence of non-consumptive mechanisms (Peckarsky et al. 2008). In fact, recent studies suggest that non-consumptive effects (or "risk effects"), including behaviorally-mediated indirect interactions (BMII), may be equally or more important than indirect effects initiated by direct consumption of prey (Dill et al. 2003, Schmitz et al. 2004, Preisser et al. 2005, Creel and Christianson 2008, and Heithaus et al. 2008b, 2009). The greater importance of risk effects partially stems from their influence on a larger proportion of a prey population and the possibility of compensatory reproduction in response to predator-inflicted mortality (Schmitz 2008, Heithaus et al. 2009).

The nature and relative importance of risk effects, however, are context dependent, and may by influenced by the energy state of prey, life-history characteristics of both predators and their prey (e.g. predator hunting mode and prey escape tactics), community diversity, habitat heterogeneity or the interaction of these factors (Schmitz 
2008, Heithaus et al. 2009). Therefore, an understanding of the natural history of predator-prey interactions is required for predicting community dynamics. Most studies to date which incorporate the importance of risk effects have been conducted in mesocosms using relatively simple communities, whereas studies in large-scale systems are relatively unexplored (but see Ripple and Beschta 2003, 2004, Creel and Christianson 2008), especially in marine settings. Furthermore, studies of cascades, especially those driven by risk effects, tend to focus on only one module of a community or overall indirect effects, and do not account for the possibility that multiple indirect pathways may serve to attenuate or amplify overall indirect effects of predators.

Understanding marine trophic cascades stemming from both consumptive and risk effects as well as their interaction has become critically important because of the unprecedented declines in top predators resulting from disturbances such as overfishing and habitat destruction (Pauly et al. 1998, Myers and Worm 2005, Myers et al. 2007). Global fisheries statistics from 1950-1994 indicate that the mean trophic level of species groups declined, resulting in a shift from landings of large piscivorous fishes towards smaller fishes (Pauly et al. 1998). Likewise, shark-targeted surveys conducted annually since 1972 off the eastern coast of the United States demonstrate large declines in many species, including $87 \%, 97 \%$ and $99 \%$ declines over the course of the survey for sandbar (Carcharhinus plumbeus), tiger (Galeocerdo cuvier), and smooth hammerhead sharks (Sphyrna zygaena), respectively (Myers et al. 2007). Currently, the ecosystem effects of these predator declines remain largely unexplored and in many cases controversial (e.g. Heithaus et al. 2008a). Although structurally different, lessons from terrestrial systems indicate that the resulting habitat shifts of herbivores that result from the removal or 
reintroduction of top predators into a system can have substantial consequences on the resulting plant community (Schmitz et al. 2000, Ripple and Beschta 2003, 2004).

Seagrasses are the foundation of highly productive ecosystems with primary productivity levels that are comparable to the world's leading agricultural crops (Phillips and McRoy 1980). Seagrasses also provide critical habitat in the form of shelter and foraging sites for many fishes and invertebrates (Connolly 1994). However, seagrass meadows are among the most threatened ecosystems on earth and are estimated to be disappearing at a rate of $110 \mathrm{~km}^{2} \mathrm{yr}^{-1}$ since 1980 (Waycott et al. 2009). The global decline has prompted an increased interest in understanding the factors driving the dynamics of seagrass communities in order to protect, or restore, these crucial habitats and the organisms they support. Multiple stressors, such as eutrophication, physical disturbances, and climate change, contribute to seagrass declines (Hughes et al. 2004, Orth et al. 2006). However, the disruption of top-down processes as a potential driver of seagrass declines is less appreciated (Heck and Valentine 2006).

Historically, top-down effects in seagrass ecosystems had been largely ignored because it was widely assumed that few animals directly consume seagrasses, and of those that do, their ingestion is infrequent and inconsequential. Heck and Valentine (2006) referred to this view as a "gross oversimplification" that may neglect the importance of seagrass-herbivore interactions. It is possible that the role of herbivory has been largely overlooked because the disappearance of large grazers, including fishes, predates and preconditions modern ecological investigations (Jackson et al. 2001). Recent studies show that the intensity of herbivory can vary widely both temporally and spatially, with anywhere from $3 \%$ to $100 \%$ of seagrass net primary production entering 
the food web via the grazing pathway (Heck and Valentine 2006). Furthermore, megagrazers, such as green turtles (Chelonia mydas) and dugongs (Dugong dugon), can affect seagrass community structure, biomass and nutritional attributes (Preen 1995, Aragones 2000 for a review, Nakoaka et al 2002, Moran and Bjorndal 2005). For example, dugong grazing can remove more than $50 \%$ of seagrass production, resulting in regrowth of nitrogen-rich species and overall higher nitrogen levels in individual plants (de Iongh et al 1995, Masini et al. 2001, Aragones et al. 2006). Herbivorous fishes also can consume seagrasses. For example, two recent studies show that herbivorous fish can consume substantial proportions of seagrass production (e.g. $80 \%$ in the Florida Keys: Kirsch et al. 2002, and 73\% off the northeast coast of Spain: Tomas et al. 2005). Understanding the interactions of teleosts in regulating seagrass dynamics, therefore, may be important for protection of seagrass communities.

To understand the role of teleost mesograzers in regulating seagrass communities, it is important to gain an understanding of their patterns of habitat use, abundance, and foraging behavior under relatively pristine conditions. Since teleost grazers are prey for higher trophic level species (e.g. larger fish, birds and marine mammals), it is important to understand spatial and temporal variation in susceptibility to predators (Paine 1980, Werner et al. 1983, Lima and Dill 1990, Turner and Mittelbach 1990). Predation-sensitive shifts in habitat use are critical in shaping the spatiotemporal patterns of grazing by large bodied herbivores in terrestrial and marine settings (Ripple and Beschta 2004, Wirsing et al. 2007), and, therefore, it is likely that predation also will influence teleost grazing and impacts on seagrasses. 
Shark Bay is perhaps one of the last remaining relatively pristine seagrass ecosystems. The area was listed as a World Heritage Area in 1991 by United Nations Educational, Scientific and Cultural Organization and satisfies all four of the natural criteria required for listing: biological diversity, ecological processes, earth history, and natural beauty. The high densities of tiger sharks, piscivores, dugongs and fishes (see Heithaus et al. 2012 for a review), combined with low anthropogenic impacts to seagrass beds and minimal fishing pressures, allows for detailed studies of diverse ecological processes in a relatively pristine system. Shark Bay is a model system for studying predator-prey interactions, particularly the importance of risk effects of top predators in marine ecosystems, due to the seasonal variation in tiger shark abundance, and the variation in the subsurface landscape - in particular the presence of discrete shallow seagrass banks separated by deep channels - which allows for replicate sampling of habitat types. The structure of the Shark Bay food web also provides a model system for investigating the dynamics of communities that feature parallel pathways for transmission of behaviorally mediated indirect effects with differing numbers of steps.

The objective of my dissertation was to elucidate the importance of top-down effects in regulating seagrass communities - particularly those deriving from risk effects of top predators and mediated by herbivorous teleosts. I start out in Chapter II using a combination of primary producer surveys, gut content, and stable isotope analyses to quantify diets of the western striped trumpeter (Pelates octolineatus) - the most abundant facultative herbivorous fish in the Shark Bay study site. I also compare the isotopic niche of $P$. octolineatus to that of a megaherbivore in the study system (green turtles, Chelonia mydas) for which stomach content data is not available. I then, in Chapter III, identify 
potential predators of $P$. octolineatus using tethering trials and investigate the seasonal and spatial patterns of predator encounter rates. In Chapter IV, I elucidate patterns of abundance of $P$. octolineatus, as well as two additional teleost species which are abundant in the study site, using a combination of fish trapping and continuous underwater video surveillance. In Chapter V, I used seagrass transplants and exclosure experiments to determine the relative effect of megagrazers and macrograzers on the establishment and persistence of three species of seagrasses. Finally, in Chapter VI, I conclude by relating my findings to the predictions of a behaviorally-mediated trophic cascade, initiated by tiger sharks (Galeocerdo cuvier) and transmitted through herbivorous fishes and their predators.

\section{References}

Aragones, L.V. 2000. A review of the role of the green turtle in tropical seagrass ecosystems. In: Pilcher N., and G. Ismail. (eds) Sea turtles of the Indo-Pacific: research management and conservation. ASEAN Academic Press, London, p.69-85.

Aragones, L.V., I.R. Lawler, W.J. Foley, and H. Marsh. 2006. Dugong grazing and turtle cropping: grazing optimization in tropical seagrass systems? Oecologia 149: 635647.

Bascompte, J.C., C.J. Melian, and E. Sala. 2005. Interaction strength combinations and the overfishing of a marine food web. Proc. Nat. Acad. Sci. USA. 102: 5443-5447.

Carpenter, S.R., J.F. Kitchell, and J.R. Hodgson. 1985. Cascading trophic interactions and lake productivity. BioScience. 35(10): 634-639.

Connolly, R.M. 1994. A comparison of fish assemblages from seagrass and unvegetated areas of a southern Australian estuary. Aust. J. Mar. Freshw. Res. 45: 1033-1044.

Creel, S., and D. Christianson. 2008. Relationships between direct predation and risk effects. Trends. Ecol. Evol. 23(4): 194-201. 
de Iongh, H.H., B.J. Wenno, and E. Meelis. 1995. Seagrass distribution and seasonal biomass changes in relation to dugong grazing in the Moluccas, East Indonesia. Aquat. Bot. 50: 1-19.

Dill, L.M., M.R. Heithaus, and C.J. Walters. 2003. Behaviorally mediated indirect interactions in marine communities and their conservation implications. Ecology. 84(5): 1151-1157.

Hairston, N.G., F.E. Smith, and L.B. Slobodkin. 1960. Community structure, population control, and competition. Am. Nat. 94(879): 421-425.

Heck, K.L.Jr., and J.F. Valentine. 2006. Plant-herbivore interactions in seagrass meadows. J. Exp. Mar. Biol. Ecol. 330: 420-436.

Heithaus, M.R., A. Frid, A.J. Wirsing, and B. Worm. 2008a. Predicting ecological consequences of marine top predator declines. Trends. Ecol. Evol. 23(4): 202-210.

Heithaus, M.R., A. J. Wirsing, J.A. Thomson, and D.A. Burkholder. 2008b. A review of lethal and non-lethal effects of predators on adult marine turtles. J. Exp. Mar. Biol. Ecol., 356: 43-51.

Heithaus, M.R., A.J. Wirsing, D. Burkholder, J. Thomson, and L.M. Dill. 2009. Towards a predictive framework for predator risk effects: the interaction of landscape features and prey escape tactics. J. Anim. Ecol. 78:556-562.

Heithaus, M.R., A.J. Wirsing, and L.M. Dill. 2012. The ecological importance of intact top-predator populations: a synthesis of 15 years of research in a seagrass ecosystem. Mar. Freshw. Res., 63(11): 1039-1050.

Hughes, A.R., K.J. Bando, L.F. Rodriquez, and S.L. Williams. 2004. Relative effects of grazers and nutrients on seagrasses: a meta-analysis approach. Mar. Ecol. Prog. Ser. 282: 87-99.

Jackson, J.B.C., M.X. Kirby, W.H. Berger, K.A. Bjornadal, L.W. Botsford, B.J. Borque, R.H. Bradbury, R. Cooke, J. Erlandson, J.A. Estes, T.P. Hughes, S. Kidwell, C.B. Lange, H.S. Lenihan, J.M. Pandolfi, C.H. Peterson, R.S. Steneck, M.J. Tegner, and R.R. Warner. 2001. Historical overfishing and the recent collapse of coastal ecosystems. Science 146: 629-638.

Kirsch, K.D., J.F. Valentine, and K.L.Jr. Heck. 2002. Parrotfish grazing on turtlegrass Thalassia testudinum: evidence for the importance of seagrass consumption in food web dynamics of the Florida Keys National Marine Sactuary. Mar. Ecol. Prog. Ser. 227: 7185.

Lima, S.L., and L.M. Dill. 1990. Behavioral decisions made under the risk of predation: a review and prospectus. Can. J. Zool. 68: 619-640. 
Masini, R.J., P.K. Anderson, and A.J. McComb. 2001. A Halodule-dominated community in a subtropical embayment: physical environment, productivity, biomass, and impact of dugong grazing. Aquat. Bot. 71: 179-197

Myers, R.A., and B. Worm. 2005. Extinction, survival or recovery of large predatory fishes. Phil. Trans. R. Soc. B. 360: 13-20.

Myers, R.A., J.K. Baum, T.D. Shepherd, S.P. Powers, and C.H. Peterson. 2007. Cascading effects of the loss of apex predatory sharks from a coastal ocean. Science. 315: 1846-1850.

Moran, K.L., and K.A. Bjorndal. 2005. Simulated green turtle grazing affects structure and productivity of seagrass pastures. Mar. Ecol. Prog. Ser. 305: 235-247.

Nakoaka, M., H. Mukai, and S. Chunhabundit. 2002. Impacts of dugong foraging on benthic animal communities in a Thailand seagrass bed. Ecol. Res. 17: 625-638.

Orth, R.J., T.J.B. Carruthers, W.C. Dennison, C.M. Duarte, J.W. Fourqurean, K.L.Jr. Heck, A.R. Hughes, G.A. Kendrick, W.J. Kenworthy, S. Olyarnik, F.T. Short, M. Waycott, and S.L. Williams. 2006. A global crisis for seagrass ecosystems. BioScience. 56(12): 987-996.

Paine, R.T. 1980. Food webs: linkage, interaction strength and community infrastructure. J. Anim. Ecol. 49(3): 667-685.

Pauly, D., V. Christensen, J.Dalsgaard, R. Froese, and F.Jr. Torres. 1998. Fishing down marine food webs. Science. 279: 860-863.

Peckarsky, B.L., P.A. Abrams, D.I. Bolnick, L.M. Dill, J.H. Grabowski, B. Luttbeg, J. L. Orrock, S.D. Peacor, E.L. Preisser, O.J. Schmitz, and G.C. Trussell. 2008. Revisiting the classics: considering nonconsumptive effects in textbook examples of predator-prey interactions. Ecology 89(9): 2416-2425.

Phillips, R.C., and C.P. McRoy. 1980. Handbook of seagrass biology: an ecosystem perspective. Garland Publishing, Inc., New York.

Preen, A.R. 1995. Impacts of dugong foraging on seagrass habitats: observational and experimental evidence for cultivation grazing. Mar. Ecol. Prog. Ser. 124: 201-213.

Preisser, E.L., D.I. Bolnick, and M.F. Benard. 2005. Scared to death? The effects of intimidation and consumption in predator-prey interactions. Ecology. 86(2): 501-509.

Ripple, W.J., and R.L. Beschta. 2003. Wolf reintroduction, predation risk, and cottonwood recovery in Yellowstone National Park. Forest. Ecol. Manag. 184(1-3): 299-313. 
Ripple, W.J., and R.L. Beschta. 2004. Wolves, elk, willows, and trophic cascades in the upper Gallatin Range of Southwestern Montana, USA. Forest. Ecol. Manag. 200(1-3): 161-181.

Schmitz, O.J. 2008. Effects of predator hunting mode on grassland ecosystem function. Science. 319: 952-954.

Schmitz, O.J., A.P. Hamback, and A.P. Beckerman. 2000. Trophic cascades in terrestrial systems: a review of the effects of carnivore removal on plants. Am. Nat. 155: 141-153.

Schmitz, O.J., V. Krivan, and O. Ovadia. 2004. Trophic cascades: the primacy of traitmediated indirect interactions. Ecol. Lett. 7: 153-163

Shurin, J.B., D.S. Gruner, and H. Hillebrand. 2006. All wet or dried up? Real differences between aquatic and terrestrial food webs. Proc. R. Soc. B. 273: 1-9.

Terborgh, J. and J.A. Estes. 2010. Trophic cascades: predators, prey, and the changing dynamics of nature. Island Press, Washington.

Tomas, F., X. Turon, and J. Romero. 2005. Seasonal and small-scale spatial variability of herbivory pressure on the temperate seagrass Posidonia oceanica. Mar. Ecol. Prog. Ser. 301: 95-107.

Turner, A.M., and G.G. Mittelbach. 1990. Predator avoidance and community structure: interactions among piscivores, planktivores, and plankton. Ecology. 71(6): 2241-2254.

Waycott, M., C.M. Duarte, T.J.B. Carruthers, R.J. Orth, W.C. Dennison, S. Olyarnik, A. Calladine, J.W. Fourqurean, K.L. Heck Jr., A.R. Hughes, G.A. Kendrick, W.J.

Kenworthy, F.T. Short, and S.L. Williams. 2009. Accelerating loss of seagrasses across the globe threatens coastal ecosystems. Proc. Natl. Acad. Sci. U.S.A. 106(30): 1237712381.

Werner, E.E., J.F.Gilliam, D.J.Hall, and G.G. Mittelbach. 1983. An experimental test of the effects of predation risk on habitat use in fish. Ecology. 64(6): 1540-1548.

Wirsing, A.J., M.R. Heithaus, and L.M. Dill. 2007. Fear factor: do dugongs (Dugong dugon) trade food for safety from tiger sharks (Galeocerdo cuvier)? Oecologia. 153: 1031-1040 
CHAPTER II:

FEEDING ECOLOGY OF AN ABUNDANT TELEOST HERBIVORE IN A SEAGRASS ECOSYSTEM 
Abstract

Teleost herbivores can play an important role in the dynamics of algal communities in coral reef systems, as well as seagrass communities near patch reefs. Their roles in seagrass ecosystems not associated with reefs, however, remains unclear. Here, I use a combination of primary producer surveys, gut content analysis, and stable isotope analysis to investigate the role of Pelates octolineatus in the relatively pristine seagrass ecosystem of Shark Bay, Western Australia. Seagrass cover was significantly greater in the middle of shallow banks compared to the edges of banks, but algal cover did not differ spatially. More than $98 \%$ of all fish analyzed had primary producers in both their stomachs and digestive tracts, and primary producers constituted the vast majority of their stomach contents. Fish caught in the middle of seagrass banks contained a greater proportion of algae relative to seagrass. Stable isotopic values suggested that algae may contribute a larger portion of assimilated food across both microhabitats than would be inferred by gut contents. Therefore, algae may be a more important food source than suggested by standing stocks and stomach contents, but ingestion rates and impacts of $P$. octolineatus on seagrasses may be underestimated by stable isotopic approaches. These results, combined with the high abundance of $P$. octolineatus in the study area, suggest that they may play a more important role in facilitating the transfer of primary production to higher trophic levels than previously appreciated. In addition, herbivores in this seagrass ecosystem, including $P$. octolineatus and green turtles (Chelonia mydas) - which occupy a similar isotopic niche, may have greater impacts on seagrass communities than might be predicted from isotopic data alone. 
Introduction

Teleosts are important herbivores in coral reef ecosystems (Lewis 1985, Carpenter 1986, Bruggemann et al. 1994, McClanahan et al. 1994, Hay 1997, Burkepile and Hay 2010). Fish can regulate the distribution, abundance, and community structure of macroalgae on reefs (e.g. Hay 1997), thereby affecting coral-macroalgal interactions (e.g. Hughes 1994). For example, Burkepile and Hay (2010) found that the species-specific effects of teleost herbivores on the colonization and succession of macroalgal communities can be critical in enhancing reef resilience in the face of disturbance. Fish can also control the abundance and species composition of seagrasses near patch reefs (Armitage and Fourqurean 2006). In contrast, the impact of teleost grazers on non-reef seagrass ecosystems remains unclear, and has generally been considered to be low (Thayer et al. 1984, White et al. 2011, Poore et al. 2012). The lack of teleost grazer impacts on seagrass ecosystems has been advanced in part because of the inability of many organisms to digest cellulose, and the estimated poor nutritional value of seagrass as a result of high C:N ratios (Lawrence 1975, Duarte 1990). Although the digestion of primary producers present a challenge to herbivorous fish, grinding dentation, complex alimentary structure, and symbiotic microbes can all assist in the processing of seagrass and algal matter (Choat and Clements, 1998).

Top-down effects in seagrass ecosystems had historically been overlooked, but Heck and Valentine (2006) challenged the view that top-down effects were unimportant in seagrass ecosystems. Indeed, it is possible that the role of herbivory has been largely overlooked because the disappearance of large grazers, including fishes, predates and preconditions modern ecological investigations (Jackson et al. 2001). Recent studies 
show that, in some systems, herbivorous fish can consume substantial proportions of seagrass production (e.g. $80 \%$ in the Florida Keys: Kirsch et al. 2002; 73\% off the northeast coast of Spain: Tomas et al. 2005), and may modify plant traits that indirectly affect other species (Pages et al. 2012). Understanding patterns of teleost herbivory across a range of conditions and contexts in seagrass ecosytems, therefore, is important for predicting responses of seagrass ecosystems to anthropogenic changes.

Such a predictive framework is important because seagrasses are the foundation of highly productive ecosystems that provide critical habitat in the form of shelter and foraging sites (Connolly, 1994), are an important carbon store (Fourqurean et al. 2012), and now are among the most threatened ecosystems on earth (Waycott et al. 2009). Heck and Valentine (2006) described a simple trophic cascade that could potentially lead to die-offs of aquatic vegetation in response to the disruption of top-down processes. They posit that the overharvesting of top predators could lead to increased numbers of their prey; including smaller predatory fishes. An increase in smaller predatory fishes would reduce populations of small grazers of seagrass epiphytes that, in turn, would lead to accumulation of epiphytic algae on leaves that could trigger reductions in seagrass biomass because of shading. Less considered is whether the loss of herbivorous fishes, or their predators, could similarly disrupt seagrass communities.

A critical first step in understanding the effects of teleost grazers on seagrass communities is to quantify spatial and temporal variation in diets. While gut or stomach content analysis is the most common method for elucidating teleost diets and provides detailed information on taxa that are consumed, it provides only a snapshot of an individual's diet and can overlook temporal and spatial variation in diets (see Hyslop 
1980). Complementary insights into trophic position of species can be obtained using stable isotope analysis (SIA), typically expressed as $\delta$ values (Peterson and Fry 1987). SIA provides time-integrated insights into relative trophic level using $\delta^{15} \mathrm{~N}$ values, as well as, the source of carbon supporting diets using $\delta^{13} \mathrm{C}$ values (Peterson and Fry 1987, Layman et al. 2012). However, isotopes do not provide detailed information on the types, or amounts, of food consumed because different food items may have similar isotopic values, and isotopes only reveal assimilated, not consumed, biomass. Therefore, a combination of both stomach content and stable isotope analysis can provide complementary insights into foraging ecology.

Shark Bay, Western Australia, offers a model system in which to investigate the potential impacts of a teleost grazer in a seagrass system; it is one of the largest intact seagrass ecosystems in the world that features large populations of both large and smallbodied herbivores, large piscivores, and top predators (e.g. Heithaus et al. 2012). The teleost Pelates octolineatus (western striped trumpeter) is a mid-sized fish (maximum length of $28 \mathrm{~cm}$ ) that has been observed consuming primary producers (Burkholder et al. 2012). It is the most abundant mid-sized teleost in the Shark Bay long-term study site (Heithaus 2004) and, therefore, could substantially impact seagrass and algal communities. In addition, Shark Bay has been the site of multiple studies investigating the trophic interactions of a diversity of species including megagrazers (green turtles, Chelonia mydas and dugongs, Dugong dugon; Burkholder et al. 2011; Wirsing et al. 2007) facilitating a community-level understanding of trophic interactions. Here, I use a combination of primary producer surveys, gut content and stable isotope analyses to investigate the distribution of potential food sources and spatial and temporal variation in 
trophic interactions of $P$. octolineatus. I also investigated factors affecting gut and stomach fullness of $P$. octolineatus and compared their trophic position and isotopic niche to another grazer in the community; the green turtle.

Methods

Study Site

Shark Bay $\left(25^{\circ} 45^{\prime} \mathrm{S}, 113^{\circ} 44^{\prime} \mathrm{E}\right)$ is a $c a .13,000 \mathrm{~km}^{2}$ subtropical embayment located along the central coast of Western Australia. The study site was in the Eastern Gulf, offshore of Monkey Mia, where water temperatures are generally high $\left(>20^{\circ} \mathrm{C}\right)$ during September to May (warm season) and drop to as low as $12^{\circ} \mathrm{C}$ during June to August (cold season) (Heithaus and Dill 2002). Approximately one-third of Shark Bay $\left(\sim 4,000 \mathrm{~km}^{2}\right)$ is covered by seagrasses. The study site consists of shallow seagrass banks $(1.5-4.5 \mathrm{~m}$ depth) which are seperated by deeper water channels $(6-12 \mathrm{~m}$ depth) that consist primarily of sand-bottoms and occasional seagrass patches (Burkholder et al. 2013a). The shallow seagrass banks can be further subdivided into interior $(<2.5 \mathrm{~m}$ depth and $>75 \mathrm{~m}$ from deep waters $)$ and edge $(2.5 \mathrm{~m}-4.5 \mathrm{~m}$ depth, and $<2.5 \mathrm{~m}$ depth that are within $75 \mathrm{~m}$ from water $>4.5 \mathrm{~m}$ depth) microhabitats (Heithaus and Dill 2006). Both of these shallow microhabitats consist of seagrasses with occasional sand patches. The community is dominated by two slow-growing and large-bodied species (Amphibolis antartica, Posidonia australis), with fast-growing, small-bodied species (Cymodocea angustata, Cymodocea serrulata, Halodule uninervis, Halophila ovalis, Halophila spinulosa, Syringodium isoetifolium; Walker et al. 1988, Burkholder et al. 2013a) occurring less frequently. Benthic communities in Shark Bay also host $c a .160$ taxa of 
macroalgae. Epiphytic red algaes (Rhodophyta) are most speciose but green algaes (Chlorophyta) are the most conspicuous (Kendrick et al. 1990). The brown algae Dictyota furcellata (Heterokontophyta) is also common (Kendrick et al. 1990).

Fish communities inside the study area are dominated by western striped trumpeters (Pelates octolineatus, previously referred to as P. sexlineatus) (Heithaus 2004). Pelates octolineatus is a member of the Terapontidae family (also spelled Teraponidae and Theraponidae), known as grunters, named for the characteristic noise made by the fish within this family. This demersal species is commonly found in estuaries, lagoons, and seagrass/algae beds around the southwestern coast of Australia, from Broome to eastern South Australia (Gomon et al. 1994). They reach a maximum length of approximately $28.0 \mathrm{~cm}$ (Gomon et al.1994). They are reported to be omnivores (Paxton et al. 1989), and egg guarders, with the eggs guarded and fanned by the male parent (Breder and Rosen, 1966). Beyond observations of $P$. octolineatus consuming uprooted primary producers (Burkholder et al. 2012) however, its diet and role in the Shark Bay ecosystem are unexplored.

\section{Field Methods}

To estimate the relative abundance of seagrasses and macroalgae within the study location, I surveyed 49 stations ( $\mathrm{n}=19$ edge, $\mathrm{n}=30$ interior) across three offshore banks between March 24 and July 30, 2012. I focused the survey on the most commonly occurring taxa including five seagrass species (Magnoliophyta: Amphibolis antartica, Posidonia australis, Cymodocea angustata, Halodule uninervis and Halophila ovalis) and four algal taxa (Rhodophyta (red algaes): Laurencia sp., Haliptilon roseum; Heterokontophyta (brown algaes): Dictyota furcellata, and Sargassum sp.). Specific 
stations were determined by stopping the vessel every $400 \mathrm{~m}$ along pre-established transects in each microhabitat of each bank. Each station was surveyed using snorkel or hookah diving. Percent cover was estimated by an observer using a $60 \mathrm{~cm} \times 60 \mathrm{~cm}$ quadrat dropped haphazardly three times at the station. I calculated the average percent cover of each species for the three drops at each station. For every site, I recorded water temperature, water depth, and GPS location. It is important to note that the seagrass/algae surveys were conducted after a "marine heat wave", in which unprecedented water temperatures exceeded more than $3^{\circ} \mathrm{C}$ above the long-term average over an extended area of Shark Bay during February and March 2011 (Pearce et al. 2011).

Samples of seagrass and algae were collected by hand at each site for stable isotope analysis. I collected up to three individuals per species per site if available. I supplemented these samples by haphazardly collecting species of seagrass and algae that were not encountered during quadrat sampling. All samples were stored on ice and frozen upon return to shore until analyzed.

I collected $P$. octolineatus from interior and edge microhabitats during both the warm (February to May) and cold seasons (June to August) of 2010-2012 using rectangular fish traps ( $34 \times 24 \times 21 \mathrm{~cm}$ with $1.2 \times 1.3 \mathrm{~cm}$ mesh) baited with squid. Bait bags prevented the ingestion of bait by fish to avoid biasing gut content analysis. Captured fish were euthanized, stored on ice and immediately frozen upon return to shore until fish could be processed. From euthanized individuals, I collected data on fork length, wet weight, conducted gut and stomach content analyses, and collected muscle 
samples for stable isotope analysis. Fish muscle tissue was collected from each fish just below the dorsal fin ensuring all skin was removed.

\section{Diet analysis}

For each fish, wet weight was determined for gut content collected from the esophagus through to the anus, as well as stomach content alone. Excess water was removed by blotting until dry. The contents were leveled in a petri dish, observed under a dissecting microscope, and the contribution of each food category (primary producers and animal matter) were estimated as a percentage of the total volume of contents. These methods provided an estimate of the relative mass of food types and an approximate mass of each food type (i.e., percentage of total volume $\mathrm{x}$ total weight of stomach contents). These methods were selected because of logistical constraints combined with individual contributions of some food types being too small to be weighed practically (Hyslop 1980). I quantified content of each prey category for all fish sampled using frequency of occurrence and mean estimated volume of contents (Bowen 1996, Jobling et al. 2001).

To determine the identity of primary producers consumed by $P$. octolineatus, I used all available stomachs. I identified all primary producers to lowest taxonomic group possible. I was unable to identify all fragments either because of state of digestion or inability to identify to genus or species; therefore, I included an additional category of "Unknown" within broader taxonomic groups if I could not identify the genus or species.

To provide an indication of fish fullness, I determined the ratio of gut or stomach content to that of body weight as

gut or stomach content wet weight $(\mathrm{g}) \times 100$

fish wet weight $(\mathrm{g})$ 
After normalizing fish content ratio data using a power transformation, I used analysis of variance (ANOVA) to determine if season, microhabitat, year, percent of primary producers observed in gut contents, soak time of trap, or fish length were significant predictors of fish content ratio $(\alpha=0.05)$. I include soak time in the analysis of fish content ratio because I wanted to account for any differences in gut content that may be attributed to differences in the amount of time the fish remained in the trap.

Because I was interested in the potential variation in effects of $P$. octolineatus foraging on different primary producer taxa, I determined the proportion of seagrass relative to algae in all stomach contents of fish that consumed $\geq 80 \%$ primary producers. I used a Kruskal-Wallis test to evaluate the influence of year, season, and microhabitat on the proportion of stomach contents that were seagrass.

Stable Isotope Analysis

All seagrass, algae and fish tissue samples were rinsed in deionized water, dried in a food dehydrator (Ezidri Ultra FD 1000 ) at $60^{\circ} \mathrm{C}$ for a minimum of $24 \mathrm{~h}$, and then ground to a fine powder. For all seagrass samples, I used a razorblade to scrape epiphyte/epibiota from leaves prior to dehydration. I used a subsample of $\sim 6$ specimens of seagrass and algae species to obtain a general overview of their isotopic signature in the study area during the course of the current study, and supplemented these data with data obtained in previous years (2005-2009; Burkholder et al. 2011, Heithaus unpublished data). I analyzed carbon isotopic signatures both with and without acidification procedures for all algae samples (previous studies in the study area showed that acidification was not necessary for seagrass; Burkholder et al. 2011). I used acidified $\delta^{13} \mathrm{C}$ values for taxa when acidification resulted in changes in carbon isotopic values of 
more than $0.3 \%$. Acidification required placing dried powder samples in petri dishes placed in an open chamber of hydrochloric acid for a minimum of 5 days, after which time the samples were again dehydrated and powdered.

No lipid extraction was performed on fish samples because $\mathrm{C}: \mathrm{N}$ ratios indicated that lipid corrections were unnecessary (i.e. C:N<3.5, Post et al. 2007; fish muscle tissue $=3.39 \pm 0.3 \mathrm{SD})$.

For analysis, $0.4-0.7 \mathrm{mg}$ of powdered samples were weighted into tin capsules and analyzed at the Florida International University Stable Isotope Laboratory. I used linear regression to investigate the relationship between stable isotope values and fish length. In addition, using only fish that consumed $\geq 80 \%$ primary producers, I use a linear regression model to investigate the relationship between percent of seagrass in stomach content in relation to fish length. I used a $\delta^{15} \mathrm{~N}-\delta^{13} \mathrm{C}$ stable isotope bi-plot and descriptive statistics of all available data to compare seagrasses to other primary producers in the system. Likewise, I describe the trophic position of $P$. octolineatus relative to green turtles (Chelonia mydas), which are another abundant herbivore in the system. In addition, I calculated the total area of the convex hull encompassing all isotopic values for both consumers to obtain an estimate of overall trophic diversity (Layman et al. 2007).

All statistical analyses were run using R (version 2.14.0; R Development Core Team 2011). 
Results

Primary Producer Surveys

Seagrass cover was significantly greater at interior stations than ones along the edge (Kruskal-Wallis, $\chi^{2}=5.52, \mathrm{df}=1, \mathrm{p}=0.02$, Figure 2.1 ). The pattern of increased seagrass cover at interior stations was driven primarily by the presence of the slowgrowing, large-bodied seagrass, $P$. australis, which was not observed in edge stations. Amphibolis antarctica dominated edge sites, but fast-growing, small-bodied species were also present. Overall algal percent cover did not differ between microhabitats (KruskalWallis, $\left.\chi^{2}=0.17, \mathrm{df}=1, \mathrm{p}=0.68\right)$.

Diet Analysis

A total of 122 fish were collected for gut and stomach content analysis, of which only one stomach was empty. All seagrass and algae species observed during the primary producer survey were also observed in the stomach contents (Figure 2.2), as were species not observed in quadrats (Rhodophyta: Ceramium sp., Chlorophyta: Penicillus sp.). Interestingly, seagrass segments contained within the stomach were not merely small bites but could be long segments of seagrass, often in excess of $3.5 \mathrm{~cm}$ (see photo insert of Figure 2.4). Laurencia sp., unknown red algaes, and Dictyota furcellata were the most frequently encountered food items in the stomach content of $P$. octolineatus. The frequency of occurrence of Laurencia sp. in fish from interior microhabitats was higher than that of those caught in edge microhabitats (Chi-squared test; $\left.\chi^{2}=9.56, \mathrm{df}=1, \mathrm{p}<0.01\right)$. 
Figure 2.1: Mean percent cover of seagrass and algae species at sites in edge $(n=19)$ and interior $(n=30)$ microhabitats. Error bars are \pm SE.

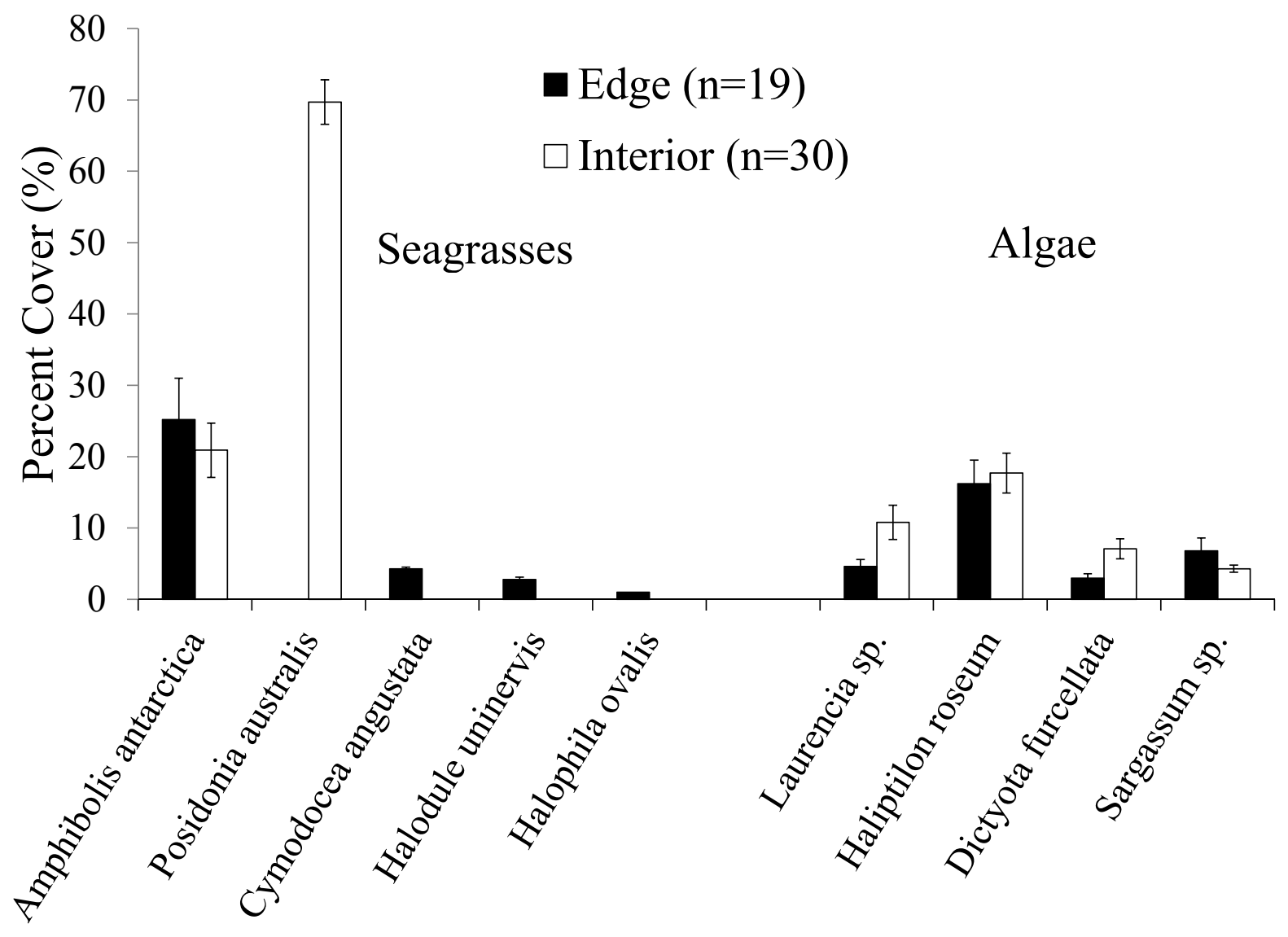


Figure 2.2: Frequency of occurrence of individual primary producer taxa in Pelates octolineatus diets (edge; $\mathrm{n}=53$, interior; $\mathrm{n}=69$ ).

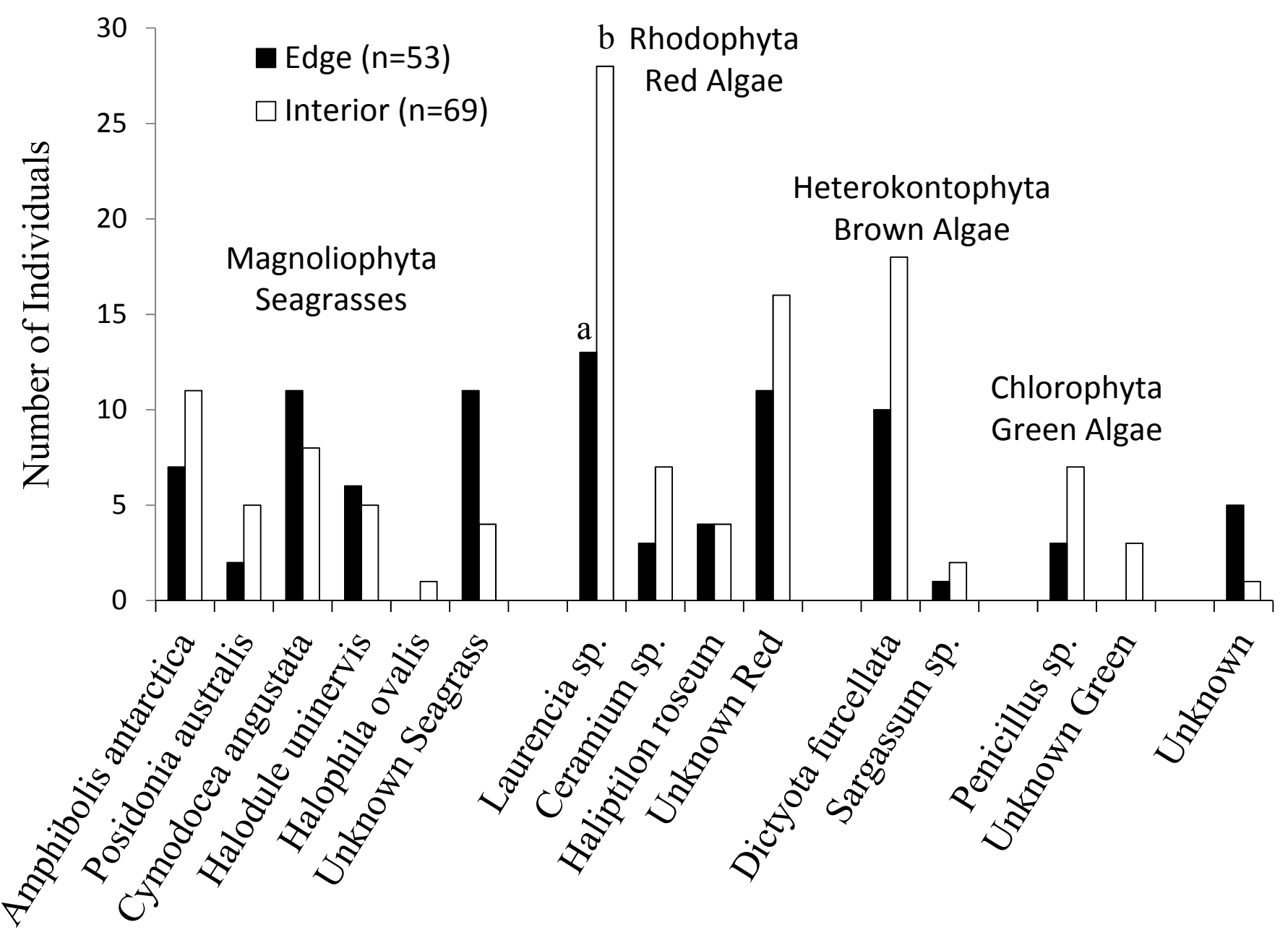


I limited the quantitative analysis of gut content, stomach content, and fish content ratio to only fish caught on a rising tide in less than 3 hours between $8 \mathrm{am}$ and $5 \mathrm{pm}$, and for years in which data was obtained in both the warm and cold seasons (2011 and 2012). Limiting the analysis minimized the influence of soak time and tide on diet analyses (Bowen 1996) and allowed for the analysis of 85 fish for gut content, and 83 fish for stomach content analysis. More than $98 \%$ of all fish analyzed were observed with primary producers in both their gut and stomach (Table 2.1). Primary producers made up the majority of their estimated volume of contents, with animal matter constituting only $8.7 \pm 19 \%$ (mean $\pm \mathrm{SD}$ ) of the gut content, and $10.4 \pm 24 \%$ of the stomach content (Table 2.1). Gut content ratio varied between years $(\mathrm{F}=16.69, \mathrm{df}=1,81, \mathrm{p}<0.001)$, with fish length $(\mathrm{F}=4.47, \mathrm{df}=1,81, \mathrm{p}=0.04)$, and with their interactions $(\mathrm{F}=10.37, \mathrm{df}=1,81, \mathrm{p}<0.01)$, whereas stomach content ratio varied with only year $(\mathrm{F}=15.26, \mathrm{df}=1,79, \mathrm{p}<0.001)$ and fish length $(\mathrm{F}=5.17, \mathrm{df}=1,79, \mathrm{p}=0.03)$. Not only did the gut and stomach content make up a greater percent of overall fish weight in 2011 (gut: 5.59 \pm 0.56 ; stomach: $2.69 \pm 0.36$ ) than in 2012 (gut: $3.24 \pm 0.32$; stomach: $1.50 \pm 0.15$ ), there was also a significant positive relationship between fish content ratio and length during 2011 that was not observed during 2012 (Figure 2.3). There was no variation between years in the amount of animal matter consumed (Kruskal-Wallis, $\chi^{2}=1.14, \mathrm{df}=1, \mathrm{p}=0.29$ ).

The majority of fish $(88 \% ; 72 / 82)$ contained at least $80 \%$ primary producers in their stomach contents; 74\% (60/82) contained only primary producers (Figure 2.4). Using only those with at least $80 \%$ primary producers, I found that fish caught in edge microhabitats contained a significantly greater proportion of seagrass (relative to algae) 
Table 2.1: Quantitative analysis of gut and stomach content for P. octolineatus caught in less than three hours on a rising tide during 2011 and 2012.

\begin{tabular}{|c|c|c|c|}
\hline 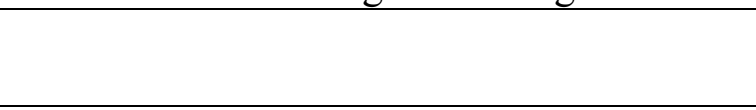 & Total & $\begin{array}{c}\text { Primary } \\
\text { Producers }\end{array}$ & $\begin{array}{l}\text { Animal } \\
\text { Matter }\end{array}$ \\
\hline \multicolumn{4}{|l|}{ Gut Content } \\
\hline Frequency of Occurrence & $\mathrm{n}=85$ & $100 \%$ & $41.2 \%$ \\
\hline Mean Estimated Mass of Contents $(\% \pm \mathrm{SD})$ & & $91.3 \pm 19 \%$ & $8.7 \pm 19 \%$ \\
\hline Gut Content Ratio $( \pm \mathrm{SD})$ & $4.35 \pm 3.1 \%$ & & \\
\hline \multicolumn{4}{|l|}{ Stomach Content } \\
\hline Frequency of Occurrence & $\mathrm{n}=83$ & $98.8 \%$ & $27.7 \%$ \\
\hline Mean Estimated Volume of Contents ( \pm SD) & & $89.6 \pm 24 \%$ & $10.4 \pm 24 \%$ \\
\hline Stomach Content Ratio $( \pm$ SD $)$ & $1.74 \pm 1.6 \%$ & & \\
\hline
\end{tabular}


Figure 2.3: Inter-annual variation in the relationship between length and A) gut content to body mass and B) stomach content to body mass ratios.
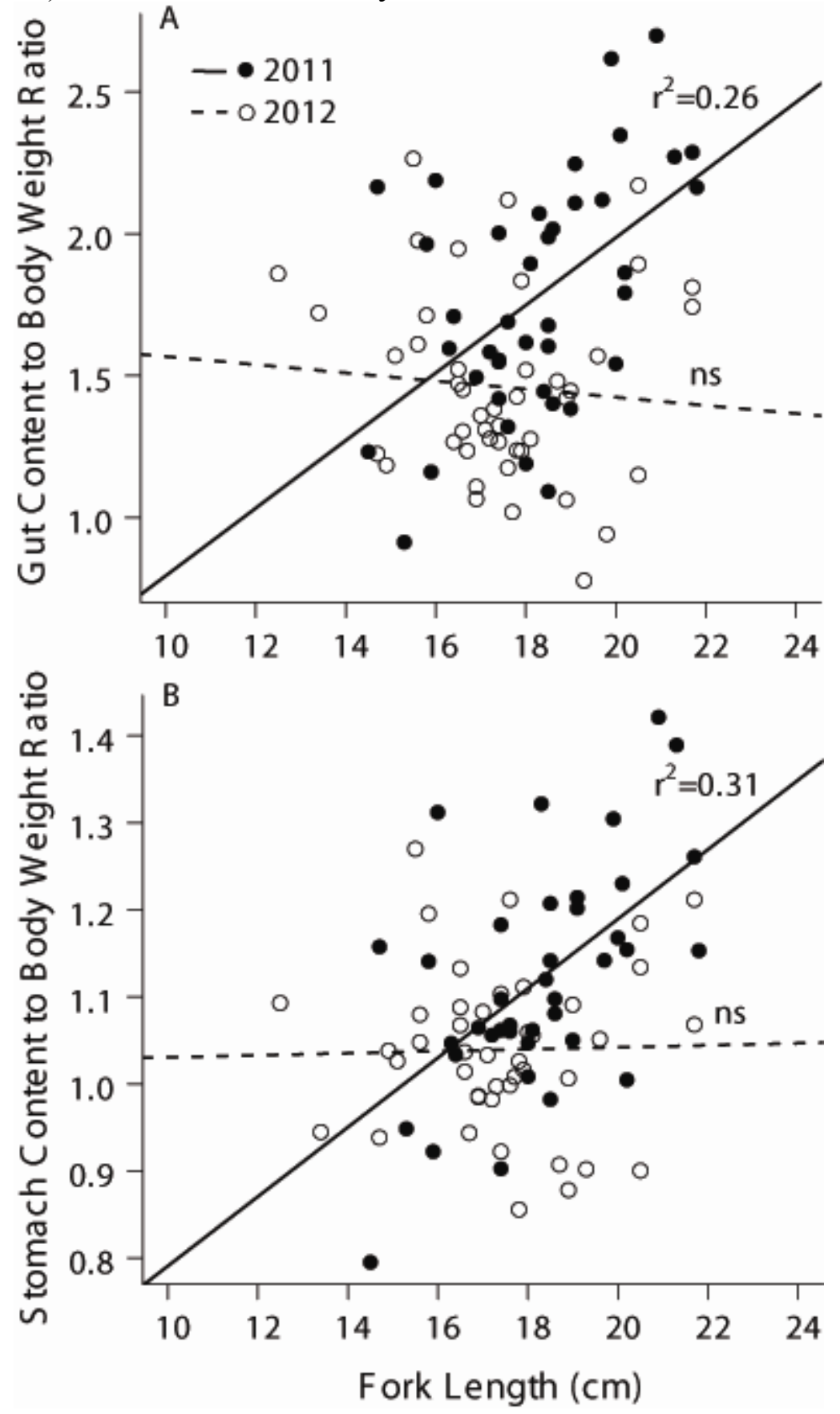
Figure 2.4: Number of individuals consuming different proportions of primary producers and animal matter. Insert picture displays a fish containing 100\% seagrass in gut (entire petri dish) and stomach contents (bottom half of petri dish).

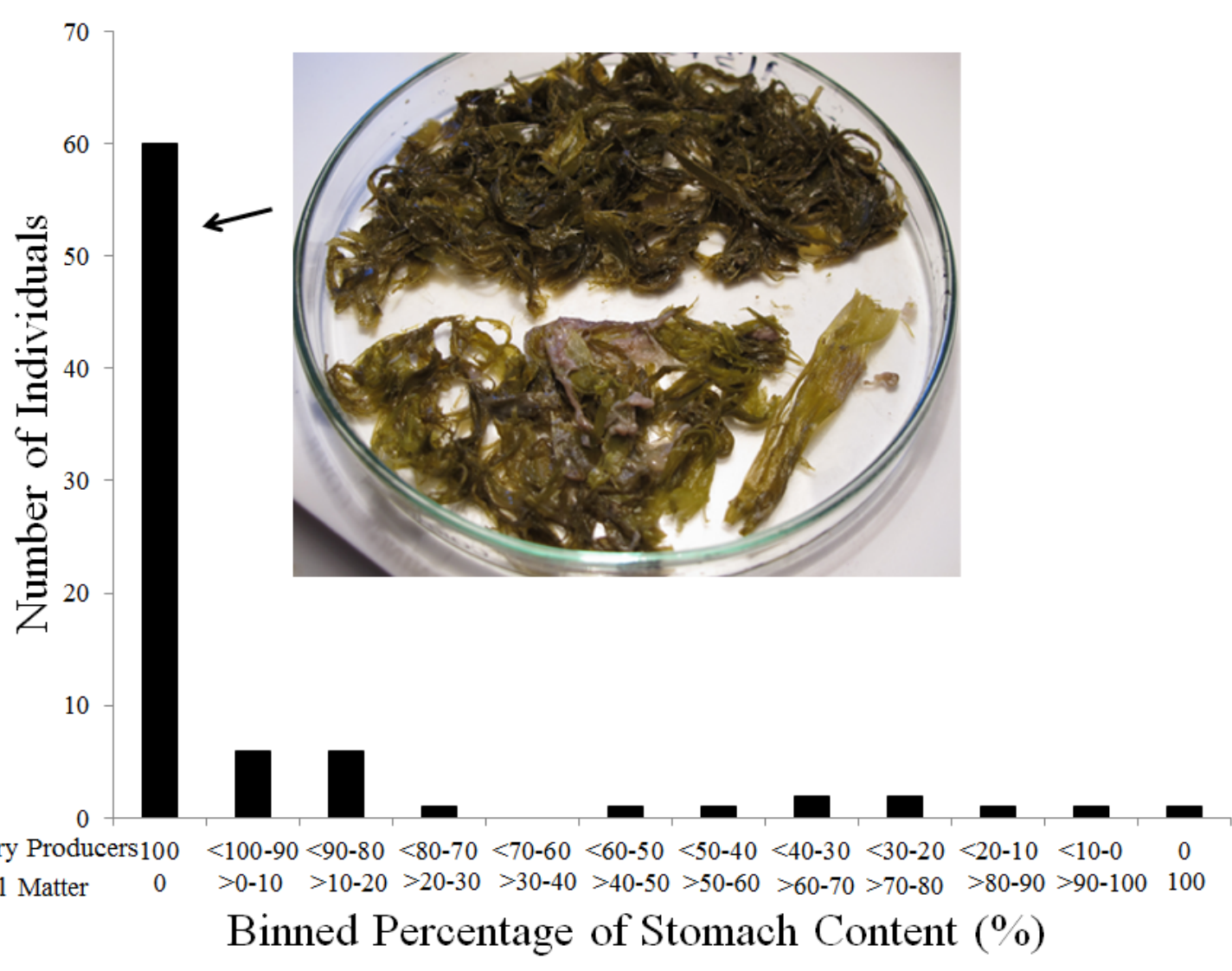


than those in interior areas (edge: $64.2 \pm 41.6 \%$, interior: $39.9 \pm 45.6 \%$, mean $\pm \mathrm{SD}$; KruskalWallis, $\chi^{2}=4.82, \mathrm{df}=1, \mathrm{p}=0.03$ ). The proportion of seagrass in stomachs did not vary between years (Kruskal-Wallis, $\chi^{2}=1.29, \mathrm{df}=1, \mathrm{p}=0.26$ ) or seasons (Kruskal-Wallis, $\left.\chi^{2}=0.17, \mathrm{df}=1, \mathrm{p}=0.68\right)$.

\section{Stable Isotope Analysis}

The mean $\delta^{15} \mathrm{~N}$ of seagrass taxa ranged from $-3.30 \%$ ( $\left.\pm 2.31 \mathrm{SD}\right)$ to $1.99 \%$ ( \pm 0.74$)$, while mean $\delta^{15} \mathrm{~N}$ of algal taxa ranged from $4.84 \%$ o $( \pm 0.60)$ to $5.68 \%$ ( \pm 0.22$)$ for red algae, $3.74 \%$ ( $( \pm 1.17)$ to $5.31 \% 0( \pm 0.71)$ for brown algae, and was $3.69 \% 0( \pm 0.18)$ for the green algae collected (Table 2.2, Figure 2.5). Seagrasses were relatively more enriched in $\delta^{13} \mathrm{C}$ compared to algae; with a range in mean $\delta^{13} \mathrm{C}$ from $-9.79 \%$ ( $\left.\pm 0.87 \mathrm{SD}\right)$ to $-7.58 \%$ o $( \pm 1.62)$ for seagrasses, $-29.47 \%$ o $( \pm 0.97)$ to $-18.03 \%$ o $( \pm 1.60)$ for red algae, $16.99 \%$ o $( \pm 0.67)$ to $-14.30 \%$ o $( \pm 1.40)$ for brown algae, and $-15.86 \%$ o $( \pm 2.17)$ for green algae.

Pelates octolineatus isotope values varied considerably (Figure 2.5). For fish collected from $2010-2012, \delta^{15} \mathrm{~N}$ ranged from $6.1 \%$ to $9.6 \%$ with a mean of $8.5 \pm 0.6 \%$ (SD), and $\delta^{13} \mathrm{C}$ ranged from $-21.3 \%$ to $-10.5 \%$ with a mean of $-16.6 \pm 2.5 \%$ (SD). The range in isotopic values increased only slightly when data from (2005-2009) were included $\left(\delta^{13} \mathrm{C}:-21.3 \%\right.$ to $-9.8 \%, 15.9 \pm 2.5 \%$; $\delta^{15} \mathrm{~N}$ : 5.5 to $9.6,8.5 \pm 0.7 \%$ ). Mean values of $\delta^{15} \mathrm{~N}$ and $\delta^{13} \mathrm{C}$ did not vary across microhabitats, seasons, or with their interactions (Table 2.3). Values of $\delta^{15} \mathrm{~N}$ did not vary with fish length $(\mathrm{F}=0.26, \mathrm{df}=1,93, \mathrm{p}=0.61$;

Figure 2.6A), but $\delta^{13} \mathrm{C}$ increased with fish length $\left(\mathrm{r}^{2}=0.13, \mathrm{~F}=13.77\right.$, $\mathrm{df}=1,93, \mathrm{p}<0.001$; 
Table 2.2: Primary producer $\delta^{15} \mathrm{~N}$ and $\delta^{13} \mathrm{C}$ stable isotope values (mean and standard deviation).

\begin{tabular}{lccccc}
\hline Species & $\mathrm{n}$ & Mean $\delta^{15} \mathrm{~N}$ & $\mathrm{SD} \delta^{15} \mathrm{~N}$ & Mean $\delta^{13} \mathrm{C}$ & $\mathrm{SD} \delta^{13} \mathrm{C}$ \\
\hline Seagrasses & & & & & \\
Amphibolis antartica & 60 & 1.26 & 0.84 & -9.77 & 0.87 \\
Posidonia australis & 12 & 1.99 & 0.74 & -8.62 & 0.73 \\
Cymodocea angustata & 8 & -0.33 & 3.23 & -9.77 & 1.14 \\
Halodule uninervis & 9 & -1.02 & 1.84 & -9.79 & 1.55 \\
Halophila ovalis & 8 & -3.30 & 2.31 & -7.58 & 1.62 \\
Red Algae & & & & & \\
Laurencia sp. & 6 & 5.54 & 0.59 & -18.03 & 1.60 \\
Haliptilon roseum & 5 & 4.84 & 0.60 & -21.7 & 1.66 \\
Coelarthrum sp. & 4 & 5.68 & 0.22 & -29.47 & 0.97 \\
Brown Algae & & & & & \\
Dictyota furcellata & 5 & 5.31 & 0.71 & -16.99 & 0.67 \\
Sargassum sp. & 24 & 3.84 & 0.82 & -14.30 & 1.40 \\
Padina sp. & 16 & 3.74 & 1.17 & -16.79 & 1.15 \\
Green Algae & & & & & \\
Penicillus sp. & 5 & 3.69 & 0.18 & -15.86 & 2.17 \\
\hline
\end{tabular}


Figure 2.5: Isotopic values of Pelates octolineatus, potential prey items, and Chelonia mydas within the study site. Closed symbols are data from 2010-2012. Open symbols represent data from 2005-2009 (Heithaus unpublished data; C. mydas data from Burkholder et al. 2011).

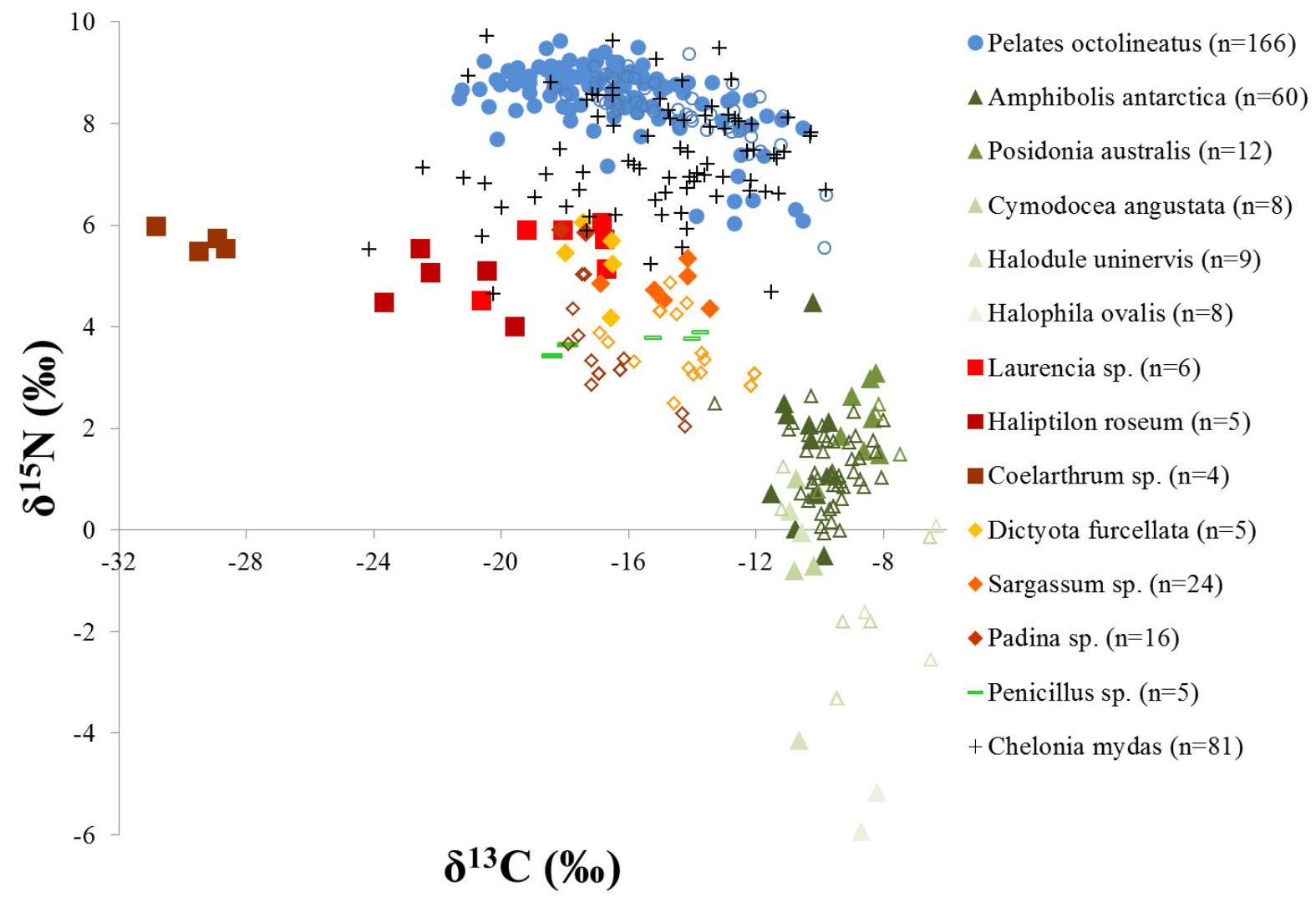


Figure 2.6: Effects of total length on A) $\left.\delta^{15} \mathrm{~N}, \mathrm{~B}\right) \delta^{13} \mathrm{C}$ and C) proportion of seagrass in stomach contents of Pelates octolineatus.
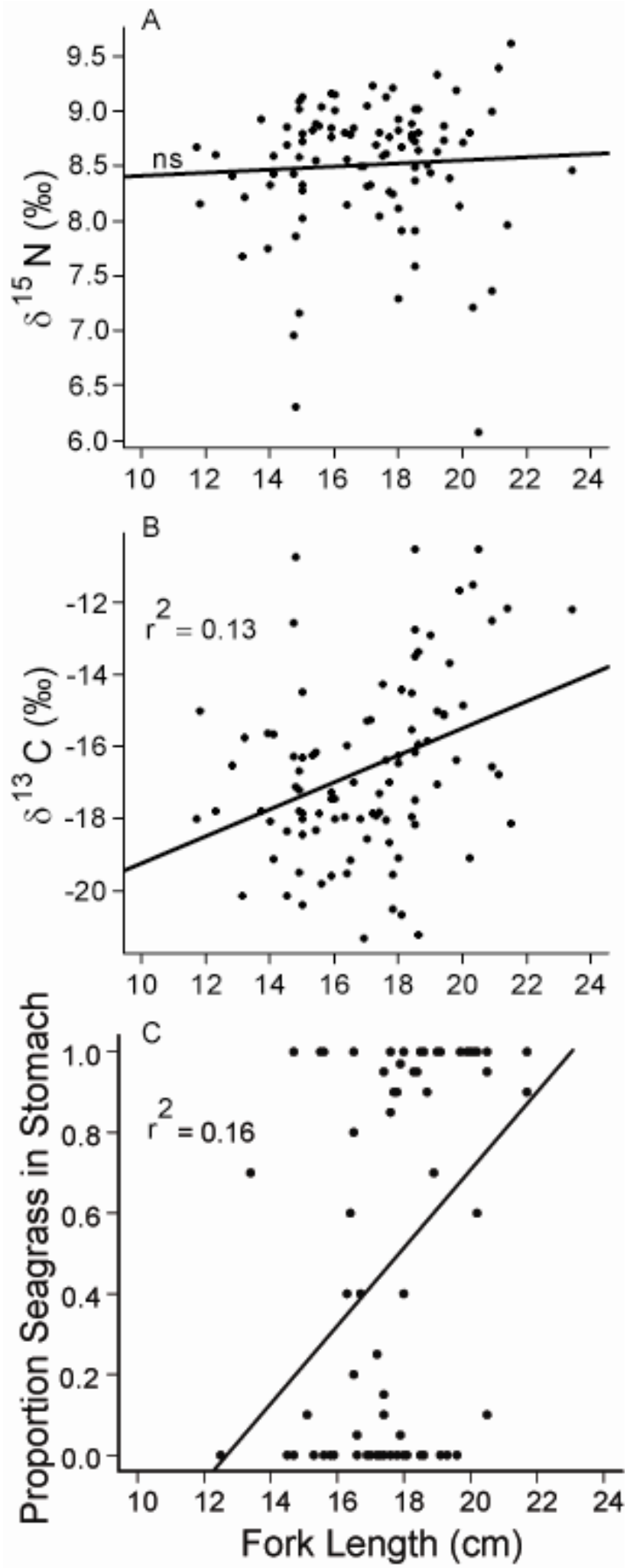
Table 2.3: Pelates octolineatus stable isotope values did not vary with season, microhabitat, or their interaction.

\begin{tabular}{lccccc}
\hline \multicolumn{1}{c}{ Predictors } & df & SS & Mean SS & F value & p value \\
\hline \multicolumn{1}{c}{$\delta^{15} \mathrm{~N}$} & & & & & \\
Season & 1 & 6.0 & 6.01 & 1.00 & 0.32 \\
Microhabitat & 1 & 8.7 & 8.66 & 1.44 & 0.23 \\
Season*Microhabitat & 1 & 6.2 & 6.22 & 1.03 & 0.31 \\
Residuals & 91 & 547.9 & 6.02 & & \\
\hline \multicolumn{1}{c}{$\delta^{13} \mathrm{C}$} & & & & & \\
Season & 1 & 0.22 & 0.22 & 0.58 & 0.45 \\
Microhabitat & 1 & 0.29 & 0.29 & 0.78 & 0.38 \\
Season*Microhabitat & 1 & 0.33 & 0.33 & 0.88 & 0.35 \\
Residuals & 91 & 34.25 & 0.38 & & \\
\hline
\end{tabular}


Figure 2.6B). In addition, $\delta^{13} \mathrm{C}$ increased with the proportion of seagrass in stomach contents $(\mathrm{F}=13.13, \mathrm{df}=1,70, \mathrm{p}<0.001$; Figure 2.6C).

Chelonia mydas had a greater range in $\delta^{15} \mathrm{~N}$ values (6.18) than did Pelates octolineatus (4.08), as well as a greater range in $\delta^{13} \mathrm{C}$ values (14.33 and 11.51, respectively). Chelonia. mydas also had a larger convex hull total area (62.4) than did $P$. octolineatus (27.3; Figure 2.7). The total area of the convex hull constructed for $P$. octolineatus displayed considerable overlap with C. mydas in the study area. Only $1.2 \%$ (2 of 166) of individual isotopic values for P. octolineatus fell outside the total area of $C$. mydas, while $37.0 \%$ (30 of 81 ) of individual isotopic values for C. mydas fell outside the total area of $P$. octolineatus. Only $17 \%$ of $P$. octolineatus and $28 \%$ of C. mydas had $\delta^{13} \mathrm{C}$ values which overlapped with the range of $\delta^{13} \mathrm{C}$ observed in seagrasses. Since primary producers may display temporal variation in isotope values that was not specifically investigated in this study, the current results should be interpreted cautiously.

Discussion

I found that the most abundant relatively large-bodied (i.e. $>5 \mathrm{~cm}$ ) teleost species in Shark Bay (Heithaus 2004, Chapter 4) consumed primarily macroalgae and seagrasses. Approximately $75 \%$ of all $P$. octolineatus sampled contained only primary producers in their stomachs and guts. The high proportion of primary producers in the diets of $P$. octolineatus combined with their high abundance in the study area suggests that these herbivorous fish may play a more important role in facilitating the transfer of primary 
Figure 2.7: Convex hulls for dietary habits of Pelates octolineatus and Chelonia mydas with mean and standard deviation in $\delta^{15} \mathrm{~N}$ and $\delta^{13} \mathrm{C}$ for seagrasses (dark green), red algae (red), brown algae (brown) and green algae (light green).

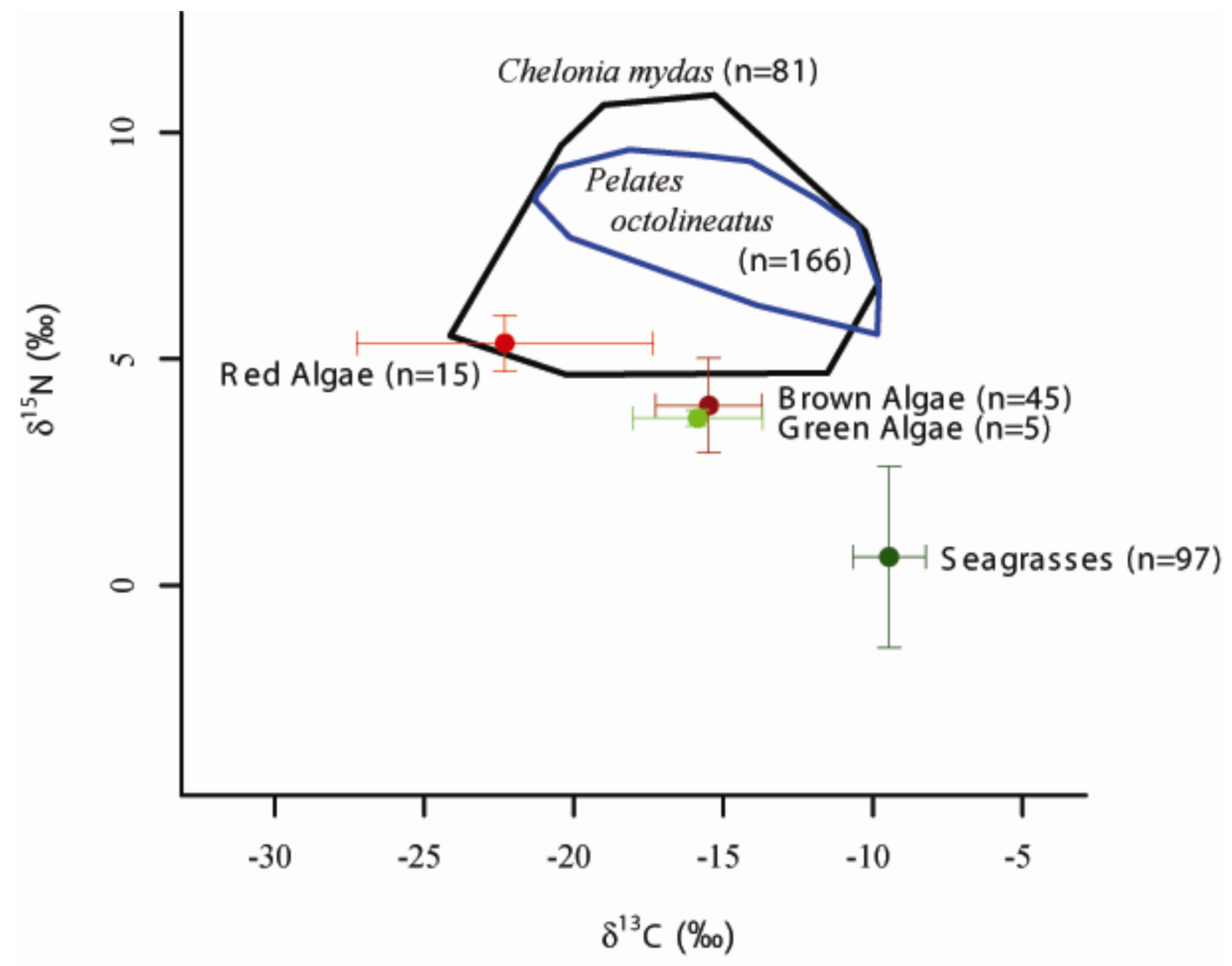


production to higher trophic levels than was previously appreciated and that teleost herbivory in pristine seagrass ecosystems may be more important than generally appreciated.

Teleost herbivores are capable of exerting considerable top-down control on primary producers in many ecosystems round the world, but these impacts are generally associated with algaes on coral reefs (Hay 1997, Burkepile and Hay 2010) and seagrasses around patch reefs (e.g. Armitage and Fourqurean). In contrast, teleosts are thought to have less impact in seagrass systems not associated with reefs (Poore et al. 2012), which may be due to a lack of studies on teleost herbivory in seagrass systems not associated with reefs, rather than a lack of impact in these habitats. Indeed, in a meta-analysis of 613 herbivory exclusion experiments (Poore et al. 2012), only 28 studies had occurred in seagrass beds, of which only one investigated the effects of fish (Gacia et al. 1999). Although we have not tested whether teleosts modify primary producer communities, we have shown that such effects are at least plausible in Shark Bay because of the large biomass that $P$. octoleneatus is capabale of removing.

Less than $1 \%$ of fish had empty stomachs, as would be expected for an herbivore (Arrington et al. 2002), and most fish had a large amount of food in their stomach. This pattern likely is driven by the generally low quality of primary producers (e.g., Bowen et al. 1995). Although the digestion of primary producer matter presents a challenge, complex gut alimentary may assist $P$. octolineatus in the processing of seagrass and algal matter. Indeed, within the Terapontidae family, fish display complex looping of the intestine during ontongeny, which may represent an important functional innovation, and 
facilitate the adoption of diverse modes of feeding - including onmivory, herbivory and detritivory - within this family (Davis et al. 2013).

Interestingly, gut content weight to body weight ratio was much lower in 2012 compared to 2011, and the positive relationship between fish content ratio and length that existed in 2011 did not in 2012. Although diet switching to prey items with higher energy content (e.g., animal matter) offers a potential explanation, this seems unlikely since the proportion of animal matter in P. octolineatus stomach contents was similar across years, as was the relative proportion of seagrass and algae. It is possible that fish in 2012 experienced lower food availability. Indeed, a "marine heatwave" in 2011, where unprecedented temperatures were observed along Western Australia, including Shark Bay (Pearce et al. 2011, Wernberg et al. 2011), led to significant declines in the cover of Amphibolis antarctica (Thomson et al. unpublished data).

In general, macroalgae may have a higher nutritional value than seagrasses (Smit et al. 2006), allowing for easier assimilation of energy and nutrients from macroalgae (Choat and Clements 1998). Both red and brown algae are commonly consumed by herbivorous fish (Bell et al. 1978, Conacher et al. 1979) and both macroalgae and epiphyte-covered seagrasses have been identified as important food sources for herbivorous fishes in other coastal systems (Mississippi salt marsh, Sullivan and Moncreiff 1990, subtropical lagoon in Bermuda, McGlathery 1995, temperate seagrass meadow in Western Australia, Smit et al. 2006). Red and brown algae were frequently encountered in the stomach contents of $P$. octolineatus in my study, and appear to be consumed at a higher rate than their relative abundance, particularly in interior 
microhabitats. Therefore, the importance of macroalgage to the diets of herbivores - and the potential importance of herbivory in structuring macroalgal abundance - might be greater than suggested by its standing stock in the study area. Further studies into algal nutritional value, palatability, and productivity as well as, more explicit studies investigating the role of grazers in structuring seagrass and algal dynamics are important to gaining further insights into the dyanmics of seagrass ecosystems.

The combination of gut contents and stable isotope analysis suggests that while macroalgae may make up a greater portion of assimilated biomass than would be expected, herbivore consumption of seagrasses might be greater than would be predicted by stable isotopic data alone. Indeed, despite roughly similar proportions of algae and seagrass in the stomachs of fishes, $\delta^{15} \mathrm{~N}-\delta^{13} \mathrm{C}$ values of $P$. octolineatus were more similar to those of algae than seagrasses, which contrasts with stomach content analysis where the mean proportional contribution of seagrass to fish diets was 0.64 and 0.40 depending on whether fish were caught in edge or interior microhabitats. Therefore, diet studies based on stable isotope data alone may overlook the contribution of seagrass.

The mis-match between views of trophic interactions based on isotopes and gut contents has important implications for understanding the ecological role of other herbivores in seagrass ecosystems. For example, the total isotopic niche space of $P$. octolineatus fell almost entirely within that of green turtles. Mixing models suggested that these turtles were assimilating a large proportion of nutrients from algae, some from gelatinous macroplankton, and - with the exception of a few individuals - relatively little from seagrasses (Burkholder et al. 2011). If turtle assimilation efficiency of seagrass is 
similar to that of these fish, then it is likely that turtle impacts on seagrass communities are greater than would be expected based on isotopic data alone. Results from recent exclosure experiments in Shark Bay show that green turtles can exert considerable topdown impacts on seagrass biomass and community structure (Burkholder et al. 2013b, this dissertation Chapter V).

Seagrass beds are threatened by myriad anthropogenic impacts, necessitating an understanding of the processes that affect seagrass ecosystem structure and function (Waycott et al. 2009, Adam et al. 2011). My current study suggests that fish may play a role in the dynamics of seagrass communities, even though seagrasses may account for relatively small portions of assimilated biomass. Therefore, further studies that directly measure the impacts of herbivorous teleosts in structuring seagrass communities will assist in effective management of these communities, and could enhance our ability to predict community trajectories under scenarios of climate change and other anthropogenic impacts.

\section{References}

Adam,T.C., R.J. Schmitt, S.J. Holbrook, A.J. Brooks, P.J. Edmunds, R.C. Carpenter, and G. Bernardi. 2011. Herbivory, connectivity, and ecosystem resilience: response of a coral reef to a large-scale perturbation. PLos ONE 6(8): e23717.

Alcoverro, T., and S. Mariani. 2004. Patterns of fish and sea urchin grazing on tropical Indo-Pacific seagrass beds. Ecography 27: 361-365.

Armitage, A.R., and J.W. Fourqurean. 2006. The short-term influence of herbivory near patch reefs varies between seagrass species. J. Exp. Marine Biol. and Ecol. 339: 65-74.

Arrington, D.A., K.O. Winemiller, W.F. Loftus, and S. Akini. 2002. How often do fishes "run on empty"? Ecology 83: 2145-2151. 
Bell, J.D., J.J. Burchmore, and D.A. Pollard. 1978. Feeding ecology of three sympatric species of leatherjackets (Pisces: Monacanthidae) from a Posidonia seagrass habitat in New South Wales. Aust. J. Mar. Freshwater Res. 29: 631-643.

Bowen, S.H. 1996. Quantitative description of diet. In: Murphy B.R., and D.W. Willis. $\left(2^{\text {nd }}\right.$ eds). Fisheries Techniques. American Fisheries Society, Maryland, p.513-532.

Bowen, S.H., E.V. Lutz, and M.O. Ahlgren. 1995. Dietary protein and energy as determinants of food quality: trophic strategies compared. Ecology 76: 899-907.

Breder, C.M. and D.E. Rosen, 1966. Modes of reproduction in fishes. T.F.H.

Publications, Neptune City, New Jersey.

Bruggemann, J.H., M.W.M. Kuyper, and A.M. Breeman. 1994. Comparative analysis of foraging and habitat use by the sympatric Caribbean parrotfish Scarus vetula and Sparisoma viride (Scaridae). Mar. Ecol. Prog. Ser. 112: 51-66.

Burkepile, D.E., and M.E. Hay. 2010. Impact of herbivore identity on algal succession and coral growth on a Caribbean Reef. PLOS ONE 5(1):e8963.

Burkholder D.A. 2012. Top down control in a relatively pristine seagrass ecosystem. FIU Electronic Theses and Dissertations. Paper 799.

Burkholder, D.A., M.R. Heithaus, and J.A. Fourqurean. 2012. Feeding preferences of herbivores in a relatively pristine subtropical seagrass ecosystem. Mar. Freshwater Res. 63: 1051-1058.

Burkholder, D. A., J. A. Fourqurean, and M. R. Heithaus. 2013a. Spatial pattern in seagrass stoichiometry indicates both N-limited and P-limited regions of an iconic Plimited subtropical bay. Mar. Ecol. Prog. Ser. 472: 101-115.

Burkholder, D. A., M. R. Heithaus, J. W. Fourqurean, A. Wirsing, and L. M. Dill. 2013 b. Patterns of top-down control in a seagrass ecosystem: could a roving apex predator (Galeocerdo cuvier) induce a behavior-mediated trophic cascade? J. Anim. Ecol. In press.

Burkholder, D.A., M.R. Heithaus, J. Thomson, and J.A. Fourqurean. 2011. Diversity in trophic interactions of green sea turtles (Chelonia mydas) on a relatively pristine coastal foraging ground. Mar. Ecol. Prog. Ser. 439: 277-293.

Carpenter, R.C. 1986. Partitioning herbivory and its effects on coral reef algal communities. Ecol. Monogr. 56: 345-363.

Choat, J.H., and K.D. Clements. 1998. Vertebrate herbivores in marine and terrestrial systems: a nutritional ecology perspective. Annu. Rev. Ecol. Syst. 29: 375-403. 
Clements, K.D., D. Raubenheimer, and J.H. Choat. 2009. Nutritional ecology of marine herbivorous fishes: ten year on. Func. Ecol. 23: 79-92.

Conacher, M.J., J.R. Lanzing, and A.W.D. Larkum. 1979. Ecology of Botany Bay, II. Aspects of the feeding ecology of the fanbellied leatherjacket, Monacanthus chinensis (Pisces: Monacanthidae), in Posidonia australis seagrass beds in Quibray Bay, Botany Bay, New South Wales. Aust. J. Mar. Freshwater Res., 30: 387-400.

Connolly, R.M. 1994. A comparison of fish assemblages from seagrass and unvegetated areas of a southern Australian estuary. Aust. J. Mar. Freshw. Res. 45: 1033-1044.

Cry, H., and M.L. Pace. 1993. Magnitude and patterns of herbivory in aquatic and terrestrial ecosystems. Nature 361: 148-150.

Davis, A.M., B.J. Pusey, R.G. Pearson, D.L. Morgan, and P.J. Unmack. 2013. Ontogenetic development of intestinal length and evolution of diet in the trophic radiation of an Australasian fish family (Terapontidae). BMC Evol. Biol. 13:53.

Duarte, C.M. 1990. Seagrass nutrient content. Mar. Ecol. Prog. Ser. 67: 201-207.

Durbin, E.G., A.G. Durbin, R.W. Langton, and A.E. Bowman. 1983. Stomach contents of silver hake, Merluccius biunearis, and Atlantic cod, Gadus morhua, and estimation of their daily rations. Fish. Bull. 81: 437-454.

Fourqurean, J.W., G.A. Kendrick, L.S. Collins, R.M. Chambers, and M.A. Vanderklift. 2012. Carbon and nutrient storage in subtropical seagrass meadows: examples from Florida Bay and Shark Bay. Mar. Freshwater Res., 63: 967-983.

Fritz, R., and Simms, E. 1992. Plant Resistance to Herbivores and Pathogens: Ecology Evolution and Genetics. University of Chicago Press, Chicago.

Gomon, M.F., C.J.M. Glover, and R.H. Kuiter (eds.), 1994. The fishes of Australia's south coast. State Print, Adelaide.

Hay, M.E. 1997. The ecology and evolution of seaweed-herbivore interactions on coral reefs. Coral Reefs. 16, Suppl.: S67-S76.

Hay, M.E., T. Colburn, and D. Dowing. 1983. Spatial and temporal patterns in herbivory on a Caribbean fringing reef: the effects on plant distribution. Oecologia 58: 299-308.

Hay, M. E., and Fenical, W. (1988). Marine plant-herbivore interactions: the ecology of chemical defense. Ann. Rev. Ecol. Syst. 19, 111-145.

Hay, M. E., Fenical, W., and Gustafson, K. (1987). Chemical defense against diverse coral-reef herbivores. Ecology 68, 1581-1591. 
Heck, K.L.Jr, G. Hays, and R.J. Orth. 2003. Critical evaluation of the nursery role hypothesis for seagrass meadows. Mar. Ecol. Prog. Ser. 253: 123-136.

Heck, K.L.Jr., and J.F. Valentine. 2006. Plant-herbivore interactions in seagrass meadows. J. Exp. Mar. Biol. Ecol. 330: 420-436.

Heithaus, M.R. 2004. Fish communities of subtropical seagrass meadows and associated habitats in Shark Bay, Western Australia. Bull. Mar. Sci. 75(1): 79-99.

Heithaus, M.R., and L.M. Dill. 2002. Food availability and tiger shark predation risk influence bottlenose dolphin habitat use. Ecology. 83: 480-491.

Heithaus, M.R., and L.M. Dill. 2006. Does tiger shark predation risk influence foraging habitat use by bottlenose dolphins at multiple spatial scales? Oikos. 114: 257-264.

Heithaus, M.R., A.J. Wirsing, D. Burkholder, J. Thomson, and L.M. Dill. 2009. Towards a predictive framework for predator risk effects: the interaction of landscape features and prey escape tactics. J. Anim. Ecol. 78:556-562.

Heithaus, M.R., A.J. Wirsing, and L.M. Dill. 2012. The ecological importance of intact top predator populations: a synthesis of 15 years of research in a seagrass ecosystem. Mar. Freshwater Res. 63: 1039-1050.

Hughes, T.P. 1994. Catastrophes, phase shifts, and large-scale degradation of a Caribbean coral reef. Science 256: 1547-1551.

Hyslop, E.J. 1980. Stomach contents analysis - a review of methods and their application. J. Fish. Biol. 17: 411-429.

Jackson, J.B.C., M.X. Kirby, W.H. Berger, K.A. Bjornadal, L.W. Botsford, B.J. Borque, R.H. Bradbury, R. Cooke, J. Erlandson, J.A. Estes, T.P. Hughes, S. Kidwell, C.B. Lange, H.S. Lenihan, J.M. Pandolfi, C.H. Peterson, R.S. Steneck, M.J. Tegner, and R.R. Warner. 2001. Historical overfishing and the recent collapse of coastal ecosystems. Science 146: 629-638.

Jobling, M., D. Coves, B. Damsgard, H.R. Kristiansen, J. Koskela, T.E. Petursdottir, S. Kadri, and O. Gudmundsson. 2001. Techniques for measuring feed intake. In: D. Houlihan, t. Boujord, and M. Jobling. (eds). Food Intake in Fish. Blackwell Science, United Kingdom, p. 49-87.

Kendrick, G.A., J.M. Huisman, and D.I. Walker. 1990. Benthic macroalgae of Shark Bay, Western Australia. Botanica Marina. 33:47-54.

Kirsch, K.D., J.F. Valentine, and K.L.Jr. Heck. 2002. Parrotfish grazing on turtlegrass Thalassia testudinum: evidence for the importance of seagrass consumption in food web 
dynamics of the Florida Keys National Marine Sactuary. Mar. Ecol. Prog. Ser. 227: $71-$ 85.

Lawrence, J.M. 1975. On the relationships between marine plants and sea urchins. Oceanogr. Mar. Biol. Annu. Rev. 13: 213-286.

Layman, C.A., M.S. Araujo, R. Boucek, E. Harrison, Z.R. Jud, P. Matich, C.M. Hammerschlag-Peyer, A. Rosenblatt, J. Vaudo, L.A. Yeager, D.M. Post, and S. Bearhop. 2012. Applying stable isotopes to examine food web structure: an overview of analytical tools. Biol. Rev. 87: 545-562.

Layman, C.A., D.A. Arrington, C.G. Montana, and D.M. Post. 2007. Can stable isotope ratios provide for community-wide measures of trophic structure? Ecology 88: 42-48.

Lewis, S.M., 1985. Herbivory on coral reefs: algal susceptibility to herbivorous fishes. Oecologia 65: 370-375.

Mariani, S., and T. Alcoverro. 1999. A multiple-choice feeding-preference experiment utilizing seagrasses with a natural population of herbivorous fishes. Mar. Ecol. Prog. Ser. 189: 295-299.

McClanahan, T.R., M. Nugues, and S. Mwachireya. 1994. Fish and sea urchin herbivory and competition in Kenyan coral reef lagoons: role of reef management. J. Exp. Mar. Biol. Ecol. 184: 237-254.

McGlathery, K.J. 1995. Nutrient and grazing influences on a subtropical seagrass community. Mar. Ecol. Prog. Ser. 189: 239-252.

Mill, A.C., J.K. Pinnegar, and N.V.C. Polunin. 2007. Explaining isotope trophic-step fractionation: why herbivorous fish are different. Func. Ecol. 21: 1137-1145.

Pages, J.F., S. Farina, A. Gera, R. Arthur, J. Romero, and T. Alcoverro. 2012. Indirect interactions in seagrasses: fish herbivores increase predation risk to sea urchins by modifying plant traits. Func. Ecol. 26: 1015-1023.

Paxton, J.R., D.F. Hoese, G.R. Allen and J.E. Hanley, 1989. Pisces. Petromyzontidae to Carangidae. Zoological Catalogue of Australia, Vol. 7. Australian Government Publishing Service, Canberra.

Pearce, A., R. Lenanton, G. Jackson, J. Moore, M. Feng, and D. Gaughan. 2011. The "marine heat wave" off Western Australia during the summer of 2010/2011. Fisheries Research Report No. 222, Department of Fisheries, Western Australia.

Peterson, B.J., and B. Fry. 1987. Stable isotopes in ecosystem studies. Ann. Rev. Ecol. Syst. 18: 293-320. 
Poore, A.G.B., A.H. Campbell, R.A. Coleman, G.J. Edgar, V. Jormalainen, P.L. Reynolds, E.E. Sotka, J.J. Stachowicz, R.B. Taylor, M.A. Vanderklift, and J.E. Duffy. 2012. Global patterns in the impact of marine herbivores on benthic primary producers. Ecol. Lett., 15: 912-922.

Post, D.M. 2002. Using stable isotopes to estimate trophic position: models, methods, and assumptions. Ecology 83: 703-718.

Post, D.M., C.A. Layman, D.A. Arrington, G. Takimoto, C.G. Montana, and J.

Quattrochi. 2007. Getting to the fat of the matter: models, methods and assumptions for dealing with lipids in stable isotope analyses. Oecologia 152: 179-19.

R Development Core Team, 2011. R: A Language and Environment for Statistical Computing. R Foundation for Statistical Computing. Available:

http://www.Rproject.org/. ISBN: 3-900051-07-0.

Smit, A.J., A. Brearley, G.A. Hyndes, P.A. Lavery, and D.I. Walker. 2006. $\delta^{15} \mathrm{~N}$ and $\delta^{13} \mathrm{C}$ analysis of a Posidonia sinuosa seagrass bed. Aquatic. Bot. 84: 277-282.

Sullivan, M.J., and C.A. Moncreiff. 1990. Edaphic algae are an important component of salt marsh food-webs: evidence from multiple stable isotope analyses. Mar. Ecol. Prog. Ser. 62: 149-159.

Thayer, G.W., K.A. Bjorndal, J.C. Ogden, S.L. Williams, and J.C. Zieman. 1984. Role of larger herbivores in seagrass communities. Estuaries 7: 351-376.

Tomas, F., X. Turon, and J. Romero. 2005. Seasonal and small-scale spatial variability of herbivory pressure on the temperate seagrass Posidonia oceanica. Mar. Ecol. Prog. Ser. 301: 95-107.

Valentine, J.F., K.L. Jr. Heck., D. Blackmon, M.E. Goecker, J. Christian, R. Kroutil, K.D. Kirsch, B. Peterson, M. Beck, and M.A. Vanderklift. 2007. Food web interactions along seagrass-coral reef boundaries: effects of piscovore reductions on cross-habitat energy exchange. Mar. Ecol. Prog. Ser. 333: 37-50.

Walker, D.I., G.A. Kendrick, and A.J. McComb. 1988. The distribution of seagrass species in Shark Bay, Western Australia, the notes on their ecology. Aquatic. Bot. 30: 205-317.

Waycott, M., C.M. Duarte, T.J.B. Carruthers, R.J. Orth, W.C. Dennison, S. Olyarnik, A. Calladine, J.W. Fourqurean, K.L. Heck Jr., A.R. Hughes, G.A. Kendrick, W.J. Kenworthy, F.T. Short, and S.L. Williams. 2009. Accelerating loss of seagrasses across the globe threatens coastal ecosystems. Proc. Natl. Acad. Sci. U.S.A. 106(30): 1237712381.

Wernberg,T., B.D. Russell, P.J. Moore, S.D. Ling, D.A. Smale, A. Campbell, M.A. Coleman, P.D. Steinbert, G.A. Kendrick, and S.D. Connell. 2011. Impacts of climate 
change in a global hotspot of temperate marine biodiversity and ocean warming. J. Exp. Mar. Biol. Ecol. 400: 7-16.

White, K.S., M.B. Westera, and G.A. Kendrick. 2011. Spatial patterns in fish herbivory in a temperate Australian seagrass meadow. Estuar. Coast. Shelf Sci. 93:366-374.

Wirsing, A.J., M.R. Heithaus, and L.M. Dill. 2007. Fear factor: do dugongs (Dugong dugon) trade food for safety from tiger sharks (Galeocerdo cuvier)?. Oecologia. 153: 1031-1040.

Wyatt, A.S.J., A.M. Waite, and S. Humphries. 2010. Variability in isotope discrimination factors in coral reef fishes: implications for diet and food web reconstruction. PloS ONE 5: e13682 
CHAPTER III:

\section{ALARM CALL PRODUCTION AND TEMPORAL VARIATION IN PREDATOR ENCOUNTER RATES FOR A FACULTATIVE TELEOST GRAZER IN A RELATIVELY PRISTINE SEAGRASS ECOSYSTEM}


Abstract

Predation risk can structure the spatial and temporal patterns and strength of grazer impacts on primary producer communities. Although teleost grazers have the potential to exert strong top-down effects on seagrass communities, relatively little is known about how risk might structure these effects. Here, I used tethering trials to identify potential predators of an abundant facultative teleost grazer, the western striped trumpeter (Pelates octolineatus, Jenyns 1840), and investigate patterns of predator encounter rates in a relatively pristine seagrass ecosystem. Pied cormorants (Phalacrocorax varius) were identified as the most common predator during 116 tethering trials that were video-recorded. Trumpeters also were preyed upon by giant shovelnose rays (Glaucostegus typus), nervous sharks (Carcharhinus cautus), and blue swimmer crabs (Portunus pelagicus). Predation events on tethered fish were higher during trials conducted during a warm period compared a colder period, which corresponded to variation in cormorant densities observed along standardized transects. Activity rates of fish that survived the tether trials were similar to those that were preyed upon. Fish vocalization rates were low throughout the majority of tethering trials, but high immediately preceding and during predatory attacks suggesting that trumpeters may produce alarm calls. Although further studies are needed, our data suggest that seasonal variation in predation risk could be an important factor in structuring the behavior and foraging impacts of an abundant facultative teleost grazer in a relatively pristine seagrass ecosystem. 
Introduction

Predation is an important driver of habitat use, abundance, and foraging behavior in diverse taxa and can limit prey population sizes (e.g. Lima and Dill 1990, Brown and Kotler 2004, Ritchie and Johnson 2009). Thus, predators may indirectly influence plant communities by altering spatial and temporal patterns and overall intensity of herbivory (e.g., Hairston et al. 1960, Schmitz et al. 2004 and Estes et al. 2011 for reviews). Recent studies suggest that non-consumptive effects (or "risk effects"), including behaviorallymediated indirect interactions (BMII) such as reduced activity and altered habitat use, may be equally or more important than indirect effects initiated by direct consumption of prey because of their tendency to affect large portions of prey populations (Dill et al. 2003, Schmitz et al. 2004, Preisser et al. 2005, Creel and Christianson 2008, Heithaus et al. 2008a).

Despite their central role in the dynamics of many systems (e.g. Estes et al. 2011), top-down effects in seagrass ecosystems have only received attention relatively recently (Valentine et al. 2007, Moksnes et al. 2008, Heithaus et al. 2009, Poore et al. 2009, Pages et al. 2012). Previously, it was thought that direct herbivory had little impact on seagrass communities and the possibility that predators could affect seagrasses through direct predation or risk effects on herbivores - especially highly mobile species - was largely overlooked (reviewed in Heck and Valentine 2006). Recently, however, it has become apparent that the intensity of herbivory can vary widely both temporally and spatially in seagrass systems, and may be at least partially driven by predators (Heck and Valentine 2006, Valentine et al. 2007, Heithaus et al. 2008b, and 2009, Moksnes et al. 2008, Lewis and Anderson 2012). For example, fish can limit the abundance of low-mobility 
herbivores (Duffy and Hay, 2000), and invertebrate mesograzer abundances increase in the absence of predators, resulting in low biomass of algae on seagrass leaves (Moksnes et al. 2008, Eriksson et al. 2009). Also, top predators can modify foraging patterns of megaherbivores, including dugongs (Dugong dugon; Wirsing et al. 2007) and green turtles (Chelonia mydas; Heithaus et al. 2007). The potential indirect effects of predators on primary producers mediated through herbivorous fish are less known, but are likely (see Armitage and Fourqurean 2006). Indeed, fish can remove substantial amounts of primary production and are at risk from a diversity of piscivores in many locations, making predation risk to teleost grazers in seagrass ecosystems of particular interest (Kirsch et al. 2002, Tomas et al. 2005, Armitage and Fourqurean 2006).

Predation risk is a product of the encounter rate between predator and prey and the probability of death given an encounter (Lima and Dill 1990). Measuring predation risk in relatively large-bodied and mobile species, like many teleosts, can be difficult. Restraining prey (or tethering) can provide insights into predator encounter rates and the ability to compare these encounter rates across space and through time, but the limitations of this technique must be considered (Peterson and Black 1994, Aronson and Heck 1995, Aronson et al. 2001, Lank and Ydenberg 2003). For example, although tethering removes observer bias, it impedes escape behavior (i.e. increases the probability of death in an encounter situation) and may increase attack rates (i.e. increases estimates of encounter rates) if predators are attracted to tethered individuals. Continuous video recording of tethering trials, however, offers the potential for a more complete retrospective evaluation of the degree to which biases of tethering may differ between 
treatments (Peterson and Black 1994). It also has the potential to provide insights into anti-predator behaviors, such as the use of alarm calls.

Shark Bay, Western Australia, has been used as a model system for investigations of top-down processes, particularly risk effects, in a relatively pristine seagrass ecosystem (Heithaus et al. 2009). Although predation sensitive foraging of large-bodied herbivores (dugongs and green turtles) (Heithaus et al. 2007, Wirsing et al. 2007), and their resulting impacts on seagrass (Heithaus et al. 2007, Burkholder et al. 2012 and 2013a), has been studied in Shark Bay, less attention has been given to the potential for risk-sensitive foraging behavior of fish grazers and how this may impact seagrass ecosystem dynamics. The teleost Pelates octolineatus (western striped trumpeter; Terapontidae) is the most abundant mid-sized teleost (maximum length of $28 \mathrm{~cm}$ ) in the long-term Shark Bay study site (Heithaus 2004) and has been observed consuming substantial proportions of primary producers (Burkholder et al. 2012, Davis et al. 2012, Bessey unpublished data). Therefore, western striped trumpeters could impact seagrass and algal communities (Burkholder et al. 2012). Little is known, however, about the specific predators of $P$. octolineatus and how encounter rates with predators might vary in space and time. Likewise, little is known about the use of anti-predator behaviors, such as alarm calls, by these soniforous fish. Here, I used tethering trials with continuous video surveillance to identify potential predators of western striped trumpeters, investigate patterns of predator encounter rates, and determine whether fish might use alarm calls when threatened by predators. 
Methods

Study Site

The study occurred in the Eastern Gulf of Shark Bay offshore of the Monkey Mia Dolphin Resort. Shark Bay $\left(25^{\circ} 45^{\prime} \mathrm{S}, 113^{\circ} 44^{\prime} \mathrm{E}\right)$ is a ca. $13,000 \mathrm{~km}^{2}$ subtropical embayment in Western Australia with approximately one-third of its area $\left(\sim 4,000 \mathrm{~km}^{2}\right)$ covered by seagrass meadows (Walker et al. 1988). Water temperatures are generally high $\left(>20^{\circ} \mathrm{C}\right)$ during September to May (warm season) and drop to as low as $12^{\circ} \mathrm{C}$ during June to August (cold season) (Heithaus and Dill 2002, 2006).

The study site is made up of a series of shallow offshore banks $(<4.5 \mathrm{~m}$ depth) surrounded by deeper waters $6-12 \mathrm{~m}$ depth. Shallow banks are largely covered by seagrass, although the community composition varies with depth, while deeper waters are largely unvegetated (Burkholder et al. 2013b). Western striped trumpeters are largely confined to shallow habitats and are concentrated in vegetated areas (Heithaus 2004).

\section{Tethering Trials}

I tethered individual western striped trumpeters at least $100 \mathrm{~m}$ apart within shallower (mean water depth $\pm \mathrm{sd}=2.1 \pm 0.4 \mathrm{~m}$ ) and deeper (mean water depth $\pm \mathrm{sd}=$ $4.4 \pm 0.5 \mathrm{~m}$ ) portions of three separate seagrass banks in our study site. I chose $100 \mathrm{~m}$ as a conservative distance that would exceed the visual (Strod et al. 2008), electrosensory (Haine et al. 2001), and the echolocation range (Wilson et al. 2013) of potential predators foraging in a seagrass meadow (e.g., small sharks, large teleosts, dolphins, marine birds); thereby minimizing the likelihood of multiple predation events by a single individual predator. I used continuous video surveillance to determine time to attack of tethered fish, predator identity, as well as to make post-hoc comparisons of tethered fish behavior. 
A total of 116 tethered fish were deployed over nine days during the warm period (April 3- May 8, 2012; mean water temperature $=22.8 \pm 0.7^{\circ} \mathrm{C} ; \mathrm{n}=30$ in deeper and $\mathrm{n}=31$ in shallower microhabitats), and eight days in the cold period (June 30-August 4, 2012; mean water temperature $=15.5 \pm 0.6^{\circ} \mathrm{C} ; \mathrm{n}=27$ in deeper and $\mathrm{n}=28$ in shallower microhabitats). It was necessary to place tethered fish in patches of sand or sparse seagrass within each microhabitat to prevent tethered fish from becoming entangled in seagrass shoots. Although this method likely increases the rate of predation on tethered fish above that which would occur were fish able to hide in dense seagrass, western striped trumpeters do occur in sparse seagrass habitats and this method facilitates identification of potential predators while providing an index of relative encounter rates through time.

Tethered fish were obtained on the day of trials using squid-baited fish traps $(34 \times 24 \times 21 \mathrm{~cm} ; 12 \times 13 \mathrm{~mm}$ mesh) and measured for fork length (mean $\pm \mathrm{sd}=$ $16.7 \pm 1.9 \mathrm{~cm})$. Individual fish were tethered to a swivel on the end of a stake using a 30 $\mathrm{cm}$ long leash of monofilament fishing line tied through the membrane behind the lower jaw of the fish and out the mouth. The $30 \mathrm{~cm}$ leash allowed for natural swimming behavior of fish (representative video provided below) while limiting the range of movement to within the field of view of the camera. The length of leash also minimized entanglement of tethered fish with structure in the immediate vicinity. The stake was positioned $80 \mathrm{~cm}$ in front of an $8 \mathrm{~kg}$ I-beam that was mounted with a GoPro Hero (Woodman Labs, http://gopro.com, Nov.20'2012) underwater camera. Fish were tethered between 9am-2:30pm because grazers typically display diurnal feeding patterns 
(Helfman 1986). Continuous video footage of each trial was obtained for the duration of the trial (mean $\pm \mathrm{sd}=186 \pm 26 \mathrm{mins}$ ). All equipment was collected at the end of each day and all remaining fish were released. All fish that were not preyed upon survived the tether trials and were in apparent good health and readily swam away. Video footage was used to determine the identity of attacking predators. In addition, the video footage from 40 trials where tethered fish survived was reviewed to determine if a potential predator was observed within the field of view ( $\mathrm{n}=40 ; 10 /$ microhabitat/period $)$.

Tethering fish allowed me to limit escape and anti-predator behavior as interacting determinants of mortality. However, to investigate behavioral differences in tethered fish that might lead to increase attraction of predators, I determined activity rates and vocalizations using video footage of trials. The activity rate of a fish was measured as the average number of seconds spent swimming (caudal fin movement) versus stationary (no caudal fin movement) during five different randomly assigned 1-min segments of a trial. I determined the activity rate of 88 different fish; 60 fish that survived ( 30 from the warm period and 30 from the cold period), and 28 fish that were preyed upon. In addition, I recorded whether each fish was heard vocalizing at any time during the analysed footage. Vocalization was also determined for the minute immediately prior to the predation event for preyed upon fish.

A representative video of tethered fish behavior, as well as, behaviour of conspecific fishes near the tethered individual are provided as supplemental material online at: 
https://www.dropbox.com/s/8xs68gayq6br1zw/TetherTrialMovie_BesseyHeithaus_June1 7.wmv.

\section{Belt Transects}

To compare attack rates on tethered fish to abundances of pied cormorants, the most abundant air-breathing predator in the study area (Heithaus 2005), I conducted visual surveys of cormorant abundance along pre-established belt transects ( $\sim 3.2 \mathrm{~km}$ long) over the seagrass banks where tether trials were conducted. I completed eight passes over seagrass banks during five different days in the warm period and eight passes over seven different days in the cold period. Although surveys corresponded to the general timing of tether trails ( $\mathrm{n}=8$ in April and $\mathrm{n}=8$ in July), surveys were not conducted on days when tethering occurred to prevent disturbance. Belt transects were driven at $6-9 \mathrm{~km} / \mathrm{hr}$ in a $5.5 \mathrm{~m}$ boat containing at least three observers. Observers recorded the number and GPS location of all cormorants sighted within a $60 \mathrm{~m}$ sighting belt before the boat passed their position. To minimize sighting bias, surveys were conducted in Beaufort wind conditions of 2 or less. If a cormorant flew away as the boat approached, observers noted the landing location to ensure that each individual was counted only once. The combination of slow survey speeds and cormorant diving patterns (long surface intervals and short dive durations; Dunphy-Daly et al. 2010) make it unlikely that any individuals were missed during surveys. I calculated cormorant density (birds $\left./ \mathrm{km}^{2}\right)$ as $n_{t} / A_{t}$ where $\mathrm{n}_{\mathrm{t}}$ is the number of cormorants sighted on transect $t$, and $A_{t}$ is the area of the transect $\left(\mathrm{km}^{2}\right)$. 


\section{Statistical Analysis}

I examined the effects of period (cold/warm), depth (shallower/deeper), their interaction, and fish length on the probability of fish survival using a generalized linear model with a binomial link function that considered the outcome for each fish to be either a success (survived for duration of tether deployment) or failure (death by predation). The non-significant interaction term was removed from the model (period $\mathrm{x}$ depth, $\mathrm{p}=0.29)$. Because transect data passed a Lilliefors Test for normality $(\mathrm{D}=0.19, \mathrm{p}=0.13), \mathrm{I}$ used a Students t-Test to compare cormorant densities obtained in the cold period to those of the warm period. I used non-parametric statistics (Mann-Whitney Test) to analyze post hoc behavioral data from video footage because these data were not normally distributed nor would a transformation enable normalization (Lilliefors Test for normality; swim time: $\mathrm{D}=0.21, \mathrm{p}<0.01$; vocalization: $\mathrm{D}=0.27, \mathrm{p}<0.01$ ). All analyses were conducted in R (version 2.14.0; R Development Core Team 2011).

Results

Of 116 tethered fish, only 3 escaped their tether; one during a cold period trial in the deeper microhabitat and two during warm period trials in shallower microhabitats. These were excluded from analyses. The probability that a fish was preyed upon was more than three times higher during the warm period $(41 \%, 24$ of 59$)$ than the cold period (13\%, 7 of 54; Table 3.1). There was no significant difference in the probability that a fish was preyed upon between microhabitats [18.5\% (5 of 27) in cold/deeper; 7.4\% (2 of 27 ) in cold/shallower; $40 \%$ (12 of 30) in warm/deeper; $41.4 \%$ (12 of 29$)$ in 
Table 3.1: Logistic regression results of parameters affecting the probability of western striped trumpeter predation events during tether trials.

\begin{tabular}{lcccc}
\hline Parameter & Estimate & Std. Error & $\mathrm{z}$ value & $\operatorname{Pr}(>|\mathrm{z}|)$ \\
\hline Intercept & -2.19 & 2.11 & -1.03 & 0.30 \\
Period & 1.54 & 0.49 & 3.16 & $0.002 *$ \\
Depth & -0.26 & 0.45 & -0.58 & 0.56 \\
Fish Length & 0.02 & 0.12 & 0.20 & 0.85 \\
\hline
\end{tabular}


warm/shallower], and also did not vary with fish length (Table 3.1). Video surveillance allowed for the identification of all predators (Table 3.2, Figure 3.1). The most common predator during the cold period was the giant shovelnose ray $(\mathrm{n}=3)$, while pied cormorants took the most fish $(\mathrm{n}=18)$ during the warm period. All attacked fish were successfully removed from their tether, with the exception of two unsuccessful attacks by blue swimmer crabs (Portunus pelagicus). For fish that were preyed upon, there was no significant difference in time until successful attack between cold and warm period trials (cold: $90 \pm 25$ mins, warm: $106 \pm 11$, Mann-Whitney Test: $W=69, p=0.49$ ). All taxa of successful predators also were observed at least once in the field of view of a trial in which the tethered fish was not attacked (Table 3.3). In the two trials where a cormorant was seen swimming through the field of view, the cormorants did not appear to have observed the tethered fish. This was likewise the case for four sightings of shovelnose rays (Glaucostegus typus) and two sightings of nervous sharks (Carcharhinus cautus). On three occasions, however, two with a shovelnose ray, and one with a nervous shark, the predator was seen entering the field of view at least six times without attacking the tethered fish before leaving the field of view without returning.

Densities of pied cormorants were more than twice as high during the warm period $\left(\operatorname{mean} \pm \mathrm{sd}=62.9 \pm 24 \mathrm{birds} / \mathrm{km}^{2}\right)$ than the cold period $(25.2 \pm 9.5)($ Figure 3.2A, Student t-Test: $\mathrm{t}=-4.08, \mathrm{p}<0.01)$.

There was no significant difference in activity rates between fish that were preyed upon and those that survived (mean \pm sd; survived: $39.7 \pm 2.7 \mathrm{~s} / \mathrm{min}$; preyed upon: $45.0 \pm$ 3.6, Mann-Whitney Test: $\mathrm{W}=707, \mathrm{p}=0.23$ ). However, fish were significantly less active during the cold period (Figure 3.2B, Mann-Whitney Test: $\mathrm{W}=681, \mathrm{p}=0.03$ ). 
Table 3.2: Number of western striped trumpeters preyed upon by each identified predator during both the cold and warm period.

\begin{tabular}{lcc}
\hline Predator & Cold & Warm \\
\hline Pied Cormorant (Phalacrocorax varius) & 2 & 18 \\
Giant Shovelnose Ray (Glaucostegus typus) & 3 & 3 \\
Nervous Shark (Carcharhinus cautus) & & 3 \\
Blue Swimmer Crab (Portunus pelagicus) & 2 & \\
\hline
\end{tabular}


Figure 3.1: Video screen shots identifying predators of tethered western striped trumpeters.

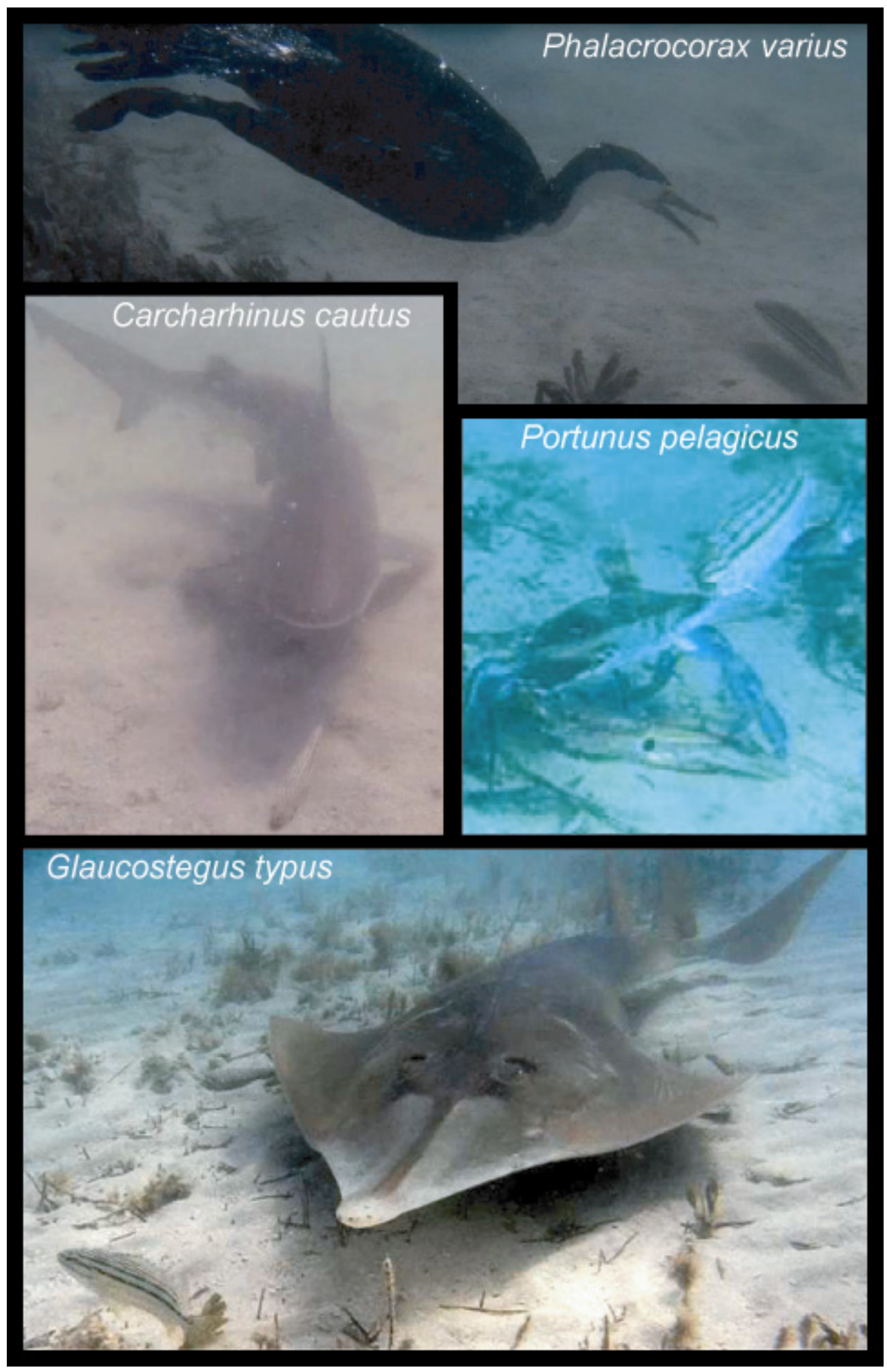


Table 3.3: Number of trials where a predator was observed but did not successfully attack the tethered fish during 40 analyzed trials (10/depth/period).

Potential Predator

Pied Cormorant (Phalacrocorax varius)

Giant Shovelnose Ray (Glaucostegus typus)

Nervous Shark (Carcharhinus cautus)

Cold Warm

Blue Swimmer Crab (Portunus pelagicus)

$1 \quad 1$

$5 \quad 1$

12

3 
Figure 3.2: A) Cormorant density (birds $/ \mathrm{km}^{2}$ ) per period corresponding with timing of tether trials, and B) activity rate (mean time fish spent swimming versus stationary $\mathrm{s} / \mathrm{min}$ ) of tethered fish by period. Letters represent differences between groups (A: Student t-test, $\mathrm{t}=-4.08, \mathrm{p}=0.01$; B: Mann-Whitney Test, $\mathrm{W}=681, \mathrm{p}=0.03$ ).
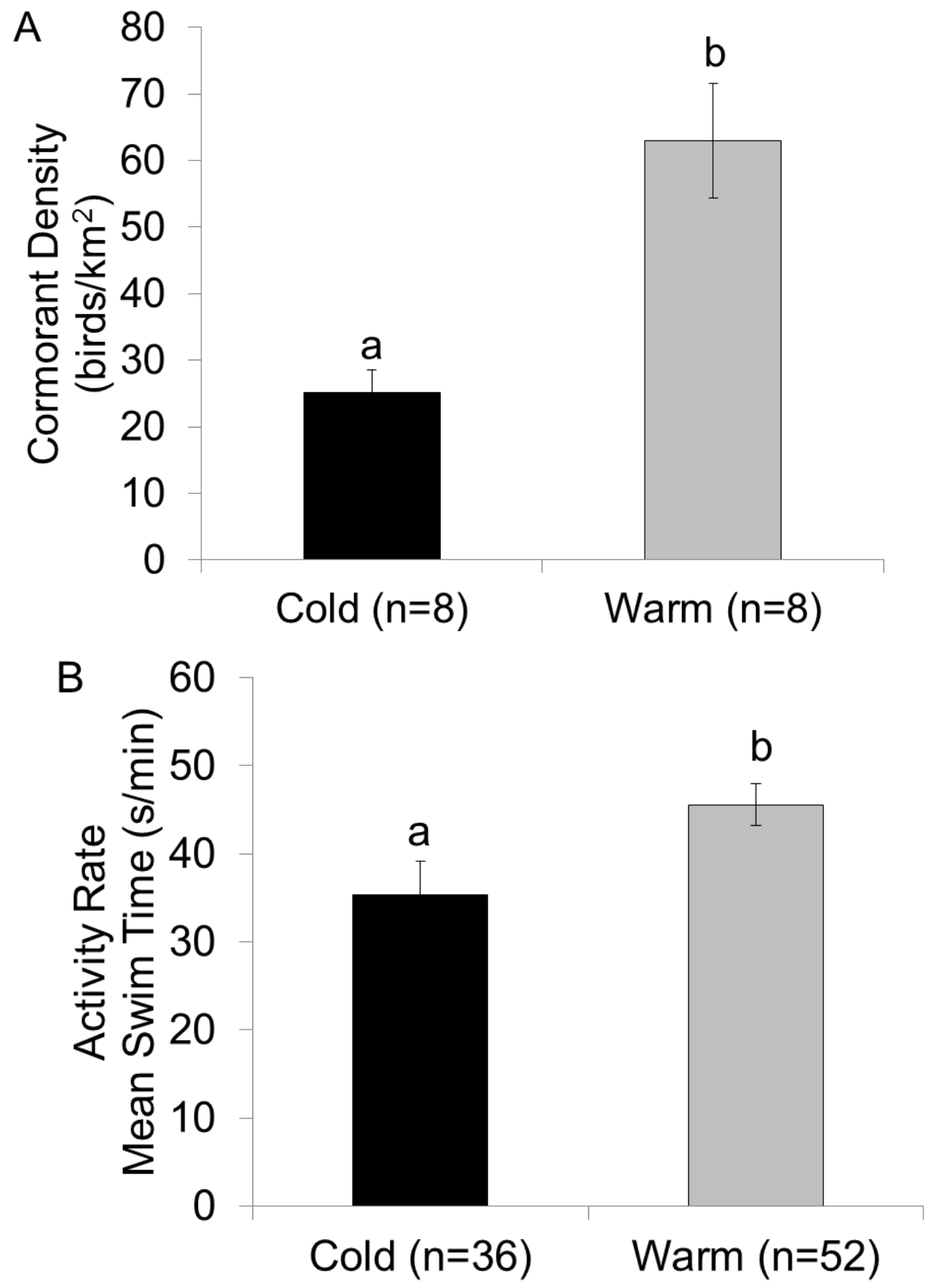
The probability that a fish vocalized during any of the five randomly analyzed minutes was relatively low, with no statistically significant difference in vocalization between fish which survived compared to those that were preyed upon (mean $\pm \mathrm{sd}$; survived: $0.11 \pm 0.02$ vocalization occurrence/min, preyed upon: $0.13 \pm 0.04$, MannWhitney Test: $\mathrm{W}=865, \mathrm{p}=0.80$ ). In contrast, the probability of vocalizations occurring was significantly higher immediately prior to, and during, the attack (Figure 3.3, MannWhitney Test: $\mathrm{W}=2389, \mathrm{p}<0.001)$. Vocalizations were recorded for all fish that were preyed upon with one exception.

\section{Discussion}

Tether trials revealed that western striped trumpeters can experience high encounter rates with predators, but these rates were temporally variable as was the relative abundance of different potential predators. During the cold period, fish were preyed upon by pied cormorants, giant shovelnose rays and blue swimmer crabs, while in the warm period, fish were taken by cormorants, shovelnose rays and nervous sharks. Because untethered trumpeters are likely to escape attacks by shovelnose rays and swimmer crabs, cormorants and nervous sharks are likely the only predators observed during tethering trials that are a threat to striped trumpeters. Indeed, in nearshore waters of Shark Bay, diets of nervous sharks were dominated by teleosts ( $c a .70 \%$ by volume) and terapontid fishes accounted for an estimated $4.6 \%$ by volume of the stomach content, which was among the highest percentage for any teleost consumed (White et al. 2004). 
Figure 3.3: Vocalization occurrence of western striped trumpeter per minute at random intervals compared to at attack. Letters represent differences between groups based on a Mann-Whitney Test $(\mathrm{W}=2389, \mathrm{p}<0.001)$.

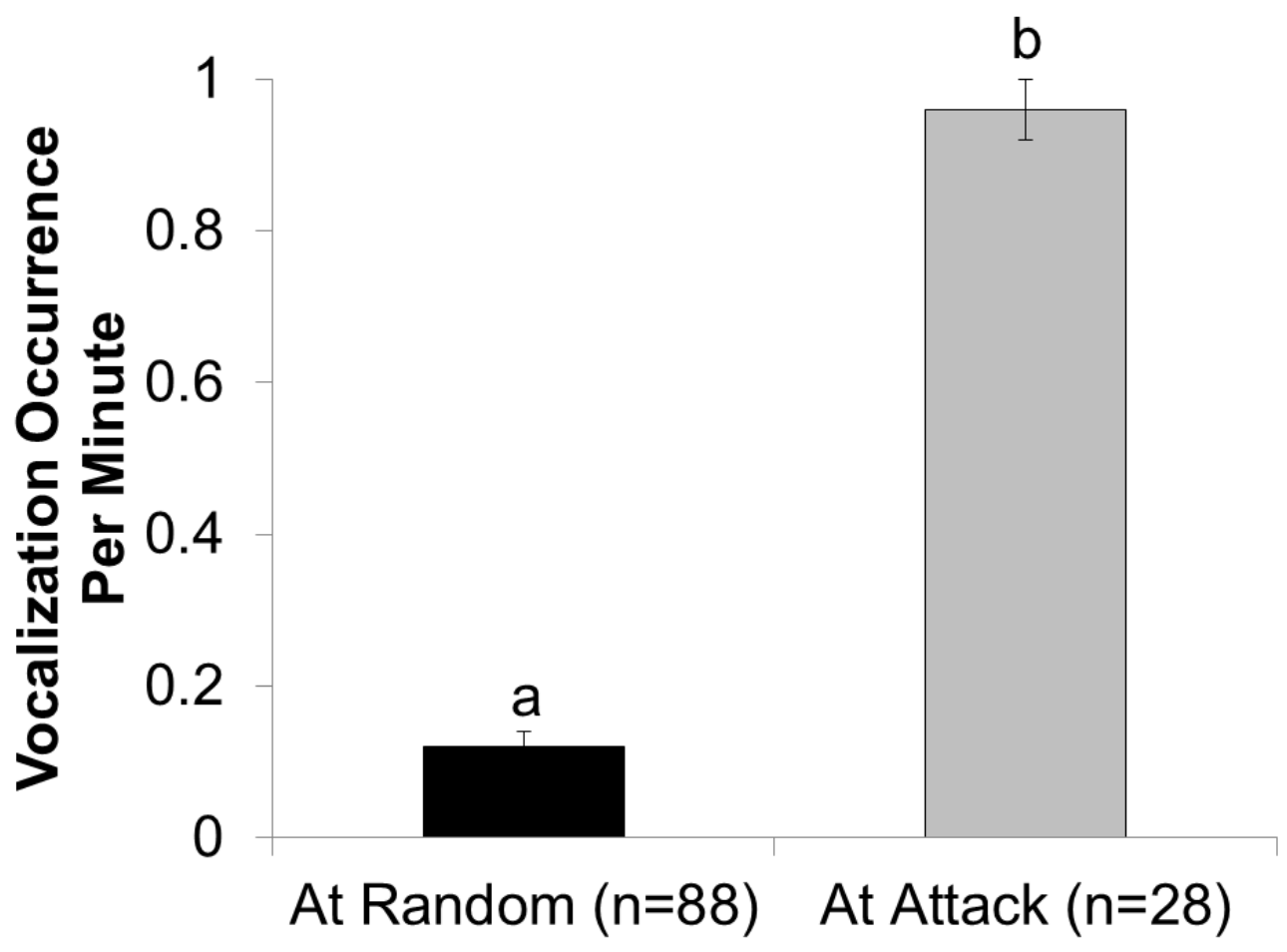


Pied cormorants primarily consume teleosts ( $\sim 90 \%$ by weight for cormorants; del Hoyo et al. 1992). In Queensland, Australia, terapontid fishes accounted for an estimated 5.1\% of the mass of pied cormorant diets (Blaber and Wassenberg 1989). Diet studies of pied cormorants are not available for Shark Bay. While cormorants were very effective in capturing tethered fish once encountered, it is likely that risk to free-swimming fish, especially those over heavily vegetated areas would be lower. Indeed, the evasive swimming before the appearance of predators in video fames suggests that fish would have had time to seek refuge in dense seagrass before being attacked. Nervous sharks may face similar difficulties during prey capture in heavily vegetated areas.

The giant shovelnose ray is reported to consume teleosts in the study area but they accounted for a small proportion of their diets ( $\sim 9 \%$, Vaudo and Heithaus 2011). Little is known about ray foraging behavior, and it is possible that rays would be able to catch trumpeters at night or as an ambush predator. Blue swimmer crabs are unlikely to be able to take a free-swimming, healthy trumpeter. During our tether trials, there were two unsuccessful attacks by blue swimmer crabs on tethered fish.

Not all known predators of western striped trumpeters were observed during tether trials. Indo-Pacific bottlenose dolphins (Tursiops aduncus) prey heavily upon striped trumpeters (Heithaus and Dill 2002), but none were observed taking tethered fish. The lack of dolphin predation could be a consequence of lower densities of dolphins than other predators in the study area (e.g. Heithaus and Dill 2002, Heithaus 2005) combined with the relatively small number of days where tethering occurred, or perhaps dolphins avoided the tethering apparatus. Therefore, while I have gained insights into potential predators of western striped trumpeters and temporal variation in encounter rates with 
these predators, work remains to be done to investigate the lethality of different predator types and to gain further insights into encounter rates over a variety of bottom types (e.g. more heavily vegetated areas).

Differences in encounter rates with predators between the cold and warm periods were consistent with temporal variation in cormorant densities on belt transects. Indeed, cormorant densities in the warm period were twice those during the cold period when fewer fish were preyed upon by cormorants. The presence of shovelnose rays year round, and nervous sharks taking trumpeters during warm months, is consistent with seasonal variation in abundances of these species in the bay (White and Potter 2004, Vaudo and Heithaus 2009). Interestingly, there were no seasonal differences in the length of time fish were tethered before being preyed upon. Since cormorant density was more than two times higher during the warm period, it would be reasonable to predict that fish would be consumed faster, as well as, more frequently in the warm period. However, cormorants are a visual predator, and perhaps the lack of difference in length of time until predation event was driven by seasonal changes in the physical condition of the bay waters. Shark Bay experiences increased winds during the warm season, which results in reduced water clarity and increased turbidy (Smith and Atkinson 1983). These physical conditions in turn reduce water visibility, increase suspended particulates, and reduce light penetration which could reduce predator detection rates of prey (Abrahams and Kattenfeld 1997, Abrahams et al. 2007). Alternatively, it is possible that foraging cormorants were disturbed during tether deployments, and durations until removal may reflect the time until cormorants returned to the area to forage. 
Investigations into the role of cormorants in transmitting top-down effects in Shark Bay could be informative. Habitat use by cormorants in the study area appears to be influenced by a trade-off between food and the risk of tiger shark predation (Heithaus 2005, Heithaus et al. 2009). Predation-sensitive foraging could lead to reduced risk of predation for western striped trumpeter in areas dangerous to cormorants during times when tiger shark abundance is higher. Indo-Pacific bottlenose dolphins also exhibit such predation-sensitive habitat shifts (Heithaus and Dill 2002, 2006) and resulting spatiotemporal variation in risk to western striped trumpeters could lead to differential impacts of fish on primary producer communities in space and time. Recent findings that predation-sensitive foraging by megagrazers can transmit indirect effects of tiger sharks on seagrass (Heithaus et al. 2007, Burkholder et al. 2013b) suggests that investigating the shark-piscivore-trumpeter-primary producer trophic pathway could provide insights into the dynamics of seagrass ecosystems.

My study investigated the variation of diurnal predator encounter rates. However, encounter rates may also vary depending on time of day (Helfman 1986, Danilowicz and Sale 1999). Piscivory on coral reefs was hypothesized to be highest during crepuscular periods (dawn and dusk) because it is a period during which few fish are evident above the reef. Indeed, tethering trials conducted in the US Virgin Islands revealed that diurnal periods had the lowest relative risk of predation on a commonly occurring reef fish compared to dusk and nocturnal periods (Danilowicz and Sale 1999). Further tethering trials conducted during crepuscular and noncturnal periods would be required to determine if time of day may affect the predator encounter rates of western striped trumpeters. 
My tethering trials provided interesting information on anti-predator behavior of western striped trumpeters, specifically the production of alarm calls. Members of the Terapontidae family, including western striped trumpeters, are known to make a characteristic grunting sound when caught by fishers, but the function of these calls is unknown. Although I heard calls during periods when predators were not present, they were not common. Instead, calls where very frequent just prior to a predatory attack. Therefore, while calls likely serve multiple social functions, western striped trumpeters appear to produce alarm calls. Such calls have been suggested for other teleosts. For example, Heyd and Pfieffer (2002) reported vocal behavior in 19 species of catfish and suggested it may serve as an important means of warning and defense. Many fishes from the family Sciaenidae (croakers and drums) produce disturbance calls, yet their exact function is not known (Ramcharitar et al. 2006). Alarm calls could be important in structuring predator-prey interactions involving trumpeter schooling behavior (Sherman 1977). For example, alarm calls by one member of a school are likely to reduce foraging efficiency of an attacking predator or group of predators since individual trumpeters likely could obtain cover in seagrass before a successful series of attacks are made. Therefore, it is possible that small group sizes observed for cormorants (Heithaus 2005) and dolphins (Heithaus and Dill 2002) in shallow waters are necessitated by such effective anti-predator behavior by striped trumpeters. For the caller, benefits of calling might accrue from a confusion effect as other school members flee. Further studies investigating conspecific responses to calls would provide further insights into the importance and implications of alarm calls. 
Tethering impedes escape behaviour and may increase encounter and attack rates relative to untethered prey, therefore, data from experiments like the current study must be interpreted cautiously (Peterson and Black 1994). The methods were designed to minimize particular biases of tethering to facilitate comparisons of predator types and encounter rates across time. For example, tethering in sparse seagrass and sandy areas minimized entanglement with seagrass and the possibility that fish would never leave shelter which may have underestimated predator encounter rates. Tethering in sandy areas, however, may have led to elevated encounter rates because fish were more visible to predators than if they were over dense seagrass, which typifies the shallowest portions of seagrass banks. Post-hoc analyses suggests that fish behaviour while tethered - which did not involve high-speed swimming or erratic swimming and did not differ between individuals that were preyed upon and those that were not - likely did not elevate encounter rates with predators. The proportion of time tethered fish were swimming was slightly higher during the warm than the cold period, which could have increased detection probabilities by cormorants. However, video footage revealed both cormorants and nervous sharks swimming near tethered and active fish but not observing them suggesting that activity levels were not solely responsible for differences in attack rates between periods.

Relating results from tethering to absolute predation risk is difficult (ZimmerFaust et al. 1994), as is determining the relationship between attack rates on tethered fish to predator density (Kneib and Scheele 2000). It is generally thought that both absolute encounter rates and mortality rates are higher during tethering trials than would occur on free-swimming individuals. This may be the case in this study since the tether inhibited 
anti-predator behavior over both long (e.g. moving to safer microhabitats, schooling) and short (i.e. effective escape during attack) time scales. Constraining habitat choice is especially relevant because western striped trumpeters are typically found in heavily vegetated areas (Heithaus 2004) which would reduce detection rates by visual predators and provide hiding places during an encounter. Mismatches between predation rates obtained from tethering and true predation rates in free-ranging individuals could also be driven by non-additive multi-predator effects (Crowder et al. 1997). Although unexplored in Shark Bay, the production of an alarm call could confuse one predator but attract another, or alternatively, increased schooling behaviour may be an effective antipredator behaviour in response to some predators but not others (Jablonski 1999).

Even with the drawbacks of tethering studies, by using the same technique in all trials, remotely video recording the entire trial, and relating results to predator abundance and diet, my methods provided insight into the predator-prey relationship of an abundant facultative grazer in a relatively pristine ecosystem (Aronson and Heck 1995; Aronson et al. 2001). The continuous video footage allowed me to determine the predator identity of all successful fish attacks, frequency of potential predators in the field of view, and monitor differences in tethered fish activity rates in contrasting depths and periods. I learned that cormorants were responsible for the majority of striped trumpeter predation events, and that encounter rates varied between cold and warm periods in accordance with cormorant density in the study area. I also learned that the types of predators threatening western striped trumpeters may change seasonally, and that trumpeters may use alarms calls in response to predatory attacks. The current study has provided the essential first step to investigating how predation may affect teleost grazing patterns in 
Shark Bay. Further studies are needed to investigate seasonal differences in striped trumpeter abundance, habitat use, and grazing rates and to determine if these aspects may be influenced by piscivores.

\section{References}

Abrahams, M., and M. Kattenfeld. 1997. The role of turbity as a constraint on predatorprey interactions in aquatic environments. Behav. Ecol. Sociobiol. 40:169-174.

Abrahams, M., M. Mangel, and K. Hedges. 2007. Predator-prey interactions and changing environments: who benefits? Phil. Trans. R. Soc. B. 362: 2095-2104.

Armitage, A.R., and J.W. Fourqurean. 2006. The short-term influence of herbivory near patch reefs varies between seagrass species. J. Exp. Marine Biol. and Ecol. 339: 65-74.

Aronson, R.B., and K.L. Jr. Heck. 1995. Tethering experiments and hypothesis testing in ecology. Mar. Ecol. Prog. Ser. 121: 307-309.

Aronson, R.B., K.L. Jr. Heck, and J.F. Valentine. 2001. Measuring predation with tethering experiments. Mar. Ecol. Prog. Ser. 214: 311-312.

Blaber, S.J.M., and T.J. Wassenberg. 1989. Feeding ecology of the piscivorous birds Phalcrocorax varius, P. melanoleucos, and Sterna bergii in Moreton Bay, Australia: diets and dependence on trawler discards. Mar. Biol. 101: 1-10.

Brown J.S., and B.P. Kotler. 2004. Hazardous duty pay and the foraging cost of predation. Ecol. Lett. 7: 999-1014.

Burkholder, D.A., M.R. Heithaus, and J.A. Fourqurean. 2012. Feeding preferences of herbivores in a relatively pristine subtropical seagrass ecosystem. Mar. Freshwater Res. 63: 1051-1058.

Burkholder, D.A., M.R. Heithaus, J.W. Fourqurean, A. Wirsing, and L.M. Dill. 2013a. Patterns of top-down control in a seagrass ecosystem: could a roving apex predator induce a behaviour-mediated trophic cascade? J. Anim. Ecol. (In press).

Burkholder, D. A., J. A. Fourqurean, and M. R. Heithaus. 2013b. Spatial pattern in seagrass stoichiometry indicates both N-limited and P-limited regions of an iconic Plimited subtropical bay. Mar. Ecol. Prog. Ser. 472: 101-115.

Creel, S., and D. Christianson. 2008. Relationships between direct predation and risk effects. Trends. Ecol. Evol. 23(4): 194-201. 
Crowder, L.B., D.D. Squirres, and J.A. Rice. 1997. Nonadditive effects of terrestrial and aquatic predators on juvenile estuarine fish. Ecology 78(6): 1796-1804.

Danilowicz, B.S., and P.F. Sale. 1999. Relative intensity of predation on the French grunt, Haemulon avolineatum, during diurnal, dusk, and nocturnal periods on a coral reef. Mar. Bio. 133: 337-343.

Davis, A.M., P.J. Unmack, B.J. Pusey, J.B. Johnson, and R.G. Pearson. 2012. Marinefreshwater transitions are associated with the evolution of dietary diversification in terapontid grunters (Teleostei: Terapontidae). J. Evol. Biol. 1163-1179.

del Hoyo, J., A. Elliot, and J. Sargatal. 1992. Handbook of the Birds of the World, vol.1: Ostrich to Ducks. Lynz Edicions, Barcelona, Spain.

Dill, L.M., M.R. Heithaus, and C.J. Walters. 2003. Behaviorally mediated indirect interactions in marine communities and their conservation implications. Ecology. 84(5): 1151-1157.

Duffy, J.E., and M.E. Hay. 2000. Strong impacts of grazing amphipods on the organization of a benthic community. Ecol. Monograph. 70(2): 237-263.

Dunphy-Daly, M.M., M.R. Heithaus, A.J. Wirsing, J.S.F. Mardon, and D.A. Burkholder. 2010. Predation risk influences the diving behavior of a marine mesopredator. Open Ecol. J. 3: 8-15.

Eriksson, B.K., L. Ljunggren, A. Sandstrom, G. Johansson, J. Mattila, A. Rubach, S. Raberg, and M. Snickars. 2009. Declines in predatory fish promote bloom-forming macroalgae. Ecol. Appl. 19(8): 1975-1988.

Estes, J.A., J. Terborgh, J.S. Brashares, M.E. Power, J. Berger, W.J. Bond, S.R. Carpenter, T.E. Essington, R.D. Holt, J.B.C. Jackson, R.J. Marquis, L. Oksanen, T. Oksanen, R.T. Paine, E.K. Pikitch, W.J. Ripple, S.A. Sandin, M. Scheffer, T.W. Schoener, J.B. Shurin A.R.E. Sinclair, M.E. Soule, R. Virtanen, and D.A. Wardle. 2011. Trophic downgrading of planet Earth. Science. 333: 301-306.

Haine, O.S., P.V. Ridd, and R.J. Rowe. 2001. Range of electrosensory detection of prey by Carcharhinus melanopterus and Himantura granulate. Mar. Freshwater. Res. 52: 291-296.

Hairston, N.G., F.E. Smith, and L.B. Slobodkin. 1960. Community structure, population control, and competition. Am. Nat. 94(879): 421-425.

Heck, K.L.Jr., and J.F. Valentine. 2006. Plant-herbivore interactions in seagrass meadows. J. Exp. Mar. Biol. Ecol. 330: 420-436. 
Heithaus, M.R. 2004. Fish communities of subtropical seagrass meadows and associated habitats in Shark Bay, Western Australia. Bull. Mar. Sci. 75(1): 79-99.

Heithaus, M.R. 2005. Habitat use and group size of pied cormorants (Phalacrocorax varius) in a seagrass ecosystem: possible effects of food abundance and predation risk. Mar. Bio., 147: 27-35.

Heithaus, M.R., and L.M. Dill. 2002. Food availability and tiger shark predation risk influence bottlenose dolphin habitat use. Ecology. 83: 480-491.

Heithaus, M.R., and L.M. Dill. 2006. Does tiger shark predation risk influence foraging habitat use by bottlenose dolphins at multiple spatial scales? Oikos. 114: 257-264.

Heithaus, M.R., A. Frid. A.J. Wirsing, L.M. Dill, J. Fourqurean, D. Burkholder, J. Thomson, and L. Bejder. 2007. State-dependent risk-taking by green sea turtles mediates top-down effects of tiger shark intimidation in a marine ecosystem. J. Anim. Ecol., 76: 837-844.

Heithaus, M.R., A. Frid, A.J. Wirsing, and B. Worm. 2008a. Predicting ecological consequences of marine top predator declines. Trends. Ecol. Evol. 23(4): 202-210.

Heithaus, M.R., A. J. Wirsing, J.A. Thomson, and D.A. Burkholder. 2008b. A review of lethal and non-lethal effects of predators on adult marine turtles. J. Exp. Mar. Biol. Ecol., 356: $43-51$.

Heithaus, M.R., A.J. Wirsing, D. Burkholder, J. Thomson, and L.M. Dill. 2009. Towards a predictive framework for predator risk effects: the interaction of landscape features and prey escape tactics. J. Anim. Ecol. 78:556-562.

Helfman, G.S. 1986. Fish behavior by day, night, and twilight. In: Pitcher, T.J. (ed). The behavior of teleost fishes. Croom-Helm, London, pp. 366-387.

Heyd, A., and W. Pfeiffer. 2000. Sound production in catfish (Siluroidei, Ostariophysi, Teleostei) and its relationship to phylogeny and fright reaction. Revue. Suisse De Zoologie. 107(1): 165-211.

Jablonski, P. G. 1999. A rare predator exploits prey escape behavior: the role of tailfanning and plumage contrast in foraging of the painted redstart (Myioborus pictus).

Behav. Ecol. 10: 7-14.

Kirsch, K.D., J.F. Valentine, and K.L.Jr. Heck. 2002. Parrotfish grazing on turtlegrass Thalassia testudinum: evidence for the importance of seagrass consumption in food web dynamics of the Florida Keys National Marine Sactuary. Mar. Ecol. Prog. Ser. 227: 7185. 
Kneib, R.T., and C.E.H. Scheele. 2000. Does tethering of mobile prey measure relative predation potential? an empirical test using mummichogs and grass shrimp. Mar. Ecol. Prog. Ser. 198: 181-190.

Lank, D.B., and R.C. Ydenberg. 2003. Death and danger at migratory stopovers: problems with "predation risk". J. Avian Bio. 34: 225-228.

Lewis, L.S., and T.W. Anderson. 2012. Top-down control of epifauna by fishes enhances seagrass production. Ecology 93(12): 2746-2757.

Lima, S.L., and L.M. Dill. 1990. Behavioral decisions made under the risk of predation: a review and prospectus. Can. J. Zool. 68: 619-640.

Moksnes, P-O., M. Gullstrom, K. Tryman, and S. Baden. 2008. Trophic cascades in a temperate seagrass community. Oikos 117: 763-777.

Pages, J.F., S. Farina, A. Gera, R. Arthur, J. Romeros, and T. Alcoverro. 2012. Indirect interactions in seagrasses: fish herbivores increase predation risk to sea urchins by modifying plant traits. Func. Ecol. 26: 1015-1023.

Peterson, C.H., and R. Black. 1994. An experimentalist's challenge: when artefacts of intervention interact with treatments. Mar. Ecol. Prog. Ser. 111: 289-297.

Poore, A.G.B., A.H. Campbell, and P.D. Steinberg. 2009. Natural densities of mesograzers fail to limit growth of macroalgae or their epiphytes in a temperate algal bed. J. Ecol. 97: 164-175.

Preisser, E.L., D.I. Bolnick, and M.F. Benard. 2005. Scared to death? The effects of intimidation and consumption in predator-prey interactions. Ecology. 86(2): 501-509.

R Development Core Team. 2011. R: a language and environment for statistical computing. R Foundation for Statistical Computing, Vienna, http://www.R-project.org.

Ramcharitar, J., D.P. Gannon, and A.N. Popper. 2006. Bioacoustics of fishes of the family Sciaenidae (croakers and drums). Trans. Am. Fish. Soc. 135(5): 1409-1431.

Ritchie, E.G., and C.N. Johnson. 2009. Predator interactions, mesopredator release and biodiversity conservation. Ecol. Lett. 12: 982-998.

Schmitz, O.J., V. Krivan, and O. Ovadia. 2004. Trophic cascades: the primacy of traitmediated indirect interactions. Ecol. Lett. 7: 153-163

Sherman, P.W. 1977. Nepotism and the evolution of alarm calls. Science 197: 12461253.

Smith S.V., and M.J. Atkinson. 1983. Mass balance of carbon and phosphorus in Shark Bay, Western Australia. Limnol. Oceanogr. 28: 625-639. 
Strod, T., I. Izhaki, Z. Arad, and G. Katzir. 2008. Prey detection by great cormorant (Phalacrocorax carbo sinensis) in clear and in turbid water. J. Exp. Biol. 211: 866-872.

Tomas, F., X. Turon, and J. Romero. 2005. Seasonal and small-scale spatial variability of herbivory pressure on the temperate seagrass Posidonia oceanica. Mar. Ecol. Prog. Ser. 301: 95-107.

Valentine, J.F., K.L. Jr. Heck., D. Blackmon, M.E. Goecker, J. Christian, R. Kroutil, K.D. Kirsch, B. Peterson, M. Beck, and M.A. Vanderklift. 2007. Food web interactions along seagrass-coral reef boundaries: effects of piscovore reductions on cross-habitat energy exchange. Mar. Ecol. Prog. Ser. 333: 37-50.

Vaudo, J.J., and M.R. Heithaus. 2009. Spatiotemporal variability in a sandflat elasmobranch fauna in Shark Bay, Australia. Mar. Bio. 156(12): 2579-2590.

Vaudo, J.J., and M.R. Heithaus. 2011. Dietary niche overlap in a nearshore elasmobranch mesopredator community, Mar. Ecol. Prog. Ser. 425: 247-260.

Walker, D.I., G.A. Kendrick, and A.J. McComb. 1988. The distribution of seagrass species in Shark Bay, Western Australia, the notes on their ecology. Aquatic. Bot. 30: 205-317.

White, W.T., and I.C. Potter. 2004. Habitat partitioning among four elasmobranch species in nearshore, shallow waters of a subtropical embayment in Western Australia. Mar. Biol. 145: 1023-1032.

White, W.T., M.E. Platell, and I.C. Potter. 2004. Comparisons between the diets of four abundant species of elasmobranchs in a subtropical embayment: implications for resource partitioning. Mar. Biol. 144: 439-448.

Wilson, C.J., P.S. Wilson, C.A. Greene, and K.H. Dunton. 2013. Seagrass meadows provide an acoustic refuge for estuarine fish. Mar. Ecol. Prog. Ser. 472: 117-127.

Wirsing, A.J., M.R. Heithaus, and L.M. Dill. 2007. Fear factor: do dugongs (Dugong dugon) trade food for safety from tiger sharks (Galeocerdo cuvier)?. Oecologia. 153: 1031-1040.

Zimmer-Faust, R.K., D.R. Fielder, K.L. Jr. Heck, L.D. Coen, S.G. Morgan. 1994.

Effects of tethering on predatory escape by juvenile blue crabs. Mar. Ecol. Prog. Ser. 111: 299-303. 
CHAPTER IV:

SPATIAL AND TEMPORAL VARIATION IN THE ABUNDANCE OF THREE DOMINANT TELEOSTS WITHIN A SEAGRASS ECOSYSTEM 
Abstract

Spatial and temporal variation in abundance shapes the scale and magnitude at which herbivores might impact primary producer communities. Yet, for herbivorous fishes in seagrass ecosystems - especially those that have been relatively unimpacted by humans - relatively little is know about patterns of abundance. I used a combination of fish trapping and unbaited remote underwater video surveillance (URUVS) to investigate spatial and temporal variation in relative abundance of three commonly occurring teleost species within the seagrass meadows of Shark Bay, Western Australia. Two species are grazers on macroalgae and seagrasses or their epiphytes (Pelates octolineatus and Monacanthus chinensis, respectively), while the other is an abundant invertivore (Pentapodus vitta). All target species were observed in both edge and interior microhabitats of shallow seagrass banks during both the warm and cold season. Unbaited remote underwater surveillance revealed there was a greater number of both $P$. octolineatus and $P$. vitta in interior compared to edge microhabitats during the cold season. In addition, $P$. octolineatus lengths were significantly greater for fish caught in interior microhabitats. Within shallow seagrass beds, these species have the potential to exert considerable impacts on epiphytes (M. chinensis), seagrass and macroalgae ( $P$. octolineatus), and invertebrates ( $P$. vitta) that may vary seasonally and spatially. 
Introduction

Seagrass beds provide both abundant food resources and shelter for a diverse array of marine organisms, including economically important finfish (Connolly 1994, Heck et al. 2003). Although seagrass ecosystems are among the most productive systems in the world, they are also among the most threatened, and are estimated to be disappearing at a rate of $110 \mathrm{~km}^{2} \mathrm{yr}^{-1}$ since 1980 (Waycott et al. 2009). Multiple factors, including climate change, habitat degradation, and eutrophication have all contributed to seagrass declines (Hughes et al. 2004, Orth et al. 2006), which in turn leads to the reduction of crucial habitat for the organisms they support. The global decline has prompted an increased interest in understanding the factors driving the dynamics of seagrass communities and their inhabitants.

Teleost grazers may play an important role in seagrass community dynamics (Armitage and Fourqurean 2006). However, to understand their role in these communities, it is important to gain an understanding of their patterns of habitat use and abundance under relatively pristine conditions. Shark Bay, Western Australia, offers a model system in which to investigate the relative abundance of teleost grazers in a seagrass system; it is one of the largest intact seagrass ecosystems in the world and features a high abundance of at least two facultative herbivore grazers; the western striped trumpeter (Pelates octolineatus, previously referred to as $P$. sexlineatus), and the fan-bellied leatherjacket (Monacanthus chinensis) (Travers and Potter 2002, Heithaus 2004).

Multiple techniques are used to investigate fish abundance and distribution, including seining, trawling, fish trapping, visual census and underwater video 
surveillance (Munro 1974, Jacobsen and Kushlan 1989, Collins 1990, Travers and Potter 2002, Edgar et al. 2004, Harvey et al. 2007), all of which have their own biases. For example, fish trapping can underestimate fish densities (Jacobsen and Kushlan 1989) and result in selective sampling of communities (Ovegard et al. 2011), while baited remote underwater video surveillance can attract greater numbers of predatory and scavenging species (Harvey 2007) and converting counts to density data can be difficult (Miller and Hunte 1987). Using the same technique in different habitats or times of the year, however, facilitates insights into relative abundance and distribution providing the particular method employed is not biased by the differences presented by contrasting habitats or seasons. Employing multiple techniques with differing biases concurrently can provide even greater insights (Harvey et al. 2012, Nett et al. 2012).

In this study, I use a combination of fish trapping and un-baited remote underwater video surveillance (URUVS) to obtain insight into the factors affecting relative abundance and distribution of two common teleost herbivores, and one abundant invertivore (that could prey upon invertebrate grazers) in the relatively pristine seagrass ecosystem of Shark Bay, Western Australia.

Methods

Study Site

This study was conducted in the Eastern Gulf of Shark Bay $\left(25^{\circ} 45^{\prime} \mathrm{S}, 113^{\circ} 44^{\prime} \mathrm{E}\right)$, Western Australia, in the seagrass banks offshore of Monkey Mia. Water temperatures are generally high during September to May (warm season; $>20^{\circ} \mathrm{C}$ ), but can reach as low as $12^{\circ} \mathrm{C}$ during June to August (cold season; $<20^{\circ} \mathrm{C}$ ) (Heithaus and Dill 2002). The 
shallow seagrass banks can be divided into edge $(2.5 \mathrm{~m}-4.5 \mathrm{~m}$ depth, and $<2.5 \mathrm{~m}$ depth that are within $75 \mathrm{~m}$ from water $>4.5 \mathrm{~m}$ depth) and interior $(<2.5 \mathrm{~m}$ depth and $>75 \mathrm{~m}$ from deep waters) microhabitats, which consist of seagrasses, algae, and occasional sand patches (Heithaus and Dill 2006). The shallow seagrass banks are bisected by deep water channels (6-12 m depth) that consist primarily of sand-bottoms and occasional seagrass patches (Burkholder et al. 2013).

The seagrass beds of the study site are dominated by two slow-growing and largebodied species (Amphibolis antartica, Posidonia australis), but fast-growing, smallbodied species (Cymodocea angustata, Cymodocea serrulata, Halodule uninervis, Halophila ovalis, Halophila spinulosa, Syringodium isoetifolium) also occur less frequently throughout the understory and along the periphery of the more dominate seagrass species (Walker et al. 1988, Burkholder et al. 2013). The percent cover of seagrass in the interior microhabitat is significantly greater than that of the edge microhabitat ( $\sim 90 \%$ compared to $\sim 30 \%$, respectively, Chapter II). The area also hosts an abundance of macroalgae; ca. 160 taxa (Kendrick et al. 1990), with red algae (Laurencia sp., Haliptilon roseum; Rhodophyta) and brown algae (Dictyota furcellata, and Sargassum sp.; Heterokontophyta) commonly occurring in the study area (Chapter II). The percent cover of these commonly occurring algae do not differ between edge and interior microhabitats.

A greater abundance of teleost species can be caught in vegetated areas of the study site compared to deeper water habitats (Heithaus 2004), with the most abundant species being Pelates octolineatus (previously referred to as Pelates sexlineatus). P. octolineatus (Terapontidae) is an omnivore (Paxton et al. 1989), although primary producers 
constitute the large majority of stomach contents (Chapter II). They are a demersal species that reach a maximum length of approximately $28.0 \mathrm{~cm}$ (Gomon et al. 1994). $M$. chinensis (Monacanthidae) is also an omnivore which consumes considerable amounts of seagrass and algae (Bell et al. 1978). M. chinensis inhabit estuaries, reefs and weed bottoms, and reach a maximum length of approximately $38.0 \mathrm{~cm}$ (May and Maxwell 1986). P. vitta is an abundant bycatch species in recreational fisheries which reaches a maximum length of $26.0 \mathrm{~cm}$ and has a life span of eight years (Mant et al. 2006). The distribution of these target species within edge and interior microhabitats of the shallow seagrass banks has not been previously investigated.

\section{Field Methods}

I used two methods with different biases - fish trapping and unbaited remote underwater video surveillance (URUVS) - to assess spatial and temporal variation in relative abundances. I deployed rectangular fish traps ( 34 × 24 x $21 \mathrm{~cm}$ with $1.2 \times 1.3 \mathrm{~cm}$ mesh, with straight $10 \mathrm{~cm}$ conical entrances that tapered from a $6 \mathrm{~cm}$ to $4 \mathrm{~cm}$ diameter opening) concurrently in edge and interior microhabitats of three banks. Each trap contained a bait bag filled with $\sim 100 \mathrm{~g}$ of whole squid tube. Fish traps were haphazardly dropped within randomly assigned sections (north, middle, and south) of each seagrass bank, specifically avoiding sand. Traps were deployed during daylight hours for 90-180 minutes (mean $\pm \mathrm{SD}=131 \pm 18 \mathrm{~min}$ ), between 0800-1700. For each trap deployment, I recorded the GPS location, depth, water temperature, soak time, identity and quantity of fish taxa. All fish obtained from traps were identified to lowest possible taxonomic group and measured for fork length $( \pm 0.1 \mathrm{~cm})$. Fish trapping was conducted over the cold seasons (June-August) and the warm seasons (February - May) of 2011 and 2012. The 
mean water temperatures corresponding to trap deployments were $26.4 \pm 1.4^{\circ} \mathrm{C}$ $\left(\right.$ mean $\pm \mathrm{SD}$ ) and $17.6 \pm 2.3^{\circ} \mathrm{C}$ during the warm and cold season, respectively. The mean depths corresponding to trap deployments were $4.25 \pm 0.5 \mathrm{~m}$ (mean $\pm \mathrm{SD})$ and $2.06 \pm 0.5 \mathrm{~m}$ for edge and interior microhabitats, respectively. For the purposes of analyses I collapsed data from multiple years.

For URUVS, I used GoPro Hero (Woodman Labs, http://gopro.com, Nov.20’2012) underwater cameras, mounted to 8kg I-beams. URUVS were deployed in edge and interior microhabitats of seagrass banks during the cold seasons (July to August) of 2011 and 2012, and the warm season of 2012 (February to May). The mean water temperature corresponding to URUVS deployments was $24.2 \pm 1.9^{\circ} \mathrm{C}$ and $18.2 \pm 1.5^{\circ} \mathrm{C}$ during the warm and cold seasons, respectively. Cameras sat at a height of $c a .70 \mathrm{~cm}$ above the sea floor, which allowed for a standardized view parallel to the sea floor but above the seagrass canopy. Cameras were deployed for 120-240 min, and provided continuous video surveillance (mean $\pm \mathrm{SD}=199 \pm 24 \mathrm{~min})$. Video recordings were analyzed by stopping the video every 5 minutes, identifying all fish to lowest possible taxonomic group, and quantifying the total number of each species in the screen shot. I summed the total number of fish and species observed from these frames thereby limiting the chances of counting the same individual multiple times. The first 15 minutes of each video was not included in analysis to avoid disturbance from the presence of the boat during deployment. Because water clarity limited visibility, especially during the warm season, I limited URUVS data analysis to include only videos that allowed for identification of fish up to approximately two meters in front of the camera. As a result, 
only 14 useable URUVS deployments were obtained during the warm season (five in edge and nine in interior microhabitats). Due to the small sample size for microhabitat comparisons, these data are not presented. Rather, I focus analyses of URUVS data on a comparison of relative fish abundance between interior and edge microhabitats during the cold season. The mean depths corresponding to camera deployments were $3.71 \pm 1.0 \mathrm{~m}$ $(\mathrm{mean} \pm \mathrm{SD})$ and $1.77 \pm 0.5 \mathrm{~m}$ for edge and interior microhabitats, respectively.

I determined the number of fish caught or sighted per trap or camera deployment for the three most abundant species. Catches, or sightings, per deployment were nonnegative, and right skewed, due to data being zero-inflated. In some cases, treating the zeros separately can provide a more efficient estimate of abundance since the sample mean is sensitive to the occasional extreme observation (Pennington 1983, Syrjala 2000), and theory suggest that the count values and excess zeros may be generated by separate processes (Long 1997). To account for this, I examined the effects of season (cold/warm), microhabitat (edge/interior), and the interaction of season and microhabitat on catches using a zero-inflated Poisson regression; a Poisson distribution with log link function for the count model and a binomial distribution with a logit link for predicting excess zeros (eg. complete absence of the species in the trap; Martin et al. 2005, Bolker 2008). I used a zero-inflated Poisson regression to analyze URUVS data which included only microhabitat as a predictor. I computed the expected number of fish sightings per microhabitat using predictions from the zero-inflated Poisson regression model.

A linear regression was also used to investigate the effect of season and microhabitat on log transformed fish length, and a Tukey's Test was used to determine 
multiple pairwise comparisons. For one species, the normalization of fish length data was not possible, in which case I used non-parametric statistics to evaluate any seasonal or habitat effects (Kruskal-Wallis Test). All analyses were conducted in R (version 3.0.0; R Development Core Team 2011).

Results

I deployed 82 traps over 12 different days during the cold season; 38 in edge microhabitat and 44 in interior microhabitat. I deployed 43 traps over 6 different days in the warm season; 21 in edge and 22 in interior microhabitats. I captured eight species during the cold season, nine species during the warm season, and a total of 974 fish (Table 4.1). The three most abundant species in fish traps during both seasons were Pelates octolineatus (Teraponidae), Monacanthus chinensis (Monacathidae), and Pentapodus vitta (Nemipteridae).

When fish were present in the trap, there was effect of soak time on catches $(\mathrm{F}=2.80, \mathrm{df}=1,98, \mathrm{p}=0.10)$. There was also no significant relationship of season, microhabitat, or their interaction, in either the number of fish caught per trap deployment, or the probability of catching at least one fish, for any of the species analyzed (Table 4.24.4).

A total of 67 usable URUVS were obtained during the cold season over 16 different days (38 in edge microhabitat, 29 in interior microhabitat). Soak time of cameras did not affect the average number of fish observed per frame grab during URUVS deployments $(\mathrm{F}=0.52, \mathrm{df}=1,61, \mathrm{p}=0.48)$. The probability of sighting at 
Table 4.1: Composition and number of species caught in traps by season and microhabitat.

\begin{tabular}{|c|c|c|c|c|}
\hline \multirow[b]{2}{*}{ Species } & \multicolumn{2}{|c|}{ Cold } & \multicolumn{2}{|c|}{ Warm } \\
\hline & Edge & Interior & Edge & Interior \\
\hline \multicolumn{5}{|l|}{ Terapontidae } \\
\hline Pelates octolineatus & 162 & 149 & 106 & 101 \\
\hline Amniataba caudavittata & & 1 & & \\
\hline Monacanthidae & & & & \\
\hline Monacanthus chinensis & 73 & 49 & 97 & 87 \\
\hline $\begin{array}{l}\text { Unidentified Monacanthus sp. } \\
\text { Nemipteridae }\end{array}$ & 1 & & & \\
\hline Pentapodus vitta & 36 & 25 & 20 & 37 \\
\hline Tetraodontidae & & & & \\
\hline $\begin{array}{l}\text { Torquigener pleurogramma } \\
\text { Mullidae }\end{array}$ & & 3 & & \\
\hline $\begin{array}{l}\text { Upeneus sp. } \\
\text { Lethrinidae }\end{array}$ & & & 1 & 2 \\
\hline $\begin{array}{l}\text { Lethrinus sp. } \\
\text { Pseudochromidae }\end{array}$ & & 1 & 6 & 7 \\
\hline $\begin{array}{l}\text { Labracinus lineatus } \\
\text { Latidae }\end{array}$ & 2 & & 2 & \\
\hline Psammoperca waigiensis & & & 1 & 3 \\
\hline Labridae & & & & \\
\hline Choerodon sp. & & & 1 & \\
\hline Unidentified sp. & & & 1 & \\
\hline
\end{tabular}


Table 4.2: Zero-inflated model results of parameters affecting $P$. octolineatus catch per trap deployment.

\begin{tabular}{lcccc}
\hline Parameter & Estimate & Std. Error & $\mathrm{z}$ value & $\operatorname{Pr}(>|\mathrm{z}|)$ \\
\hline$\quad$ Count Model & & & & \\
Intercept & 1.55 & 0.78 & 2.00 & 0.05 \\
Season & 0.43 & 0.48 & 0.91 & 0.36 \\
Microhabitat & 0.10 & 0.31 & 0.33 & 0.74 \\
Season*Microhabitat & 0.15 & 0.19 & -0.81 & 0.42 \\
$\quad$ Zero-Inflated Model & & & & \\
Intercept & 4.25 & 3.82 & -1.11 & 0.27 \\
Season & 2.72 & 2.16 & 1.26 & 0.21 \\
Microhabitat & 0.82 & 1.48 & 0.56 & 0.58 \\
Season*Microhabitat & 0.64 & 0.84 & -0.77 & 0.45 \\
\hline
\end{tabular}


Table 4.3: Zero-inflated model results of parameters affecting $M$. chinensis catch per trap deployment.

\begin{tabular}{lcccc}
\hline Parameter & Estimate & Std. Error & $\mathrm{z}$ value & $\operatorname{Pr}(>|\mathrm{z}|)$ \\
\hline$\quad$ Count Model & & & & \\
Intercept & 2.65 & 0.89 & 2.97 & $<0.01 *$ \\
Season & -0.57 & 0.61 & -0.93 & 0.35 \\
Microhabitat & -0.09 & 0.36 & -0.26 & 0.79 \\
Season*Microhabitat & -0.02 & 0.25 & -0.07 & 0.95 \\
$\quad$ Zero-Inflated Model & & & & \\
Intercept & -0.76 & 3.65 & -0.21 & 0.84 \\
Season & -0.46 & 2.10 & -0.22 & 0.83 \\
Microhabitat & -0.46 & 1.42 & -0.32 & 0.75 \\
Season*Microhabitat & 0.61 & 0.82 & 0.74 & 0.46 \\
\hline
\end{tabular}


Table 4.4: Zero-inflated model results of parameters affecting P.vitta catch per trap deployment.

\begin{tabular}{lcccc}
\hline Parameter & Estimate & Std. Error & $\mathrm{z}$ value & $\operatorname{Pr}(>|\mathrm{z}|)$ \\
\hline$\quad$ Count Model & & & & \\
Intercept & 0.42 & 1.91 & 0.22 & 0.83 \\
Season & 0.24 & 1.18 & 0.20 & 0.84 \\
Microhabitat & 0.27 & 0.72 & 0.37 & 0.71 \\
Season*Microhabitat & -0.19 & 0.46 & -0.42 & 0.67 \\
$\quad$ Zero-Inflated Model & & & & \\
Intercept & 6.46 & 4.00 & 1.61 & 0.11 \\
Season & -3.88 & 2.36 & -1.65 & 0.10 \\
Microhabitat & -2.95 & 1.60 & -1.84 & 0.07 \\
Season*Microhabitat & 1.81 & 0.94 & 1.93 & 0.05 \\
\hline & & & &
\end{tabular}


least one $P$. octolineatus during a URUVS deployment during the cold season did not differ between microhabitats (Table 4.5), but the predicted number of $P$. octolineatus sighted per camera deployment, when present, was greater for interior (8.9) than edge (8.1) microhabitats (Table 4.5). No effect of microhabitat was observed for the probability of sighting M. chinensis, nor the number sighted (Table 4.6). Although the probability of sighting $P$. vitta did not differ between microhabitats, the predicted number of $P$. vitta sighted was almost three times greater in interior (9.2) than edge (3.3) microhabitats (Table 4.7).

The three focal species of fish caught in traps were typically between $5 \mathrm{~cm}$ to 25 $\mathrm{cm}$ (Figure 4.1). Pelates octolineatus lengths caught in interior microhabitats during the cold season were significantly greater than those caught in edge microhabitats during both seasons, and greater than those caught in interior microhabitats during the warm season (Table 4.8, Figure 4.2). Both M. chinensis and P. vitta were slightly larger during the cold season (Table 4.7, Figure 4.3). 
Table 4.5: Zero-inflated model results for the effect of microhabitat on P. octolineatus sightings during URUVS in the cold season.

\begin{tabular}{lcccc}
\hline Parameter & Estimate & Std. Error & $\begin{array}{c}z \\
\text { value }\end{array}$ & $\operatorname{Pr}(>|z|)$ \\
\hline$\quad$ Count Model & & & & \\
Intercept & 2.96 & 0.06 & 52.05 & $<0.001^{*}$ \\
Microhabitat & 0.29 & 0.08 & 3.39 & $<0.001^{*}$ \\
$\quad$ Zero-Inflated Model & & & & \\
Intercept & 0.32 & 0.33 & 0.97 & 0.33 \\
Microhabitat & 0.32 & 0.51 & 0.63 & 0.53 \\
\hline
\end{tabular}


Table 4.6: Zero-inflated model results for the effect of microhabitat on $M$. chinensis sightings during URUVS in the cold season.

\begin{tabular}{lcccc}
\hline Parameter & Estimate & Std. Error & $\mathrm{z}$ value & $\operatorname{Pr}(>|\mathrm{z}|)$ \\
\hline \multicolumn{1}{c}{ Count Model } & & & & \\
Intercept & 2.16 & 0.06 & 36.96 & $<0.001^{*}$ \\
Microhabitat & -0.15 & 0.10 & -1.57 & 0.12 \\
$\quad$ Zero-Inflated Model & & & & \\
Intercept & -2.14 & 0.53 & -4.05 & $<0.001^{*}$ \\
Microhabitat & 0.80 & 0.70 & 1.13 & 0.26 \\
\hline
\end{tabular}


Table 4.7: Zero-inflated model results for the effect of microhabitat on $P$. vitta sightings during URUVS in the cold season.

\begin{tabular}{lcccc}
\hline Parameter & Estimate & Std. Error & $\mathrm{z}$ value & $\operatorname{Pr}(>|\mathrm{z}|)$ \\
\hline \multicolumn{1}{c}{ Count Model } & & & & \\
Intercept & 2.64 & 0.05 & 49.25 & $<0.001^{*}$ \\
Microhabitat & -0.90 & 0.12 & -7.77 & $<0.001^{*}$ \\
$\quad$ Zero-Inflated Model & & & & \\
Intercept & -0.65 & 0.34 & -1.91 & 0.06 \\
Microhabitat & 0.30 & 0.51 & 0.58 & 0.56 \\
\hline
\end{tabular}


Figure 4.1: Size (fork length) distributions of three common teleosts.
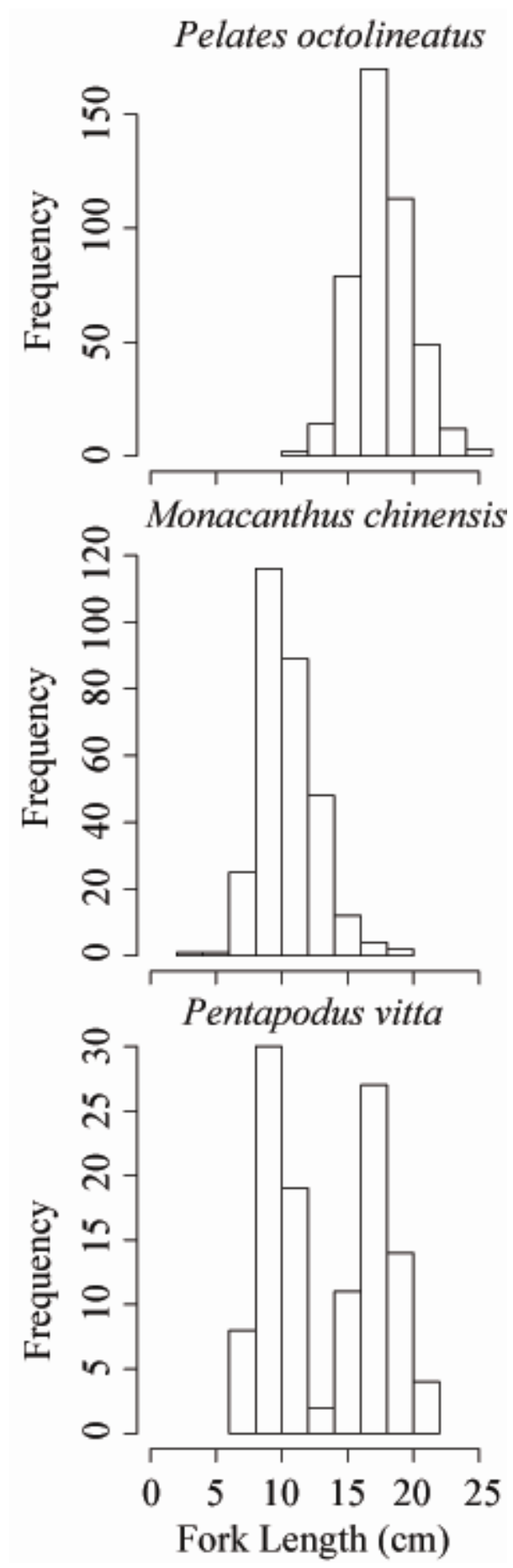
Table 4.8: ANOVA results for possible predictors of fish length.

\begin{tabular}{lccccc}
\hline \multicolumn{1}{c}{ Predictors } & $\mathrm{df}$ & SS & Mean SS & F value & p value \\
\hline \multicolumn{1}{c}{ P. octolineatus } & & & & & \\
Season & 1 & 0.11 & 0.11 & 7.45 & $<0.01^{*}$ \\
Microhabitat & 1 & 0.75 & 0.75 & 52.84 & $<0.001^{*}$ \\
Season*Microhabitat & 1 & 0.15 & 0.15 & 10.57 & $<0.001^{*}$ \\
Residuals & 439 & 6.23 & 0.01 & & \\
$\quad$ M. chinensis & & & & & \\
Season & 1 & 0.22 & 0.22 & 5.02 & $0.03 *$ \\
Microhabitat & 1 & 0.13 & 0.13 & 3.03 & 0.08 \\
Season*Microhabitat & 294 & 0.03 & 0.03 & 0.63 & 0.43 \\
Residuals & 12.68 & 0.04 & & \\
\multicolumn{1}{c}{$P$. vitta } & Kruskal-Wallis Test & & & \\
Season & $\mathrm{df}=1$ & $\chi 2=7.39$ & $\mathrm{p}<0.01 *$ & & \\
Microhabitat & $\mathrm{df}=1$ & $\chi 2=0.63$ & $\mathrm{p}=0.43$ & & \\
\hline
\end{tabular}


Figure 4.2: Spatial and temporal patterns of fork length of $P$. octlineatus.

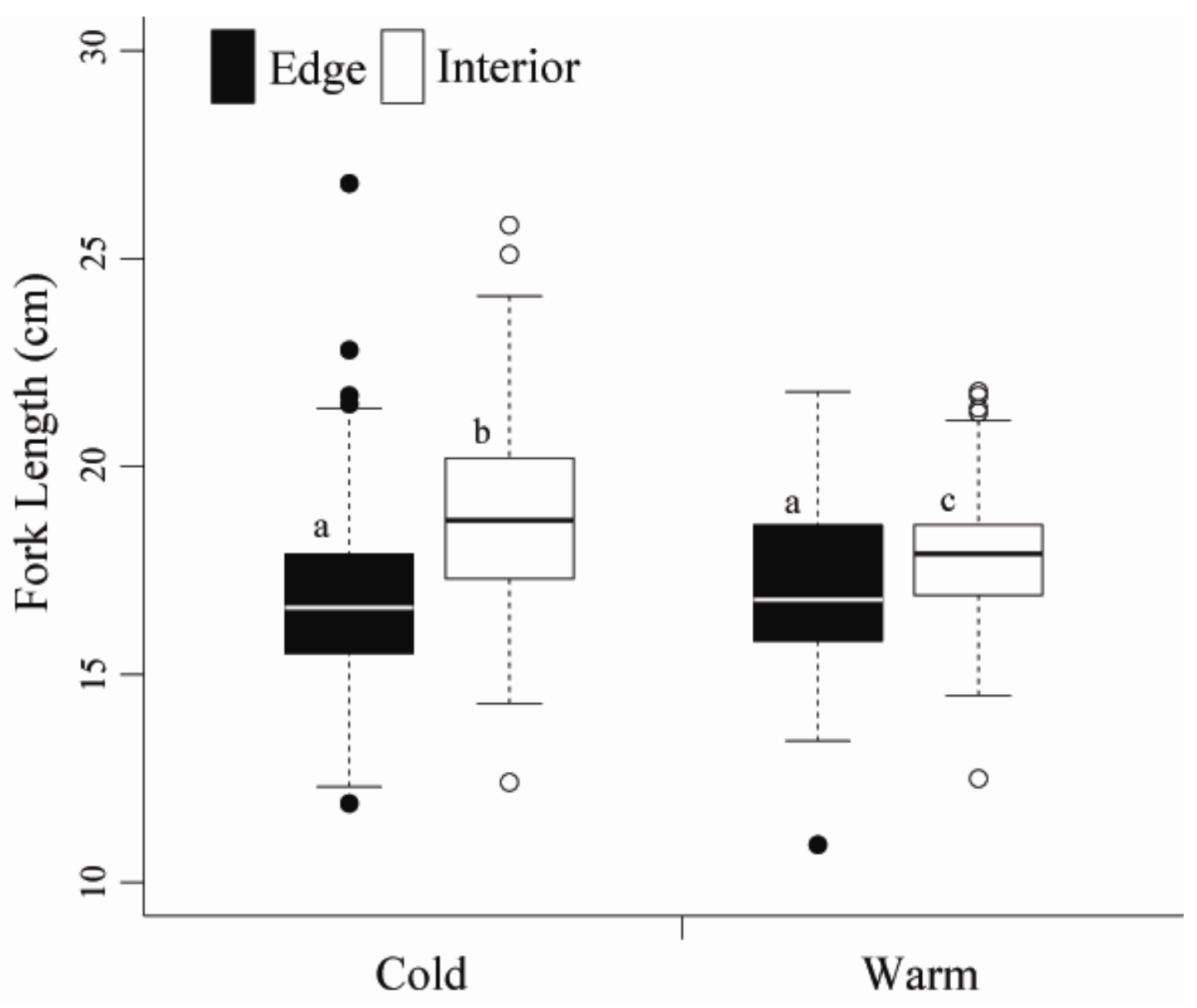


Figure 4.3: Seasonal variation in the sizes of $M$. chinensis and P. vitta.
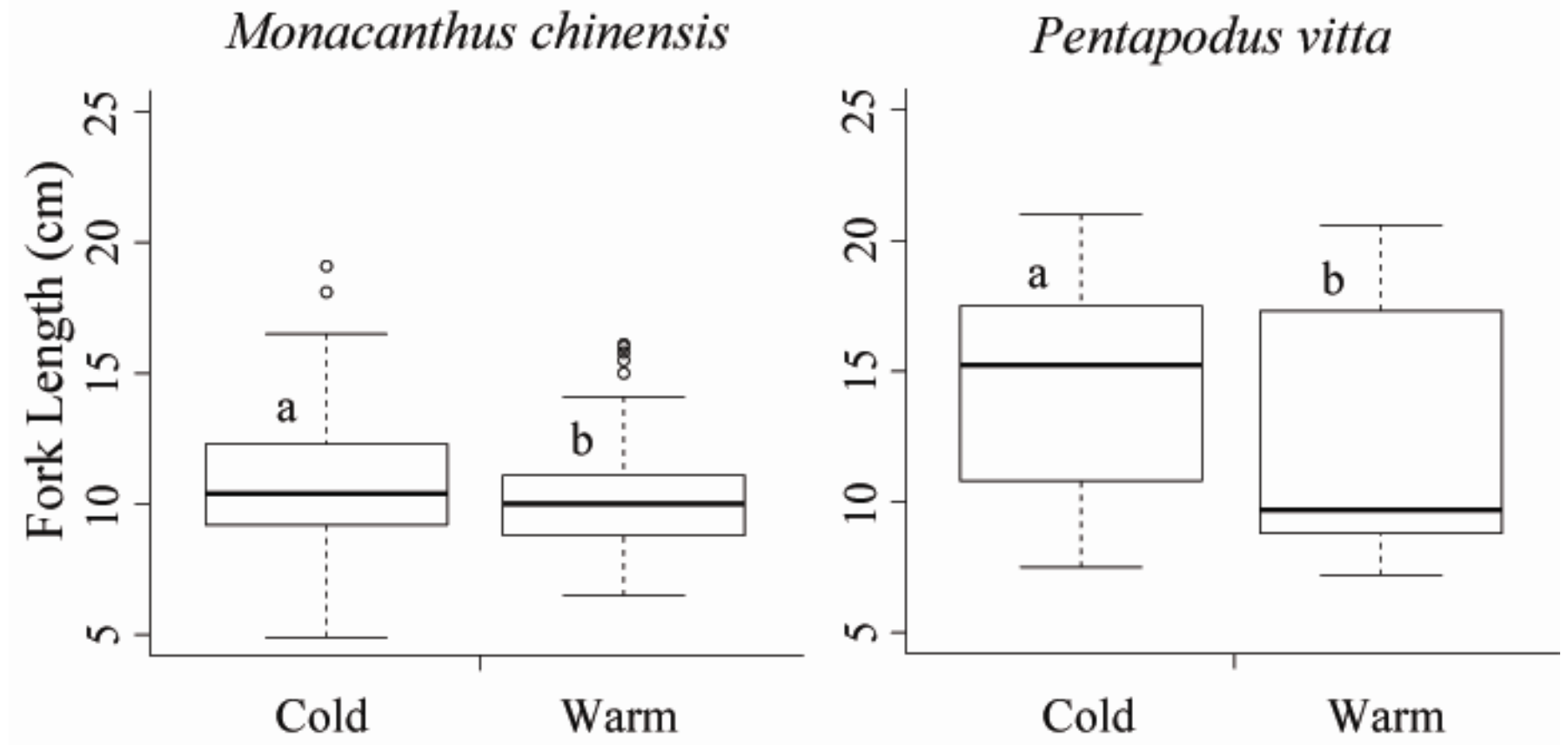


\section{Discussion}

The current study was aimed at investigating spatiotemporal patterns in habitat use and relative abundance of three commonly occurring fish species, Pelates octolineatus, Monacanthus chinensis, and Pentapodus vitta, within seagrass habiats. All three species were observed in both microhabitats during both seasons, and un-baited remote underwater video surveillance (URUVS) revealed there was a greater number of both $P$. octolineatus and $P$. vitta in interior compared to edge microhabitats during the cold season. In addition, $P$. octolineatus lengths were significantly greater for fish caught in interior microhabitats. Mean fish length of all species was greater during the cold season. Identifying these patterns in relative fish abundance and habitat use is an important first step in understanding the scale and magnitude at which they might impact primary producer communities or those of small invertebrates.

The factors shaping the distributions of these teleosts within seagrass beds remains poorly understood. Predation-sensitive shifts in habitat are important in shaping the spatiotemporal patterns of grazing by large-bodied herbivores (e.g., dugongs, Dugong dugon) in the study system (Wirsing et al. 2007). It is likely that the relative affinity of fish for dense seagrass beds (primarily Amphibolis antarctica) found in previous studies (Heithaus 2004), where my trap and camera deplopyments were focused, is driven at least partially by the risk of predation. The 3-dimensional structural complexity of seagrasses are proposed to impede the sight and movement of active visual predators (Heck and Orth 1980) rendering increased protection for prey items such as teleost fish (Heck et al. 2003). Whether smaller-scale patterns are associated with predation risk, however, is less clear. I observed a relatively greater number of both $P$. octolineatus and 
$P$. vitta in URUVS deployed in interior microhabitats during the cold season which would be consistent with predictions based on predation-sensitive foraging. Teleost fish should be less willing to move out of dense interior seagrass cover during the cold season because two major piscivores in the study site, dolphin and cormorants, can forage freely in shallow seagrass banks without risk from tiger sharks (Heithuas and Dill 2006).

The greater number of fish and the larger size of $P$. octolineatus caught in interior microhabitats are also consistent with predictions based on the distribution of food for these species. Primary producers are the primary diet item of $P$. octolineatus in the study area (Chapter II). Although algae are found in similar abundance in both microhabitats, the percent cover of seagrass is greater in interior compared to edge microhabitats. Nevertheless, the preferred forage species of seagrass is more abundance in edge microhabitats (Burkholder et al. 2012, Chapter II). The higher percent cover of seagrass in interior microhabitats should render increase surface area for invertebrates, thereby increasing food abundance for $P$. vitta. To test such a hypothesis, knowledge of the relative quality and amount of preferred food items for all species in each microhabitat would need to be obtained.

Patterns revealed by URUVS data were not consistent with patterns revealed from fish trapping data. I was unable to detect any seasonal or spatial patterns using my fish trapping data. Potential biases associated with trap data are trap saturation (Sheaves 1995), or alternatively, escape behavior (Munro 1974). I was unable to detect a relationship between soak time and number of fish caught. The mean soak time for traps was approximately 2 hours $(131 \pm 18$; mean $\pm \mathrm{SD})$ and the mean number of fish caught per trap was 9, but trap deployments containing over 20 fish were obtained during the entire 
range of soak times. If traps were to become saturated I would predict total catch to asymptote at the carrying capacity of the trap, alternatively, if fish were escaping I would predict total catch to decrease with soak time. I found no evidence of either. A recent study in the United States Virgin Islands used underwater video to record rectangular traps similar to those used in the present study, albeit larger, and found that fish spent an average of fifteen minutes in traps before escaping (Renchen et al. 2012). This limits the use of fish traps in obtaining absolute abundance estimates, and even relative abundance estimates if the probability of encountering fish varies between deployment locations, making URUVS data a more useful technique in some studies. In my current study system, useable URUVS data were more difficult to obtain during the warm season because of decreased water visibility.

\section{References}

Armitage, A.R., and J.W. Fourqurean. 2006. The short-term influence of herbivory near patch reefs varies between seagrass species. J. Exp. Marine Biol. and Ecol. 339: 65-74.

Bell, J.D., J.J. Burchmore, and D.A. Pollard. 1978. Feeding ecology of three sympatric species of leatherjackets (Pisces: Monacanthidae) from a Posidonia

seagrass habitat in New South Wales. Aust. J. Mar. Freshwater Res. 29: 631-643.

Bolker, B.M. 2008. Ecological models and data in R. Princeton University Press, New Jersey, 396p.

Burkholder, D. A., J. A. Fourqurean, and M. R. Heithaus. 2013. Spatial pattern in seagrass stoichiometry indicates both N-limited and P-limited regions of an iconic P-limited subtropical bay. Mar. Ecol. Prog. Ser. 472: 101-115.

Burkholder, D.A., M.R. Heithaus, and J.A. Fourqurean. 2012 Feeding preferences of herbivores in a relatively pristine subtropical seagrass ecosystem. Mar. Freshwater Res. 63: 1051-1058. 
Collins, M.R. 1990. A comparison of three fish trap designs. Fish. Res. 9(4): $325-332$.

Connolly, R.M. 1994. A comparison of fish assemblages from seagrass and unvegetated areas of a southern Australian estuary. Aust. J. Mar. Freshw. Res. 45: 1033-1044.

Edgar, G.J., N.S. Barrett, and A.J. Morton. 2004. Biases associated with the use of underwater visual census techniques to quantify the density and size-structure of fish populations. J. Exp. Mar. Biol. Ecol. 308, 269-290.

Gomon, M.F., C.J.M. Glover, and R.H. Kuiter (eds.), 1994. The fishes of Australia's south coast. State Print, Adelaide.

Harvey, E.S., M. Cappo, J.J. Butler, N. Hall, and G.A. Kendrick. 2007. Bait attraction affects the performance of remote underwater video stations in assessment of demersal fish community structure. Mar. Ecol. Prog. Ser. 350:

$245-254$

Harvey, E.S., S.J. Newman, D.L. McLean, M.Cappo, J.J. Meeuwig, and C.L. Skepper. 2012. Comparison of the relative efficiencies of stereo-BRUVs and traps for sampling tropical continental shelf demersal fishes. Fish. Res. 125-126:

108-120.

Heck, K.L., Jr., and R.J. Orth. 1980. Seagrass habitats: the roles of habitat complexity, competition and predation in structuring associated fish and motile macroinvertebrates. Academic Press, Sydney, pp.449-464.

Heck, K.L.Jr, G. Hays, and R.J. Orth. 2003. Critical evaluation of the nursery role hypothesis for seagrass meadows. Mar. Ecol. Prog. Ser. 253: 123-136.

Heithaus, M.R. 2004. Fish communities of subtropical seagrass meadows and associated habitats in Shark Bay, Western Australia. Bull. Mar. Sci. 75(1): 7999.

Heithaus, M.R., and L.M. Dill. 2006. Does tiger shark predation risk influence foraging habitat use by bottlenose dolphins at multiple spatial scales? Oikos. 114: $257-264$.

Hughes, A.R., K.J. Bando, L.F. Rodriquez, and S.L. Williams. 2004. Relative effects of grazers and nutrients on seagrasses: a meta-analysis approach. Mar.

Ecol. Prog. Ser. 282: 87-99.

Jacobsen, T., and J. Kushlan. 1989. Sources of sampling bias in enclosure fish trapping: effects on estimates of density and diversity. Fish. Res. 5: 401-412. 
Kendrick, G.A., J.M. Huisman, and D.I. Walker. 1990. Benthic macroalgae of Shark Bay, Western Australia. Botanica Marina. 33:47-54.

Long, J. S. 1997. Regression Models for Categorical and Limited Dependent Variables. Thousand Oaks, CA: Sage Publications. Everitt, B. S. and Hothorn, T. A Handbook of Statistical Analyses Using R

Mant, J.C., M.J. Moran, and S.J. Newman. 2006. Biological characteristics and mortality of western butterfish (Pentapodus vitta), an abundant bycatch species of prawn trawling and recreational fishing in a large subtropical embayment. Fish.

Bull. 104: 512-520.

Martin, T.G, B.A. Wintle, J.R. Rhodes, P.M. Kuhnert, S.A. Field, S.A. Low-Choy, A.J. Tyre, and H.H. Possingham. 2005. Zero-tolerance ecology: improving ecological inference by modeling the source of zero observations.

Ecol. Lett. 8: 1235-1246.

May, J.L., and J.G.H. Maxwell. 1986. Trawl fish from temperate waters of Australia. CSIRO Division of Fisheries Research, Tasmania. 492 p.

Miller, R.J., and W. Hunte. 1987. Effective area fished by Antillean fish traps. Bull. Mar. Sci., 40(3): 484-493.

Munro, J.L. 1974. The mode of operation of Antillean fish traps and the relationship between ingress, escapement, catch and soak. J. Cons. Int. Explor.

Mer. 35(3): 337-350.

Nett, J.H.G., T.B. Campbell, N.E. Mandrak, and S.D. Tiegs. 2012. Detecting invasive round goby in Waldeable streams: a comparison of gear types. North Am. J. Fish. Manage. 32(2): 260-364.

Orth, R.J., T.J.B. Carruthers, W.C. Dennison, C.M. Duarte, J.W. Fourqurean, K.L.Jr. Heck, A.R. Hughes, G.A. Kendrick, W.J. Kenworthy, S. Olyarnik, F.T. Short, M. Waycott, and S.L. Williams. 2006. A global crisis for seagrass ecosystems. BioScience. 56(12): 987-996.

Ovegard, M., S. Koningson, A. Persson, and S.G. Lunneryd. 2011. Size selective capture of Atlantic cod (Gadus morhua) in floating pots. Fish. Res. 107: 239-244.

Paxton, J.R., D.F. Hoese, G.R. Allen and J.E. Hanley, 1989. Pisces. Petromyzontidae to Carangidae. Zoological Catalogue of Australia, Vol. 7. Australian Government Publishing Service, Canberra.

Pennington, M. 1983. Efficient estimators of abundance, for fish and plankton surveys. Biometrics 39: 281-286. 
R Development Core Team. 2011. R: a language and environment for statistical computing. R Foundation for Statistical Computing, Vienna, http://www.Rproject.org.

Renchen, G.F., S.J. Pittman, and M.E. Brandt. 2012. Investigating the behavioural responses of trapped fishes using underwater video surveillance. $J$.

Fish. Biol. 81, 1611-1625.

Sheaves, M.J. 1995. Effect of design modifications and soak time variations on Antillean-Z fish trap performance in a tropical estuary. Bull. Mar. Sci. 56: 475-489. Syrjala, S.E. 2000. Critique on the use of the delta distribution for the analysis of trawl survey data. ICES J. Mar. Sci. 57: 831-842.

Travers, M.J., and I.C. Potter. 2002. Factors influencing the characteristics of fish assemblages in a large subtropical marine embayment. J. Fish. Biol. 61: 764784.

Walker, D.I., G.A. Kendrick, and A.J. McComb. 1988. The distribution of seagrass species in Shark Bay, Western Australia, the notes on their ecology. Aquatic. Bot. 30: 205-317.

Waycott, M., C.M. Duarte, T.J.B. Carruthers, R.J. Orth, W.C. Dennison, S. Olyarnik, A. Calladine, J.W. Fourqurean, K.L. Heck Jr., A.R. Hughes, G.A. Kendrick, W.J.

Kenworthy, F.T. Short, and S.L. Williams. 2009. Accelerating loss of seagrasses across the globe threatens coastal ecosystems. Proc. Natl.

Acad. Sci. U.S.A. 106(30): 12377-12381.

Wirsing, A.J., M.R. Heithaus, and L.M. Dill. 2007. Fear factor: do dugongs (Dugong dugon) trade food for safety from tiger sharks (Galeocerdo cuvier)? Oecologia. 153: 1031-1040. 
CHAPTER V:

GUILD-DEPENDENT IMPACTS OF MARINE HERBIVORES ON AN INTACT

SEAGRASS COMMUNITY 
Abstract

Trophic downgrading has disrupted top-down processes across ecosystems worldwide through a variety of mechanisms. Quantifying these impacts, especially in marine ecosystems involving large-bodied species, and predicting potential future changes to marine ecosystems has been hampered by a lack of studies in communities with intact predator populations and grazer populations from multiple guilds. I used a series of $3 \times 3 \times 2$ nested factorial exclosure - transplant experiments to investigate the relative impacts of megagrazers (dugongs and sea turtles) and macrograzers (mainly fishes) in structuring an intact seagrass system that includes healthy top predator populations (Shark Bay, Western Australia). Both megagrazers and macrograzers affected the establishment and persistence of three species of seagrasses, but impacts varied between guilds, across seagrass species, and between seasons. Fish grazing had the largest impact on the establishment and persistence of species with the highest nutrient content, but these impacts were primarily observed during summer months. Temporal patterns of fish impacts on seagrasses are consistent with predictions based on a behavior-mediated trophic cascade initiated by tiger sharks. These results suggest that herbivore impacts on intact seagrass beds likely were seagrass species- and grazer guilddependent and likely were shaped by herbivore response to their predators. To be effective, conservation and restoration efforts must incorporate an understanding of these impacts, in order to protect, or restore, these crucial habitats from increasing anthropogenic pressures. 
Introduction

Understanding controls of primary producer community structure and function is a central goal of ecology, and is of increasing importance as humans alter ecosystems (Duffy 2003). Although it is widely appreciated that herbivores are capable of structuring primary producer communities in terrestrial and aquatic settings (e.g., Ripple and Beschta 2003, Burkepile and Hay 2008, Gruner et al. 2008, Griscom et al. 2011), there still is debate about the relative importance of top-down versus bottom up control (Burkepile and Hay 2006) and the context-dependence of their relative strengths. Complicating studies of potential top-down control of primary producer communities, but making them of considerable importance, is the trophic downgrading of ecosystems through the loss of large bodied grazers and predators (Post and Pederson 2008, Estes et al. 2011). The relative strength of top-down impacts from herbivory (defined as the ingestion of plant material, regardless of its assimilation; Cry and Pace 1993) on producer communities appears to be affected by a myriad of factors, such as herbivore mortality, predator activity, recruitment, availability of allochthonous food sources, physical stress, as well as the identity of different herbivores in the community and their interactions (Harrold and Reed 1985, Cry and Pace 1993, Kawamata 1998, Vanderklift et al. 2009). Lessons from terrestrial systems indicate that although large grazers (for example, ungulates) can dramatically reduce plant biomass, the mechanisms driving these impacts may be strongly regulated by less obvious grazer guilds (e.g. rodents, MacLean et al 2011).

Seagrasses are the foundation of some of the most productive ecosystems in the world (Phillips and McRoy, 1980), and provide critical habitat in the form of shelter and 
foraging sites for a diverse and large concentration of fish and invertebrate species (Connolly 1994, Heck et al. 2003). Yet, there still remain considerable gaps in our understanding of the importance of top-down processes in regulating the dynamics of seagrass ecosystems. Such an understanding is critical because seagrass meadows are among the most threatened ecosystems on earth (Waycott et al. 2009).

The potential importance of top-down effects in structuring seagrass ecosystems has been largely overlooked until recently. Indeed, it was widely assumed that few animals directly consume seagrasses, and of those that do, their ingestion is infrequent and inconsequential. This view, however, has been recently challenged (Heck and Valentine 2006). For example, in places where populations persist, large herbivores ("megagrazers"), including sirenians (sea cows) and green turtles (Chelonia mydas), can alter species composition, structure and biomass of seagrass communities (Preen 1995a, Nakaoka et al. 2002; see Aragones et al. 2006, Heithaus et al. 2012 for reviews). The importance of fish herbivory, however, has been less appreciated, but in some locations, fish can remove more than 70\% of net aboveground production (Kirsch et al. 2002, Tomas et al. 2005). The relative importance of megagrazers and fishes in structuring seagrass ecosystems in areas where they coexist or under relatively undisturbed conditions is unknown. This is in part due to the large-scale declines of megagrazers and dramatic changes in fish stocks (Pauly et al. 1998, Jackson et al. 2001), as well as changes in predator population sizes which may have impacted the intensity and spatiotemporal pattern of herbivore grazing and relative abundance, historically (e.g. Heithaus et al. 2008). Elucidating the relative effects of megagrazers and fishes under natural population densities and species interactions is important for setting restoration 
targets, predicting the consequences of declines in these taxa, and gaining insights into the context in which herbivory may play a greater or lesser role in ecosystem structure and function.

The seagrass meadows of Shark Bay, Western Australia, offer an unprecedented opportunity to investigate the ecological role of multiple grazer guilds on an intact seagrass system (Heithaus et al. 2008). One of the largest seagrass systems in the world, Shark Bay features substantial population densities of both macro- and megagrazers, including herbivorous fish, (Pelates octolineatus; Heithaus 2004), green sea turtles (Chelonian mydas; Heithaus et al. 2005), dugongs (Dugong dugon; Preen et al. 1997), and their predators (e.g. tiger sharks, Galeocerdo cuvier for megagrazers and Indo-Pacific bottlenose dolphins, Tursiops cf aduncus and pied cormorant, Phalacrocorax varius, for fishes).

Here, I used a nested exclosure - transplant experiment to quantify the effects of megagrazers and fishes on the establishment and persistence of three species of fastgrowing seagrasses in shallow seagrass beds. I found that although some megagrazer impacts were apparent, fish grazing appears to be a much stronger structuring force in the spatial context of the study, possibly due to a behavior-mediated trophic cascade initiated by tiger sharks and transmitted through a four-step food web module. 
Methods

Study System

Shark Bay, Western Australia $\left(25^{\circ} 45^{\prime} \mathrm{S}, 113^{\circ} 44^{\prime} \mathrm{E}\right)$ is a ca. $13,000 \mathrm{~km}^{2}$ semienclosed subtropical bay featuring $c a .4000 \mathrm{~km}^{2}$ of seagrass beds. Monospecific stands of the temperate seagrasses Amphibolis antarctica, and to a lesser extent Posidonia australis, dominate the community with several fast-growing species that are primarily tropical in origin, including Halophilia ovalis, Halophilia spinulosa, Halodule univervis, Syringodium isoetifolium, Cymodocea serrulata and Cymodocea angustata occurring patchily throughout the bay (Walker et al. 1988, Burkholder et al. 2013a). Although these fast-growing seagrass species are often associated with shallow water habitats, including in some parts of Shark Bay (Walker 1989, Masini et al. 2001), within my study site in the Eastern Gulf of Shark Bay - which is characterized by a series of shallow $(<4.5 \mathrm{~m})$ seagrass banks that are separated by deeper (6-11m) and mostly sandy bottom channels these fast-growing, tropical species are largely confined to the edges of seagrass banks (Burkholder et al. 2013a). Therefore, I focused my experiments within interior areas of seagrass banks to determine whether herbivory might inhibit the establishment and persistence of fast-growing seagrass species in these areas.

I divided herbivores into two guilds, megagrazers and macrograzers, based on the body size of herbivore that would be excluded by different cage structures. Megagrazers are all animals excluded by a $20 \mathrm{~cm}^{2}$ opening space, almost exclusively dugongs and sea turtles. Macrograzers are animals that could pass through the large mesh but are excluded by $1.2 \times 1.3 \mathrm{~cm}$ mesh, mainly fishes. Smaller epifaunal grazers were not manipulated in my experiments. 


\section{Experimental Design}

To determine the relative impacts of megagrazers and macrograzers on the establishment and persistence of fast-growing seagrass species, I conducted a series of $3 \times 3 \times 2$ factorial experiments (Figure 5.1). My two types of megagrazer treatment plots (megagrazers not excluded and megagrazers excluded) contained three types of macrograzer treatment subplots (Open - allowed for grazing, cage control (CC) allowed for fish grazing, and Cage (ME) - excluded fish grazing) that were each replicated three times within larger plots. Experimental plots were spaced approximately $10 \mathrm{~m}$ apart at three replicate sites which were also spaced $10 \mathrm{~m}$ apart.

To test 1) whether megagrazers might be repelled by the presence of macrograzer cages in the megagrazers not excluded plots or 2) if the presence of macrograzer cages attracted herbivorous fishes, one of my experiments featured a Full Control treatment. The full control plots were the same size as megagrazer plots but contained only three replicates of Open subplots and where located away from any other manipulations. If the presence of macrograzer cages affected megagrazers, I would expect that full control subplots would experience greater loss of seagrass than open subplots in the megagrazer not excluded plots. If macrograzer cages attracted grazing fishes, then open plots in treatments with any structure should experience higher seagrass losses than open subplots in full control plots. 
Figure 5.1: Diagram of the experimental design showing replicate sites (1-3) within one interior seagrass bed, where each site contains megagrazer treatment plots that A) are full controls; no exclusions, B) megagrazers no excluded, and C) megagrazers excluded.

Each plot was $2.6 \times 3.0 \mathrm{~m}$, which consisted of nine $30 \mathrm{~cm} \times 30 \mathrm{~cm}$ macrograzer treatment subplots, spaced $50 \mathrm{~cm}$ apart. Macrograzers exclusion cage (ME) subplots contain $30 \times 30$ $\mathrm{x} 20 \mathrm{~cm}$ tall cages made of $\sim 1 \mathrm{~cm}$ wire mesh. Cage controls $(\mathrm{CC})$ are the same as macrograzer cages but have open ends enabling fish to access the subplot and still encounter the presence of a cage, and open subplots (Open) have no cage

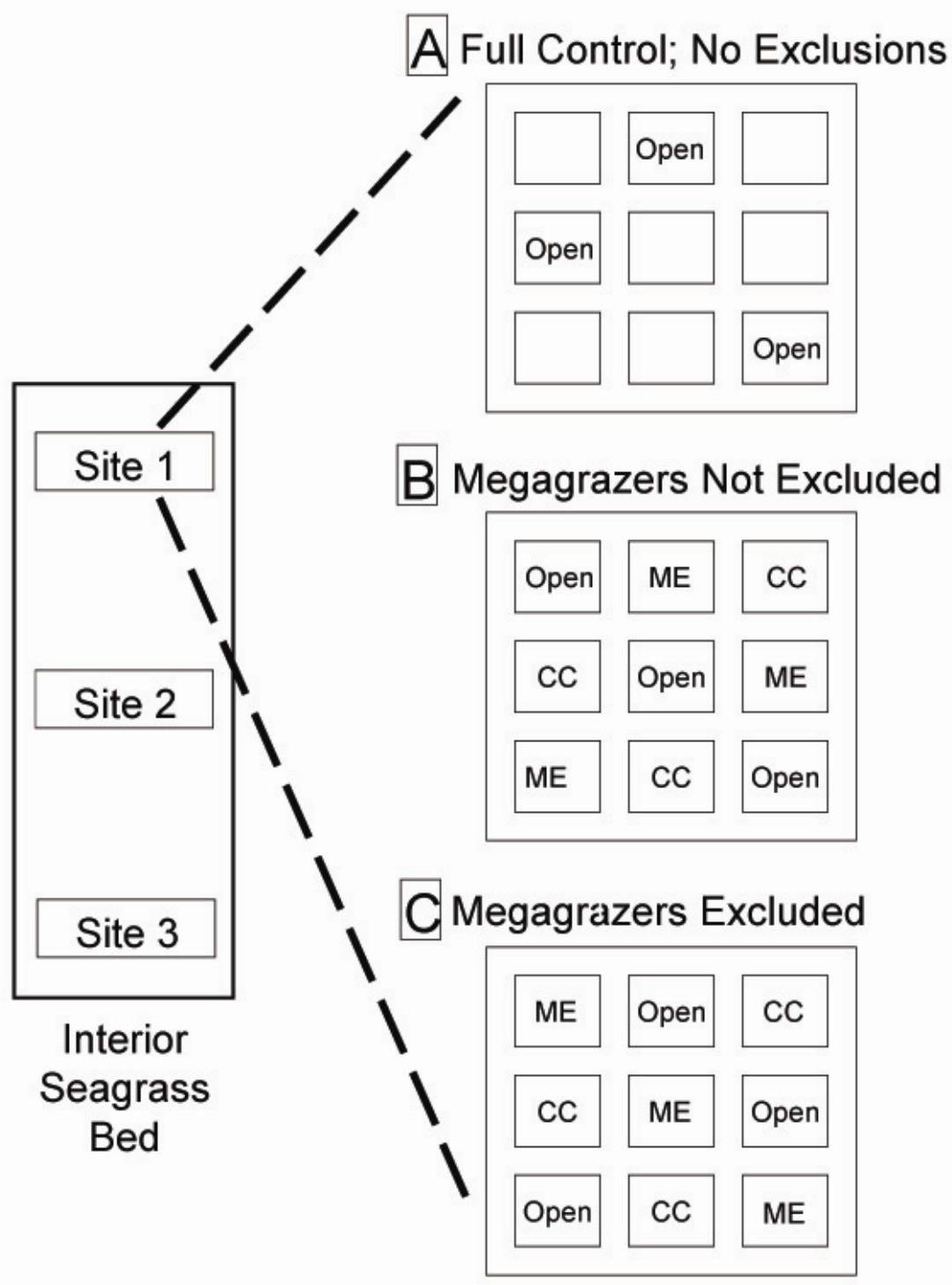


Figure 5.2: a) Surface view of a megagrazers excluded plot $(2.6 \times 3.0 \mathrm{~m})$ containing nine subplots $(30 \mathrm{~cm} \times 30 \mathrm{~cm})$. b) Side view of transplanted seagrass species under a cage control (CC) within a megagrazers excluded plot. c) Side view of a cage control subplot (CC) in a megagrazers not excluded plot, and d) Side view of an open control (Open) subplot surrounded by a macrograzer exclusion cage subplot (ME) and cage controls (CC) within a megagrazers not excluded plot.
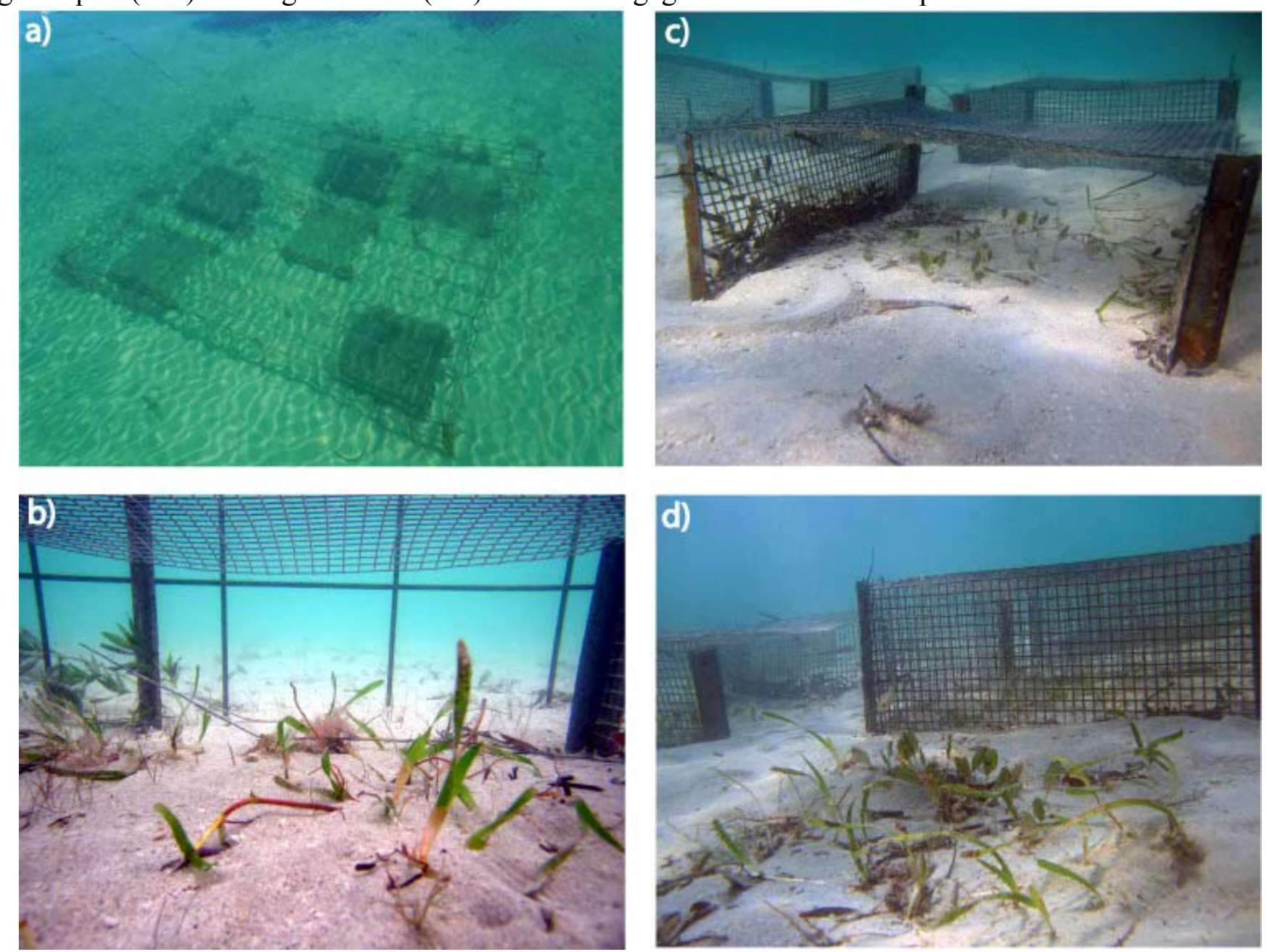
A megagrazer excluded treatment plot was constructed using a $2.6 \times 3.0 \mathrm{~m}$ steel rebar top of $20 \mathrm{~cm}^{2}$ mesh that rested atop $40 \mathrm{~cm}$ tall rebar side panels (Figure 5.2a). Macrograzer cage exclusion subplots were $30 \times 30 \times 20 \mathrm{~cm}$ tall cages made of heavy steel chicken wire of $1.2 \times 1.3 \mathrm{~cm}$ mesh. Cage controls were identical but only had two sides, which allowed macrograzers access to the subplot (Figure 5.2b,c). Subplot positions were randomly assigned within each plot such that each row and column only had one of the three treatments. I transplanted the three most common fast-growing seagrass species (Cymodocea angustata, Halodule univervis, and Halophila ovalis) into each subplot (Figure 5.2d). Transplants consisted of three seagrass segments per species, and each segment contained at least three shoots along a rhizome with an intact apical meristem (n $=9-15$ total shoots $\mathrm{x}$ species $^{-1} \mathrm{x}$ subplot $\left.^{-1}\right)$. The seagrass segments of each species were buried into the sediment with the middle of the segments overlapping; forming an asterisk pattern. Wire staples (10 cm long) secured seagrass at the middle and ends of segments.

Cages were maintained at least every two weeks for the duration of the experiments. Seagrass shoot density was quantified after 24 hours, 5 days, 9 days, 21 days, bimonthly for two months, and then once a month until completion of the experiment. To determine removal rates of established seagrasses in the absence of grazer exclusion cages, upon completion, all exclosure cages were removed and any remaining seagrass shoot densities were quantified at time of cage removal, and at 24, 96, and 210 hours after cage removal during May 2010 (removal rate experiment). I calculated removal rate using proportions of seagrass remaining relative to the shoot density at time of cage removal. 
Since the abundance and foraging behavior of several herbivores in the system may vary seasonally (Heithaus et al. 2007, Wirsing et al. 2007), I also investigated whether there might be seasonal variation in herbivore impacts on seagrasses. In addition to a 4-month experiment, I established two three week experiments as described above (with the exception of full control plots), during the warm (April) and cold (July) seasons of 2011.

Ultimately, to estimate the difference between grazer guilds, I calculated the proportional change of seagrass shoot density from the start to the end of the exclosure studies for all treatments based on the type of grazing they allowed (e.g full control plot / open subplot + megagrazer not excluded $/$ open subplot $=$ fish + megagrazing $)$.

\section{Statistical Analysis}

I used a repeated measures nested ANOVA on transformed $(\log +1)$ shoot count data. Seagrass counts from each subplot of each treatment plot where collapsed into a single mean value. All three exclosure studies were analyzed in the same manner, however, I conducted a separate analysis of Open subplots across full controls and the two meagagrazer treatements. All analyses were conducted in R (2011, free software; www.Rproject.com).

Results

4-Month Exclosure Study

All transplanted seagrass species within open subplots declined regardless of treatment type (Figure 5.3). However, seagrass species responded differently to megagrazer treatment type when placed in the open (i.e. there was a significant 
interaction of plot x species; Figure 5.3, Table 5.1). Both Cymodocea angustata and Halodule uninervis declined more rapidly in the full control plots than the megagrazer excluded plots, indicating that excluding megagrazers influences rates of seagrass loss. $C$. angustata declined more slowly in the megagrazer excluded plots compared to megagrazer not excluded plot, while $H$. uninervis responded similarily regardless of whether megagrazers were excluded. In contrast, Halophila ovalis responded similarly across all plot types, and declined more rapidly than all other species. At the conclusion of the experiment, open subplots in the megagrazer exclosures maintained low densities of $C$. angustata and H. uninervis but these species were removed completely from open subplots of both plot types that allowed megagrazer access.

Across treatments, shoot counts were influenced by a significant interaction of duration x plot x subplot x species (Table 5.2). Regardless of whether megagrazers were excluded, cage control and open subplots had similar, but decreasing, shoot counts throughout the experiment for Halodule uninervis and Halophila ovalis. Results were less consistent for Cymodocea angustata (Figure 5.3). For C. angustata, results for cage controls and macrograzer exclusion cages were more similar to one another and maintained higher shoot counts than open subplots. Interestingly, both cage control subplots and open subplots in the two primary megagrazer plot types showed little impact of grazing over the first 20-60 days of the experiment for C. angustata and H. uninervis. After day $60, H$. uninervis began to decline quickly, while $H$. ovails had declined rapidly over the first 1-10 days in all subplots subject to fish grazers. 
Figure 5.3: Mean seagrass shoot counts for both megagrazer and macrograzer treatments during the 4-month exclosure study (Sept.2009-Jan.2010). Error bars are \pm SE.
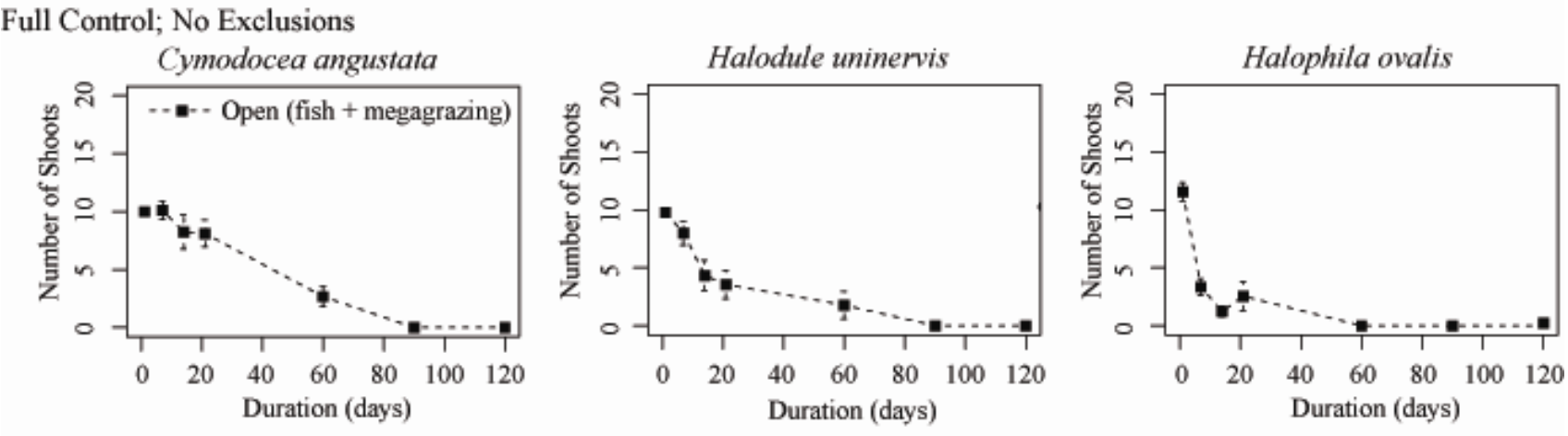

Megagrazers Not Excluded
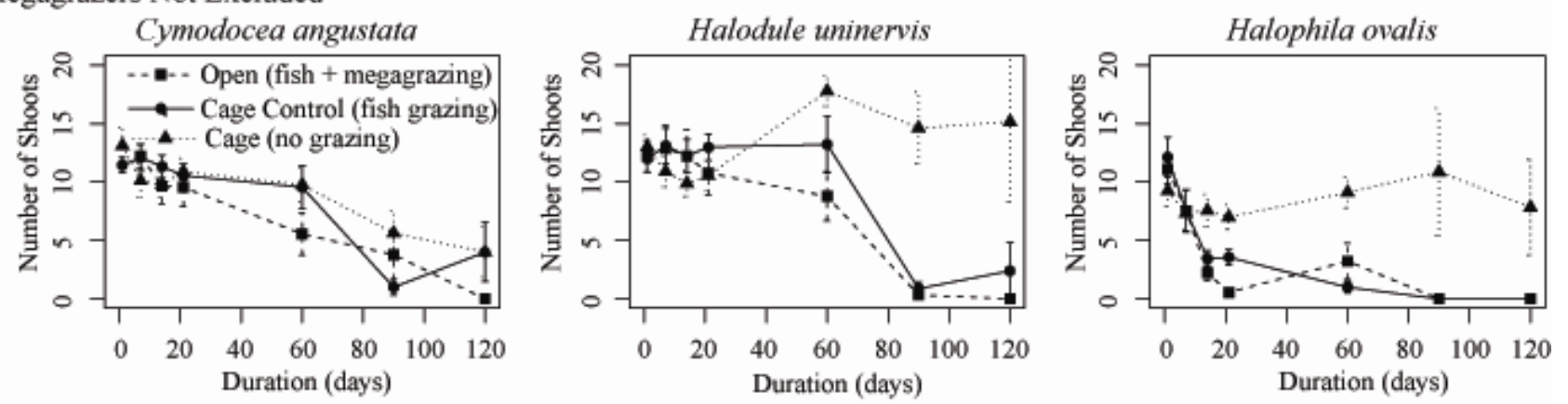

Megagrazers Excluded
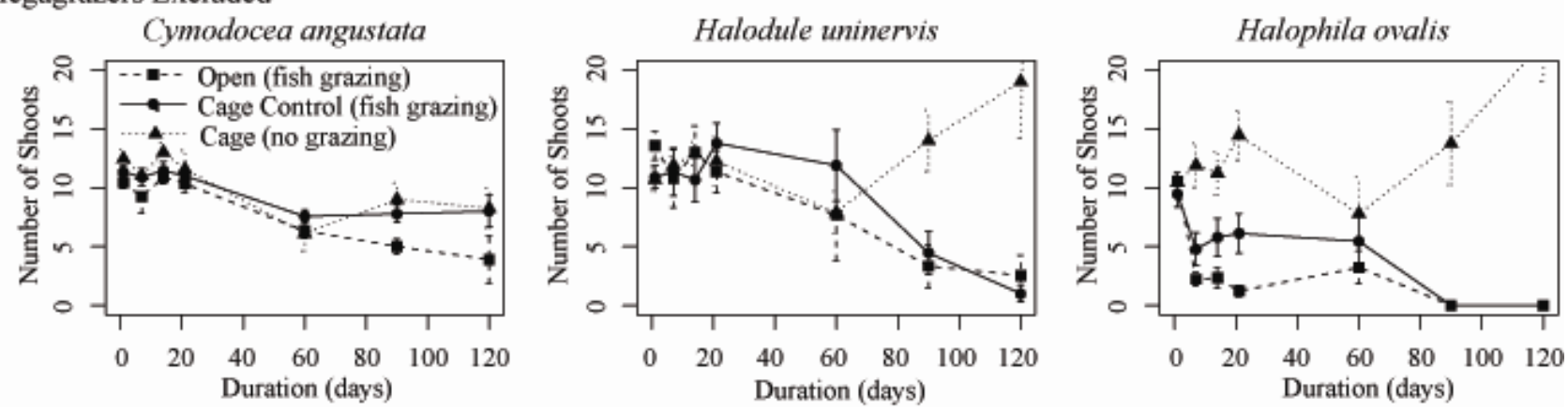
Table 5.1: Repeated measures nested ANOVA results for subplot Open of the 4-month (September 2009 - January 2010) exclosure study where three different tropical seagrass species were transplanted into different grazer treatment plots and monitored during the warm season. Analysis was conducted to determine differences in open subplots where plot levels are a) full control; no exclusions, b) megagrazers not excluded, and c) megagrazers excluded.

\begin{tabular}{lccccc}
\hline Predictors & Df & Sum Sq & Mean Sq & F value & $\operatorname{Pr}(>\mathrm{F})$ \\
\hline Plot & 2 & 7.020 & 3.510 & 5.945 & $0.003 *$ \\
Species & 2 & 73.200 & 36.598 & 61.987 & $<0.001 *$ \\
Duration:Species & 2 & 5.500 & 2.750 & 4.658 & $0.010^{*}$ \\
Plot:Species & 4 & 9.280 & 2.320 & 3.930 & $0.004 *$ \\
Duration:Plot:Species & 4 & 4.710 & 1.177 & 1.994 & 0.094 \\
Residuals & 545 & 321.780 & 0.590 & & \\
\hline
\end{tabular}


There were significant differences among species in their response to macrograzer exclusion (Figure 5.3, Tables 5.1 and 5.2). Both H. uninervis and H. ovalis had shoot counts that remained constant or increased over the 4-month experiment when fish grazers were excluded. C. angustata in macrograzer exclosures, however, declined in shoot count although not as much as it did in open plots.

Exclosure Removal Study

All species of seagrass exposed to grazing after 8 months of release from herbivory declined significantly once macrograzer cages were removed, but the rates of removal differed among species (Figure $5.4, \mathrm{~F}_{2,130}=13.557, \mathrm{p}<0.001$ ). Halophila ovalis and Halodule univervis shoots declined significantly faster than did Cymodocea angustata (Tukey Multiple Comparison Test; $\mathrm{p}=0.005$, and $\mathrm{p}<0.001$, respectively), and reached lower remaining densities. Indeed, H. ovalis and H. uninervis had more than $40 \%$ of their shoots removed within 24 hours of being exposed to herbivores and dropped to an average of less than $40 \%$ and $20 \%$ of shoots remaining, respectively, within 4 days after which time removal rates became relatively minimal. In contrast, $C$. angustata had less than $25 \%$ of its shoots removed in the first 24 hours and, on average, more than $50 \%$ of original shoots were left after nine days. 
Table 5.2: Repeated measures nested ANOVA results for the 4-month exclosure study where three different seagrass species were transplanted into different grazer treatment plots and monitored during the warm season (September 2009 - January 2010). Plot levels are megagrazers not excluded and megagrazers excluded, and subplot levels are macrograzers not excluded (Open), cage control (CC), and cages (ME - excludes fish grazing).

\begin{tabular}{lccccc}
\hline Predictors & Df & Sum Sq & Mean Sq & F value & $\operatorname{Pr}(>\mathrm{F})$ \\
\hline Plot & 1 & 1.140 & 1.139 & 2.084 & 0.149 \\
Species & 2 & 98.980 & 49.488 & 90.558 & $<0.001 *$ \\
Duration:Species & 2 & 0.930 & 0.466 & 0.853 & 0.426 \\
Plot:Species & 2 & 4.010 & 2.005 & 3.669 & $0.026 *$ \\
Duration:Plot:Species & 2 & 3.290 & 1.647 & 3.014 & $0.0495 *$ \\
Duration:Plot:Species:Subplot & 8 & 48.290 & 6.036 & 11.045 & $<0.001 *$ \\
Residuals & 1064 & 581.450 & 0.546 & & \\
\hline
\end{tabular}


Figure 5.4: Removal rates of seagrasses exposed to grazing after four months of macrograzer exclusion. Error bars are \pm SE.
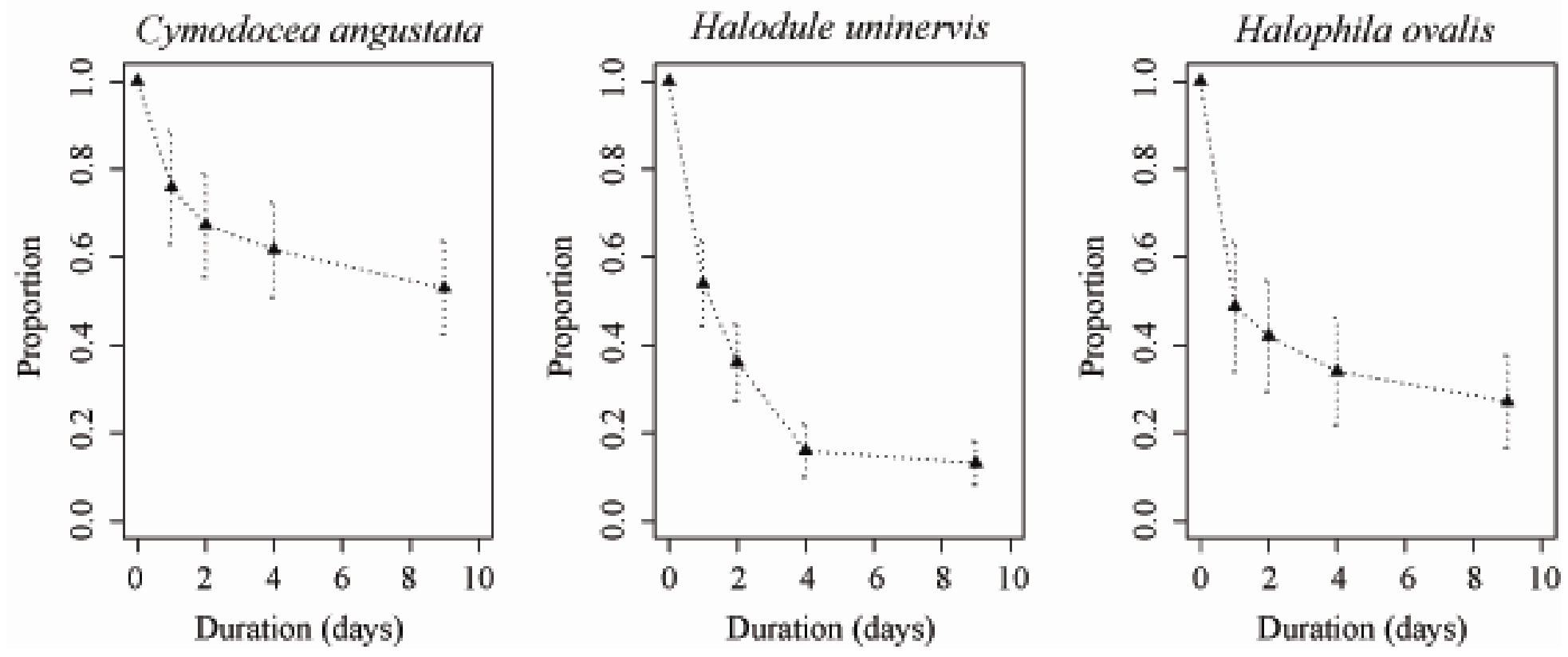
Short-term Studies - Seasonal variation in grazer impacts

All factors interacted to affect shoot counts in the short-term experiments (Table 5.3, Figures 5.5 and 5. 6). During the warm season, cage controls and open plots were similar for all species and between megagrazer plot types (Figure 5.5). Halophila ovalis and Halodule uninervis exposed to fish grazing declined rapidly and were almost totally removed within 20 days, while Cymodocea angustata declined to $c a .30 \%$ of original shoot counts when exposed to fish grazing (Figure 5.5). All three species showed little change in counts over the course of the experiment when protected from macrograzers. In contrast, during the cold season, there was relatively little change in shoot counts of $C$. angustata and H. uninervis over the course of the experiment regardless of subplot type (including those exposed to macrograzers; Figure 5.6). However, shoot counts of $H$. ovalis declined rapidly after 10 days in both subplot types exposed to fish grazing, but not within macrograzer exclosure cages. 
Table 5.3: Repeated measures nested ANOVA results for the short-term exclosure study where three different tropical seagrass species were transplanted into different grazer treatment plots and monitored over 18 days during both the warm (April 2011) and cold (July 2011) season. Plot levels are megagrazers not excluded and megagrazers excluded, and subplot levels are macrograzers excluded (Open), cage control, (CC), and cages (ME - excludes fish grazing).

\begin{tabular}{lccccc}
\hline Predictors & Df & Sum Sq & Mean Sq & F value & Pr $(>\mathrm{F})$ \\
\hline Plot & 1 & 0.730 & 0.729 & 2.613 & 0.106 \\
Season & 1 & 244.330 & 244.332 & 875.766 & $<0.001 *$ \\
Species & 2 & 132.650 & 66.323 & 237.724 & $<0.001 *$ \\
Duration:Season & 1 & 21.200 & 21.196 & 75.975 & $<0.001 *$ \\
Plot:Season & 1 & 1.240 & 1.242 & 4.452 & $0.035^{*}$ \\
Duration:Species & 2 & 17.760 & 8.881 & 31.831 & $<0.001 *$ \\
Plot:Species & 2 & 0.980 & 0.490 & 1.755 & 0.173 \\
Season:Species & 2 & 55.010 & 27.505 & 98.587 & $<0.001 *$ \\
Duration:Plot:Season & 1 & 0.060 & 0.059 & 0.210 & 0.647 \\
Duration:Plot:Species & 2 & 0.020 & 0.012 & 0.044 & 0.957 \\
Duration:Season:Species & 2 & 5.430 & 2.717 & 9.740 & $<0.001 *$ \\
Plot:Season:Species & 2 & 1.590 & 0.795 & 2.850 & 0.058 \\
Duration:Plot:Season:Subplot & 4 & 56.290 & 14.073 & 50.442 & $<0.001 *$ \\
Duration:Plot:Species:Subplot & 8 & 57.020 & 7.128 & 25.549 & $<0.001 *$ \\
Duration:Plot:Season:Species & 2 & 0.070 & 0.036 & 0.130 & 0.878 \\
Duration:Plot:Season:Species:Subplot & 8 & 9.930 & 1.241 & 4.448 & $<0.001 *$ \\
Residuals & 1323 & 369.110 & 0.279 & \\
\hline
\end{tabular}


Figure 5.5: Mean seagrass shoot counts for both megagrazer and macrograzer treatments during the short-term exclosure study in the warm season (April 2011). Error bars are \pm SE.

$$
\text { Megagrazers Not Excluded }
$$
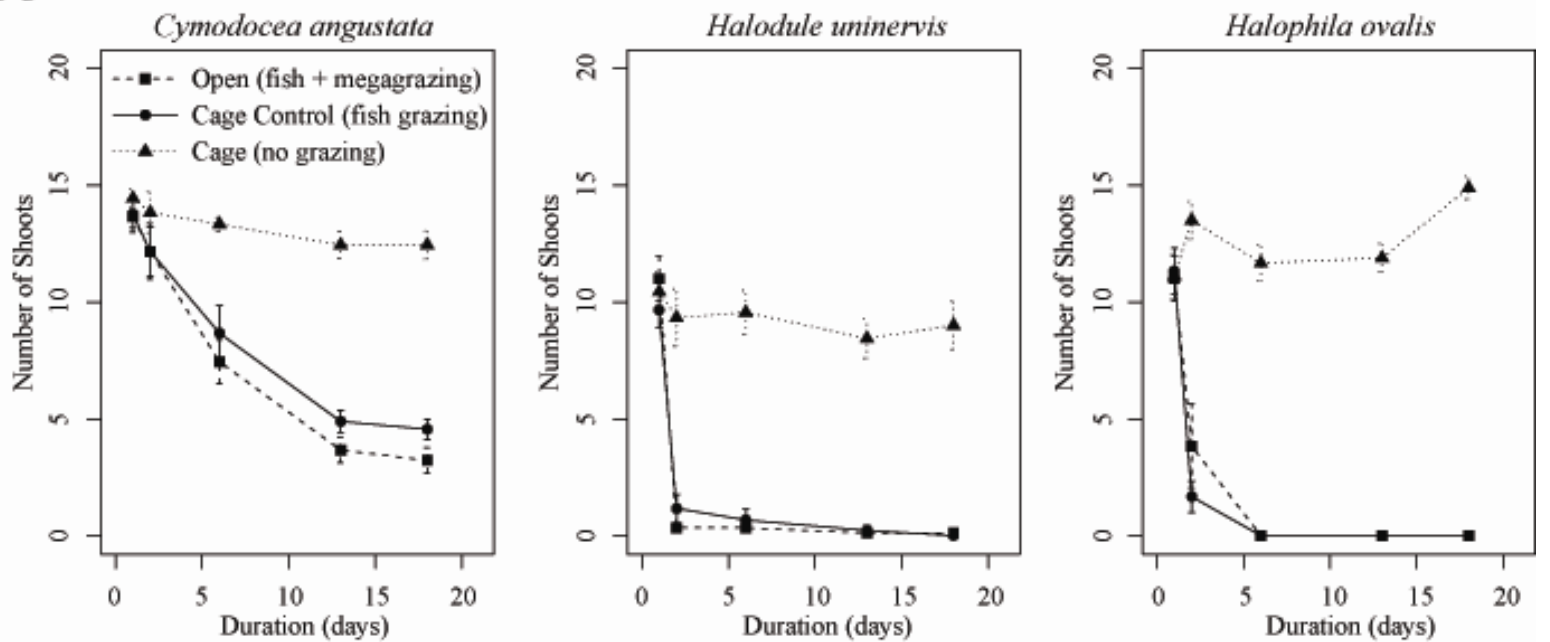

Megagrazers Excluded
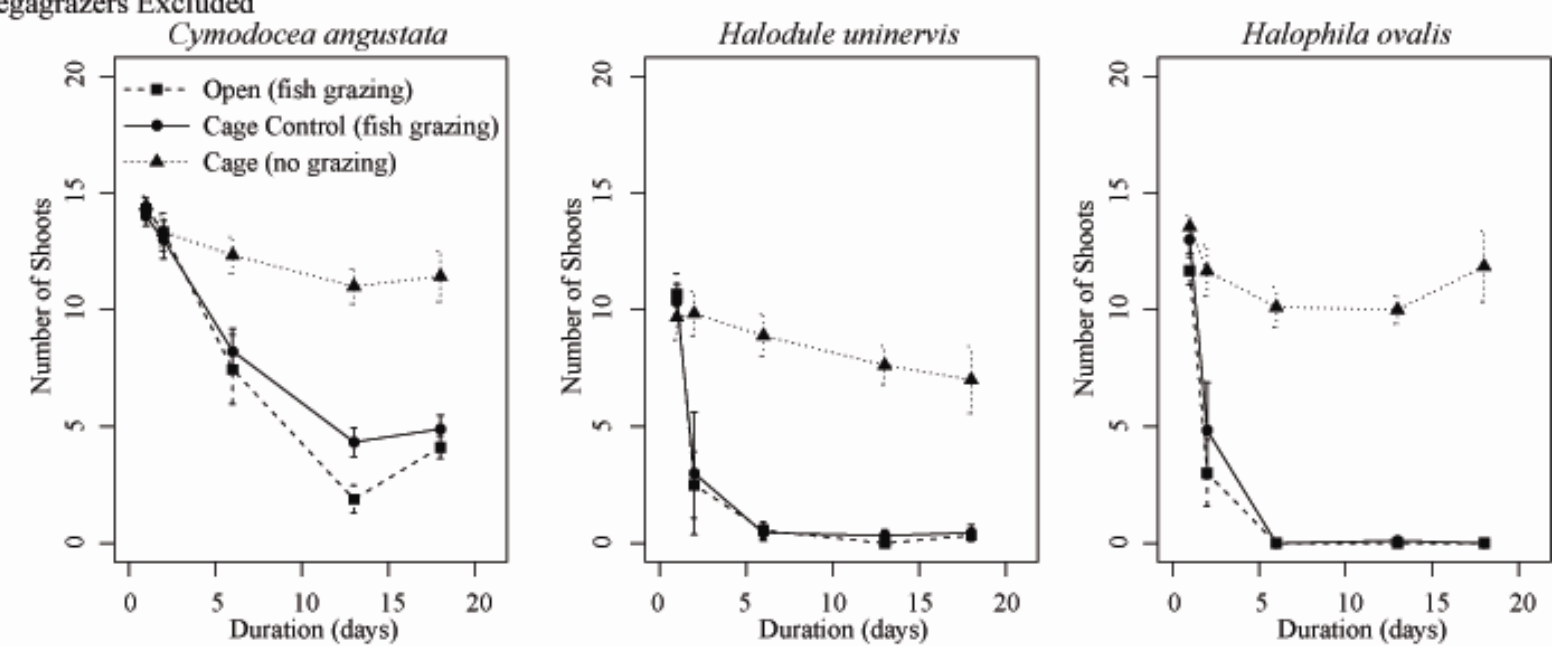
Figure 5.6: Mean seagrass shoot counts for both megagrazer and macrograzer treatments during the short-term exclosure study in the cold season (July 2011). Error bars are \pm SE.
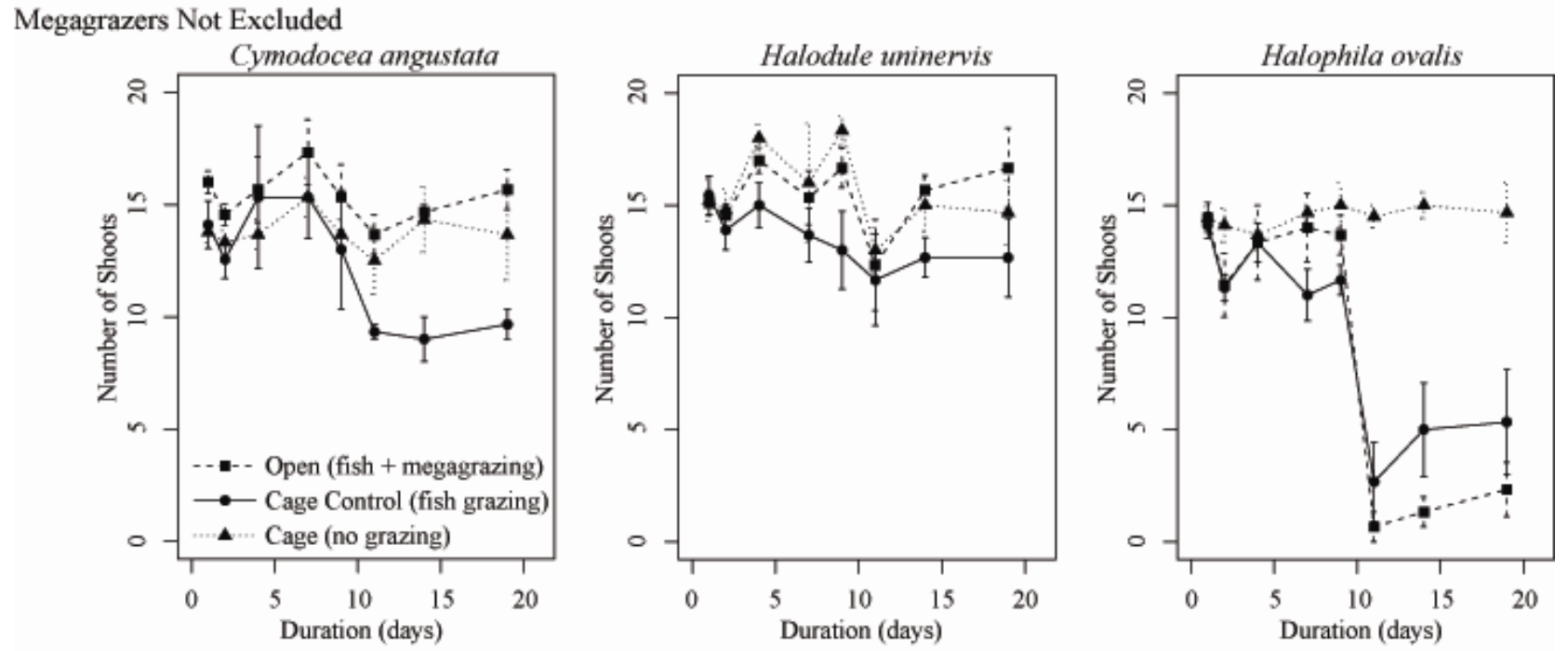

Megagrazers Excluded
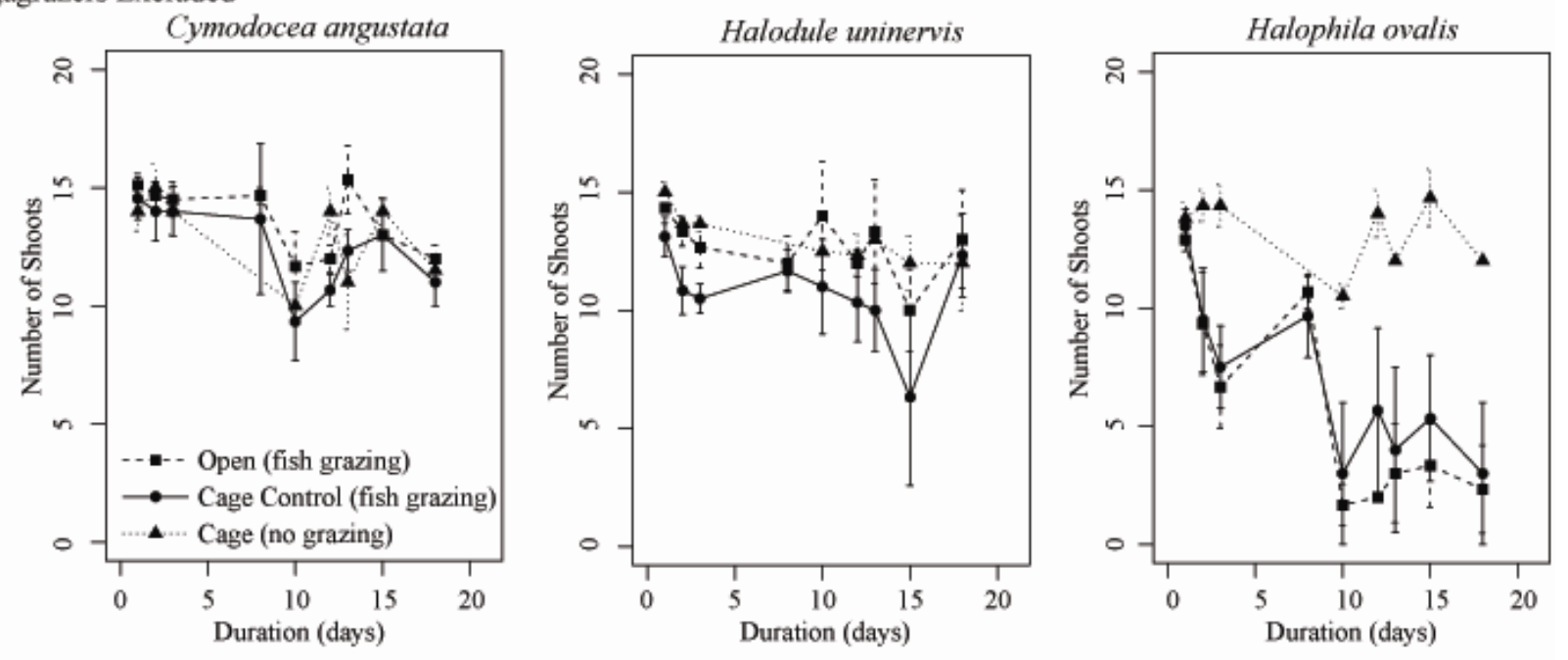


\section{Herbivore Impacts by Grazer Guild}

The proportional change in seagrass shoots attributed to each grazer guild was variable between seagrass species and season (Figure 5.7). During the 4-month exclosure study, the proportional decline in C. angustata could be predominately attributed to megagrazing, however, this species also declined in the absence of all grazing (Figure 5.7a). In contrast, both $H$. uninervis and $H$. ovalis increased by $\sim 1.3$ times in the absence of grazing, and when subjected to grazing, fish accounted for the majority of seagrass loss for both species. During the short-term exclosure study in the warm season, fish grazing accounted for the majority of seagrass loss of all species, with H. uninervis and H. ovalis declining more than C. angustata (Figure 5.7b). Comparatively, during the cold season, grazing had no clear effects on either $C$. angustata or H. uninervis, but did show some evidence for an effect of fish grazing on $\mathrm{H}$. ovalis (Figure 5.7c).

\section{Discussion}

The trophic downgrading of ecosystems has led to trophic cascades across a wide range of ecosystems (e.g. Estes et al. 2011). Our understanding of the mechanisms through which such cascades may (or may not) occur in large scale natural ecosystems, especially those including large-bodied taxa has, however, been hampered by a lack of experimental studies in relatively pristine ecosystems (e.g. Heithaus et al. 2008). My study provides the first data on the relative impacts of megagrazers and fish grazers in a seagrass ecosystem with intact populations of both grazer guilds. In addition, the presence of relatively un-impacted top predator populations makes this study an important ecological baseline for understanding herbivore impacts in seagrass ecosystems, and how they might be structured by behavior-mediated trophic cascades. 
Figure 5.7: Proportional change of seagrass shoot counts during a) the 4-month exclosure study ending in the warm season, b) the short-term exclosure study in the warm season, and c) the short-term exclosure study in the cold season. Error bars are \pm SE. Bars with the same letters are not significantly different based on post-hoc Tukey's test.

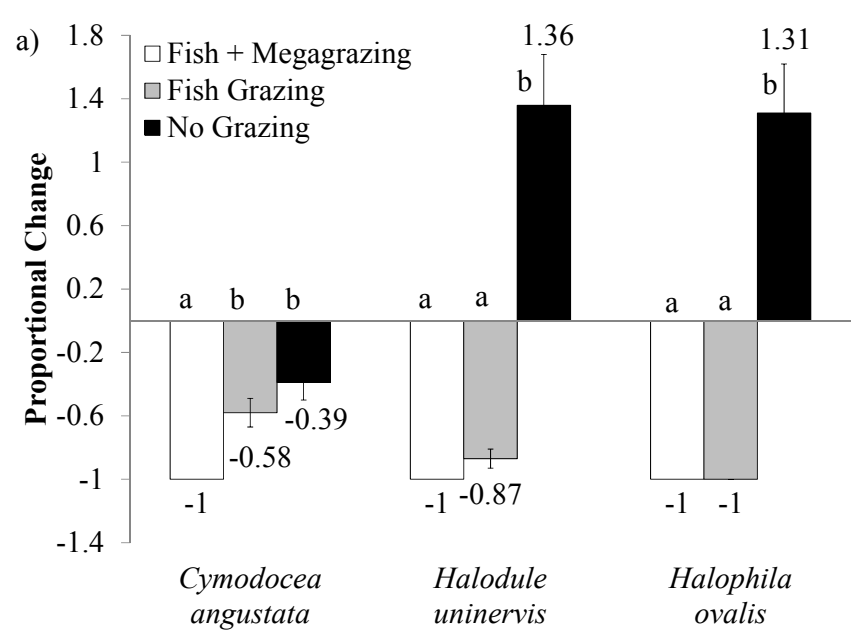




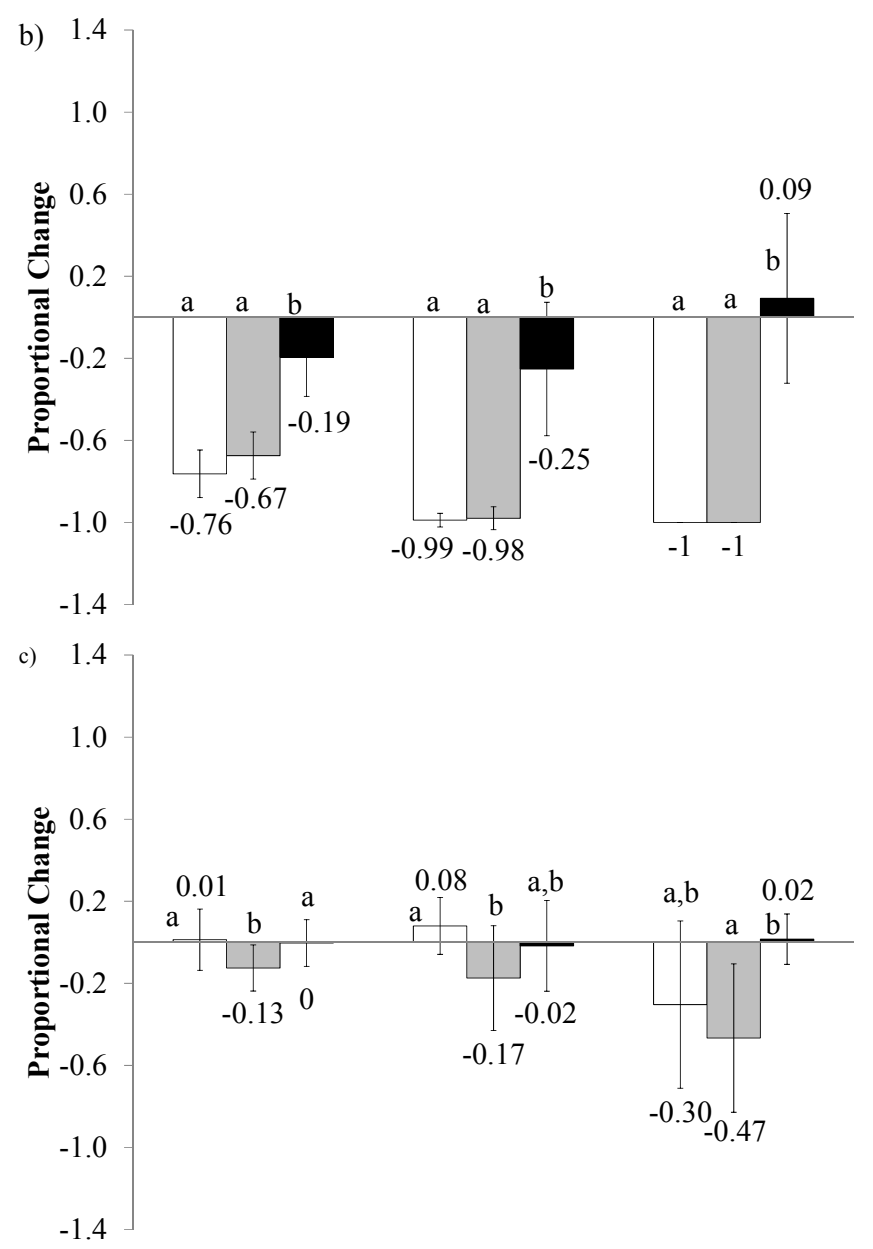


In one of the world's last remaining relatively pristine seagrass ecosystems, I used experimental manipulations to demonstrate that grazers play a critical role in structuring seagrass communities, but impacts are guild-dependent and appear be structured by the presence of top predators. Thus, my study suggests that incorporating an understanding of food web topology (e.g. Wollrab et al. 2012) and behavioral interactions (risk effects) is important for predicting ecosystem responses to top predator removal.

Seagrasses were originally thought to be subject to low levels of herbivory due to their poor nutrient value (owing to high C/N ratios) (Duarte 1990), low digestibility, and overharvesting of large marine herbivores (Thayer et al. 1984). Where grazing by fish had been measured, it was reported that carbon removal to the overall system was low compared to the high daily production of seagrass (Thayer et al. 1984). More recently, however, these ideas have been challenged, suggesting that grazing in seagrass systems has been underestimated due to methodological issues and changes in the abundances of both herbivores and predators in seagrass ecosystems (Valentine and Duffy 2006). Because fish have food-processing mechanisms that optimize energetic supplies from nutrient poor food sources (Ferreira et al. 1998), they are capable of being important herbivores in seagrass ecosystems. Indeed, Heck and Valentine (2006) suggested that future studies of herbivory in seagrass dominated ecosystems should focus on understanding foraging strategies of teleost herbivores. In some locations fish can consume a considerable biomass of seagrass (e.g. $80 \%$ in the Florida Keys: Kirsch et al. 2002, and $73 \%$ off the northeast coast of Spain: Tomas et al. 2005), although this result is not universal (White et al. 2011), suggesting both a temporal and spatial variation in seagrass grazing by fish (Kirsch et al. 2002, White et al. 2011). White et al. (2011) 
found that fish grazing in a temperate seagrass system did not influence the growth and structure of seagrass since biomass removal was small, yet, studies from tropical regions indicate that fish grazing can be a predominate factor. Although these studies indicate grazing in seagrass systems may be more pronounced in tropical versus temperate seagrass systems, a recent review of 613 marine exclusion experiments found no influence of latitude or mean annual water temperatures (Poore et al. 2012). Rather, they found that grazing impacts on plant abundance was better predicted by producer traits. Combined, these studies support the need to further examine fish grazing, and it's variation in contrasting systems, since this trophic pathway may possibly influence the structure of globally declining seagrass systems. As Shark Bay is one of the largest intact seagrass systems in the world, with substantial populations of both mega- and macrograzers, and their predators, it provides a model system to investigate not only the impacts of macrograzers such as fish, but also that of megagrazers, and how the importance of these grazer guilds may differ.

My experiments indicate that grazing by both megagrazers (dugongs and turtles) and macrograzer (fish) guilds limits the establishment of fast-growing species on shallow seagrass banks. During the 4-month study and short-term study in the warm season, both H. uninervis and $H$. ovalis were eliminated or virtually eliminated from all plots that were exposed to fish grazers. In contrast, both species became established and even grew when protected from fish grazing during the 4-month study. Seagrass declines in cage control subplots were similar to those in open subplots suggesting there was little effect from the presence of the cage structure during the warm season. Furthermore, my observations of open subplots confirmed the presence of bite marks in seagrass shoots, 
and rhizomes in the sediment, suggesting that herbivory, rather than tidal movement or current had displaced the transplanted seagrasses. Nevertheless, the presence of cages provided structure in a system with relatively little structure, which potentially could be used by herbivore predators as a safe site. Indeed, I observed many flathead fish in the cages on several visits, and in one case, even a small shark. It is possible that open subplots were grazed at a slightly lower rate in the cold season because of the potential presence of more inconspicuous herbivore predators. Although fish grazing accounted for the majority of seagrass loss for both H. uninervis and H. ovalis during the warm season, megagrazing accounted for the majority of seagrass loss for $C$. angustata during the 4-month exclosure study. Indeed, all seagrass species in open subplots with megagrazer access were eliminated. Comparatively, seagrass shoots in open subplots under megagrazer exclosures maintained low densities. Nevertheless, these results should be interpreted cautiously as there was no obvious effect on $H$. ovalis, or $H$. uninervis, and C. angustata declined even in the absence of all grazers. It is possible that physical features of the banks may limit the persistence of C. angustata more than herbivory, although, a similar study conducted in the study area found this species did become established in the absence of megagrazers (Burkholder et al. 2013b). H. ovalis was the preferred species by fish grazers, followed by H. uninervis. Burkholder et al. (2012) also found these particular seagrass species to be the most highly grazed. For these preferred forage species, my removal studies indicate, that even if they were to become established, fish grazing has the capacity to eliminate them from shallow seagrass banks. This is consistent with observations that tropical seagrass species are rare, and ephemeral, on shallow seagrass banks in the study area (Burkholder et al. 
2013a). Interestingly, during the cold season, the impacts of grazing were greatly reduced, yet fish grazers maintained a preference for H. ovalis.

Grazing impacts appear to vary temporally which raises the possibility that grazer impacts - at least by fishes - may be structured by impacts of predators. Predationsensitive foraging of herbivores within the Shark Bay study site would predict fish grazers to have greater impacts on forage species during the warm season. Like megagrazers, dolphins (a major piscivore in the study area) largely abandon the interior portions of banks during the warm months to minimize the risk of predation from tiger sharks (Heithaus and Dill 2006), thus allowing herbivorous fishes to forage more freely. As a result, fish should have larger impacts on fast-growing seagrass species than megagrazers during warm months. In contrast, during the cold months, fish predators can forage in interior seagrass banks with reduced risk from tiger shark predators. Although fish are still present over dense $A$. antarctica beds within interior habitats at this time (Heithaus 2004), fish should be less willing to move out of the protective cover of $A$. antarctica to forage in open habitats. I would not expect considerable megagrazer impacts during the winter because 1) dugong abundances are low during the lowest-risk times of the year and 2) green turtles greatly reduce their foraging rates as water temperatures decline (Thomson et al. unpublished results). My results are consistent with the predictions of a behavior-mediated trophic cascade, where increased impacts on all three fast-growing species were observed during the warm season. It is important to mention, however, that metabolic demands of fishes are also influenced by body mass, temperature and activity levels, which may also influence grazing impacts (Killen et al. 2010). Nevertheless, the idea that top-down processes and trophic cascades may be 
important regulatory processes has been the focus of extensive studies (Estes et al. 2004) and is well documented on relatively small spatial scales (Schmitz et al. 2000, 2004), yet particular examples still cause considerable debate (Kauffman et al. 2010).

Although previous studies have demonstrated the potential impacts of particular marine herbivore guilds on seagrass in isolation (Preen 1995, Kirsch et al. 2002, Moran and Bjorndal 2005, Tomas et al. 2005), our understanding of the relative importance of different guilds has been hampered by lack of studies in intact ecosystems where multiple herbivore guilds act simultaneously (Valentine and Heck 2006). The importance of herbivory could be attenuated or amplified if grazers are overexploited or are rebounding or released from risk. A recent terrestrial study conducted in South Africa found both mega- and mesoherbivores in combination could impact forest regeneration (Lagendijk et al. 2011). Some marine studies have considered the differential effects of various grazer guilds, but their primary focus is invertebrate mesograzers and fish in algal systems, or in one instance a simulated eelgrass environment (Hay and Taylor 1985, Duffy et al. 2003, Fox 2004, Matthiessen et al. 2007, Bruno et al. 2008, Vanderklift et al. 2009, Ceccarelli et al. 2011). My experiments provide in situ experimental data in an intact seagrass system enabling the investigation of guild-dependent differences that incorporate the potential effects of both mega- and macrograzers simultaneously, and indicate that guild dependent effects are both forage species, and herbivore species specific.

Understanding the role of herbivory and how different herbivore guilds, that have been subject to different histories of exploitation, may impact primary producer communities is becoming increasingly important in order to protect, or restore, crucial habitats from increasing anthropogenic pressures (Ceccarelli et al. 2011). Among these 
threatened habitats are seagrasses, which provide an estimated $\$ 1.9$ trillion per year in ecosystem services in the form of nutrient cycling, enhancement of coral reef fish production, habitat for thousands of organisms including several endangered species, in addition to being a globally significant carbon source (Waycott et al. 2009, Fourqurean et al. 2012). To date, the importance of multiple grazer guilds in intact systems has remained elusive. However, my experiments, have provided some of the first in situ data on the relative importance of multiple herbivore guilds in structuring an intact seagrass community, and provide a foundation for elucidating the ecological role of diverse herbivores on the dynamics of seagrass beds in general.

More generally, this study suggests that behavior-mediated trophic cascades initiated by highly mobile top predators may be important in structuring primary producer communities. By extension, the overexploitation of top predators has a high potential to disrupt ecosystems through multiple mechanisms, and conservation strategies should not only take into account the potential for behavior-mediated trophic cascades but of restoring top predator populations to densities necessary to preserve such interactions.

\section{References}

Aragones, L.V., I.R. Lawler, W.J. Foley, and H. Marsh. 2006. Dugong grazing and turtle cropping: grazing optimization in tropical seagrass systems? Oecologia. 149: 635647.

Bruno, J.F., K.E. Boyer, J.E. Duffy, and S.C. Lee. 2008. Relative and interactive effects of plant and grazer richness in a benthic marine community. Ecology 89(9): 2518-2528.

Burkepile, D.E., and M.E. Hay. 2006. Herbivore vs. nutrient control of marine primary producers: context-dependent effects. Ecology 87(12): 3128-3139.

Burkepile, D.E., and M.E. Hay. 2008. Herbivore species richness and feeding 
complementarity affect community structure and function on a coral reef. P. Natl. Acad. Sci. USA. 105(42): 16201-16206.

Burkholder, D. A., J. A. Fourqurean, and M. R. Heithaus. 2013a. Spatial pattern in seagrass stoichiometry indicates both N-limited and P-limited regions of a subtropical bay. Mar. Ecol. Prog. Ser., 472: 101-115.

Burkholder, D. A., M. R. Heithaus, J. W. Fourqurean, A. Wirsing, and L. M. Dill. 2013 b. Patterns of top-down control in a seagrass ecosystem: could a roving apex predator (Galeocerdo cuvier) induce a behavior-mediated trophic cascade? J. Anim. Ecol. In press.

Burkholder, D. A., M.R. Heithaus, and J.A. Fourqurean. 2012. Feeding preferences of herbivores in a relatively pristine subtropical seagrass ecosystem. Mar. Freshw. Res., 63: 1051-1058.

Ceccarelli, D.M., G.P. Jones, and L.J. McCook. 2011. Interactions between herbivorous fish guilds and their influence on algal succession on a coastal coral reef. J. Exp. Mar. Biol. Ecol. 399:60-67.

Connolly, R.M. 1994. A comparison of fish assemblages from seagrass and unvegetated areas of a southern Australian estuary. Aust. J. Mar. Freshw. Res. 45: 1033-1044.

Cry, H., and M.L. Pace. 1993. Magnitude and patterns of herbivory in aquatic and terrestrial ecosystems. Nature 361: 148-150.

Duarte, C.M. 1990. Seagrass nutrient content. Mar. Ecol. Prog. Ser. 67: 201-207.

Duffy, J.E. 2003. Biodiversity loss, trophic skew and ecosystem functioning. Ecol. Lett. 6:680-687.

Duffy, J.E., J.P. Richardson, and E.A. Canuel. 2003. Grazer diversity effects on ecosystem functioning in seagrass beds. Ecol. Lett. 6:637-645.

Estes, J.A., E.M. Danner, D.F. Doak, B. Konar, A.M. Springer, P.D. Steinberg, M.T. Tinker, and T.M. Williams. 2004. Complex trophic interactions in kelp forest ecosystems. Bull. Mar. Sci. 74(3):621-638.

Estes, J.A., J. Terborgh, J.S. Brashares, M.E. Power, J. Berger, W.J. Bond, S.R. Carpenter, T.E. Essington, R.D. Holt, J.B.C. Jackson, R.J. Marquis, L. Oksanen, T. Oksanen, R.T. Paine, E.K. Pikitch, W.J. Ripple, S.A. Sandin, M. Scheffer, T.W. Schoener, J.B. Shurin, A.R.E. Sinclair, M.E. Soule, R. Virtanen, and D.A. Wardle. 2011. Trophic downgrading of planet earth. Science 333:301-306.

Ferreira, C.E.L., A.C. Peret, and R. Coutinho. 1998. Seasonal grazing rates and food processing by tropical herbivorous fishes. J. Fish Biol. 53(A):222-235. 
Fourqurean, J.W., C.M. Duarte, H. Kennedy, N. Marba, M. Holmer, M.A. Mateo, E.T. Apostolaki, G.A. Kendrick, D. Krause-Jensen, K.J. McGlathery, O. Serrano. 2012. Seagrass ecosystems as a globally significant carbon stock. Nature Geosci. 5(7): 505509.

Fox, J.W. 2004. Effects of algal and herbivore diversity on the partitioning of biomass within and among trophic levels. Ecology 85(2): 549-559.

Griscom, B., H. Griscom, and S. Deacon. 2011. Species-specific barriers to tree regeneration in high elevation habitats of West Virginia. Restor. Ecol. 19(5): 660-670.

Gruner, D.S., J.E. Smith, E.W. Seabloom, S.A. Sandin, J.T. Ngai, H. Hillebrand, W.S. Harpole, J.J. Elser, E.E. Cleland, M.E.S. Bracken, E.T. Borer, and B.M. Bolker. 2008. A cross-system synthesis of consumer and nutrient resource control on producer biomass. Ecol. Lett. 11: 740-755.

Harrold, C., and D.C. Reed. 1985. Food availability, sea urchin grazing, and kelp forest community structure. Ecology 66: 1160-1169.

Hay, M.E., and P.R. Taylor. 1985. Competition between herbivorous fishes and urchins on Caribbean reefs. Oecologia 65: 591-598.

Heck, K.L.Jr, G. Hays, and R.J. Orth. 2003. Critical evaluation of the nursery role hypothesis for seagrass meadows. Mar. Ecol. Prog. Ser. 253: 123-136.

Heck, K.L.Jr., and J.F. Valentine. 2006. Plant-herbivore interactions in seagrass meadows. J. Exp. Mar. Biol. Ecol. 330: 420-436.

Heithaus, M.R. 2004. Fish communities of subtropical seagrass meadows and associated habitats in Shark Bay, Western Australia. Bull. Mar. Sci. 75(1): 79-99.

Heithaus, M.R., and L.M. Dill. 2006. Does tiger shark predation risk influence foraging habitat use by bottlenose dolphins at multiple spatial scales? Oikos. 114: 257-264.

Heithaus, M.R., A. Frid, A.J Wirsing, L. Bejder, and L.M. Dill. 2005. The biology of green and loggerhead turtles under risk from tiger sharks at a foraging ground. Mar. Biol. 147: $27-35$.

Heithaus, M.R., A. Frid. A.J. Wirsing, L.M. Dill, J. Fourqurean, D. Burkholder, J. Thomson, and L. Bejder. 2007. State-dependent risk-taking by green sea turtles mediates top-down effects of tiger shark intimidation in a marine ecosystem. J. Anim. Ecol., 76: 837-844.

Heithaus, M.R., A. Frid, A.J. Wirsing, and B. Worm. 2008. Predicting ecological consequences of marine top predator declines. Trends. Ecol. Evol. 23(4): 202-210. 
Heithaus, M.R., A.J. Wirsing, and L.M. Dill. 2012. The ecological importance of intact top-predator populations: a synthesis of 15 years of research in a seagrass ecosystem.

Mar. Freshw. Res., 63(11): 1039-1050.

Jackson, J.B.C., M.X. Kirby, W.H. Berger, K.A. Bjornadal, L.W. Botsford, B.J. Borque, R.H. Bradbury, R. Cooke, J. Erlandson, J.A. Estes, T.P. Hughes, S. Kidwell, C.B. Lange, H.S. Lenihan, J.M. Pandolfi, C.H. Peterson, R.S. Steneck, M.J. Tegner, and R.R. Warner. 2001. Historical overfishing and the recent collapse of coastal ecosystems. Science 146: 629-638.

Kauffman, M.J., J.F. Brodie, and E.S. Jules. 2010. Are wolves saving Yellowstone's aspen? A landscale-level test of a behaviorally mediated trophic cascade. Ecology 91(9): $2742-2755$.

Kawamata, S. 1998. Effect of wave-induced oscillatory flow on grazing by a subtidal sea urchin Strongylocentrotus nudus (A. Agassiz). J. Exp. Mar. Biol. Ecol. 224: 31-48.

Killen, S,S., D. Atkinson, and D.S. Glazier. 2010. The intraspecific scaling of metabolic rate with body mass in fishes depends on lifestyle and temperature. Ecol. Lett. 13: 184193.

Kirsch, K.D., J.F. Valentine, and K.L.Jr. Heck. 2002. Parrotfish grazing on turtlegrass Thalassia testudinum: evidence for the importance of seagrass consumption in food web dynamics of the Florida Keys National Marine Sactuary. Mar. Ecol. Prog. Ser. 227: 7185.

Lagendijk, D.D.G., R.L. Mackey, B.R. Page, and R. Slotow. 2011. The effects of herbivory by a mega- and mesoherbivore on tree recruitment in Sand Forest, South Africa. PLoS ONE 6(3): e17083.

MacLean, J.E., J.R. Goheen, D.F. Doak, T.M. Palmer, and T.P. Young. 2011. Cryptic herbivores mediate the strength and form of ungulate impacts on a long-lived savanna tree. Ecology 92(8): 1626-1636.

Masini, R.J., P.K. Anderson, and A.J. McComb. 2001. A Halodule-dominated community in a subtropical embayment: physical environment, productivity, biomass, and impact of dugong grazing. Aquat. Bot. 71: 179-197.

Matthiessen, B., L. Gamfeldt, P.R. Jonsson, and H. Hillebrand. 2007. Effects of grazer richness and composition on algal biomass in a closed and open marine system. Ecology 88(1): 178-187.

Moran, K.L., and K.A. Bjorndal. 2005. Simulated green turtle grazing affects structure and productivity of seagrass pastures. Mar. Ecol. Prog. Ser. 305: 235-247. 
Nakaoka, M., H. Mukai, and S. Chunhabundit. 2002. Impacts of dugong foraging on benthic animal communities in a Thailand seagrass bed. Ecol. Res. 17: 625-638.

Pauly, D., V. Christensen, J.Dalsgaard, R. Froese, and F.Jr. Torres. 1998. Fishing down marine food webs. Science. 279: 860-863.

Phillips, R.C., and C.P. McRoy. 1980. Handbook of seagrass biology: an ecosystem perspective. Garland Publishing, Inc., New York.

Poore, A.G.B., Campbell, A.H., Coleman, R.A., Edgar, G.J., Jormalainen, V., Reynolds, P.L. et al. (2012). Global patterns in the impact of marine herbivores on benthic primary producers. Ecol. Lett., 15, 912-922.

Post, E., and C. Pedersen. 2008. Opposing plant community responses to warming with and without herbivores. Proc. Natl. Acad. Sci. U.S.A. 105: 12353-12358.

Preen, A.R. 1995. Impacts of dugong foraging on seagrass habitats: observational and experimental evidence for cultivation grazing. Mar. Ecol. Prog. Ser. 124: 201-213.

Preen, A.R., H. Marsh, and I.R. Lawler. 1997. Distribution and abundance of dugongs, turtles, dolphins and other megagauna in Shark Bay, Ningaloo Reef and Exmouth Gulf, western Australia. Wildlife Res. 24(2): 185-208.

R Development Core Team, 2011. R: A Language and Environment for Statistical Computing. R Foundation for Statistical Computing. Available: http://www.Rproject.org/. ISBN: 3-900051-07-0.

Ripple, W.J., and R.L. Beschta. 2003. Wolf reintroduction, predation risk, and cottonwood recovery in Yellowstone National Park. Forest. Ecol. Manag. 184(1-3): 299-313.

Schmitz, O.J., A.P. Hamback, and A.P. Beckerman. 2000. Trophic cascades in terrestrial systems: a review of the effects of carnivore removal on plants. Am. Nat. 155: 141-153.

Schmitz, O.J., V. Krivan, and O. Ovadia. 2004. Trophic cascades: the primacy of trait-mediated indirect interactions. Ecol. Lett. 7: 153-163.

Thayer, G.W., K.A. Bjornal, J.C., Odgen, S.L. Williams, and J.C. Zieman. 1984. Role of large herbivores in seagrass communities. Estuaries. 93:366-374.

Tomas, F., X. Turon, and J. Romero. 2005. Seasonal and small-scale spatial variability of herbivory pressure on the temperate seagrass Posidonia oceanica. Mar. Ecol. Prog. Ser. 301: 95-107. 
Vanderklift, M.A., PS. Lavery, and K.I. Waddington. 2009. Intensity of herbivory on kelp by fish and sea urchins differs between inshore and offshore reefs. Mar. Ecol. Prog. Ser. 376: 203-211.

Valentine, J.F., and J.E. Duffy. 2006. The central role of grazing in seagrass ecology. Pages. 463-501 in A.W. Larkum, R.J. Orth, R.J., and M. Duarte, editors. Seagrasses: Biology, Ecology and Conservation. Springer, Netherlands.

Walker, D.I. 1989. Regional studies - seagrass in Shark Bay, the foundation of an ecosystem. Pages. 182-210 in A.W.D. Larkum, A.J. McComb, and S.A. shepherd, editors. Biology of Seagrasses. Elsevier, New York.

Walker, D.I., G.A. Kendrick, and A.J. McComb. 1988. The distribution of seagrass species in Shark Bay, Western Australia, the notes on their ecology. Aquatic. Bot. 30: 205-317.

Waycott, M., C.M. Duarte, T.J.B. Carruthers, R.J. Orth, W.C. Dennison, S. Olyarnik, A. Calladine, J.W. Fourqurean, K.L. Heck Jr., A.R. Hughes, G.A. Kendrick, W.J.

Kenworthy, F.T. Short, and S.L. Williams. 2009. Accelerating loss of seagrasses across the globe threatens coastal ecosystems. Proc. Natl. Acad. Sci. U.S.A. 106(30): 1237712381.

White, K.S., M.B. Westera, and G.A. Kendrick. 2011. Spatial patterns in fish herbivory in a temperate Australian seagrass meadow. Estuar. Coast. Shelf. S. 93:366-374.

Wirsing, A.J., M.R. Heithaus, and L.M. Dill. 2007. Fear factor: Do dugongs (Dugong dugon) trade food for safety from tiger sharks (Galeocerdo cuvier)? Oecologia 153: 1031-1040.

Wollrab, S., S. Diehl, and A. M. De Roos. 2012. Simple rules describe bottom-up and top-down control in food webs with alternative energy pathways. Ecol. Lett. 15: 935946. 
CHAPTER VI:

GENERAL CONCLUSIONS 
Globally, marine grazers are widely recognized as being able to exert considerable top-down impacts on primary producers, but the relative strength of topdown control varies markedly among grazer types and primary producer taxa (Poore $e t$ al. 2012). Meta-analyses of experimental manipulations in seagrass ecosystems have suggested that teleost grazer impacts are small relative to other taxa (Poore et al. 2012), but these analyses are based on few studies. In fact, some studies indicate that teleost grazers can consume substantial proportions of seagrass production (Kirsch et al. 2002; Tomas et al. 2005), and may control the abundance and species composition of seagrasses near patch reefs (Armitage and Fourqurean 2006). Teleost impacts on primary producer communities of reefs can be affected by a myriad of factors, including the identity of different herbivores in the community and their interactions, food availability, predation risk, and recruitment (Harrold and Reed 1985, Cry and Pace 1993, Hugie and Dill 1994, Vanderklift et al. 2009). This is likely to also be true in seagrass ecosystems. Complicating matters in these ecosystems, however, is the need to understand the relative importance of multiple grazer guilds, such as megagrazers and fishes, in areas where grazer species have not been dramatically reduced (Pauly et al. 1998, Jackson et al. 2001).

I used the relatively pristine seagrass ecosystem of Shark Bay, Western Australia as a model system to understand the ecological role of an abundant herbivorous teleost (Pelates octolineatus) and how this role might be affected by top-down processes. In Chapter II, I investigated spatial and temporal variation in the diets of Pelates octolineatus using both stomach contents and stable isotope analysis and documented spatial variation in potential food sources. Seagrass and macroalgae made up the 
majority of stomach contents of $P$. octolineatus, which were consumed in similar proportions. I did not find any differences in the overall amount of food consumed (gut content to body weight ratio) by fish caught in edge or interior seagrass microhabitats, although I did find that fish caught in edge microhabitats had a higher proportion of seagrass relative to algae in their stomachs. Fast-growing and small-bodied seagrass species are the preferred forage item of these teleost fish (Burkholder et al. 2012, Chapter V), which are more abundant in edge microhabitats. (Burkholder et al. 2013) There was some indication that larger fish may consume a greater proportion of seagrasses compared to algae than smaller fish. Isotopic values of $P$. octolineatus suggested that algae may contribute a larger portion of assimilated food across both microhabitats than would be inferred by gut contents. Algae, therefore, may be a more important food source than suggested by standing stocks and stomach contents, but ingestion rates and impacts of $P$. octolineatus on seagrasses may be underestimated by stable isotopic approaches.

Since predation risk can structure the spatial and temporal patterns and strength of herbivore impacts on primary producer communities, in Chapter III, I used tethering trials to identify possible predators of $P$. octolineatus and gain insights into predator encounter rates. I found that fish were more likely to be removed during the warm season and most were taken by pied cormorants (Phalacrocorax varius). This, combined with data from belt transects, suggests that risk from pied cormorants during my study likely was higher during the warm season, which contrasts with seasonal patterns of cormorant abundance documented previously (Heithaus 2005). Unfortunately, it remains unclear how commonly pied cormorants prey upon free-swimming $P$. octolineatus, and the overall 
risk from cormorants relative to other known trumpeter predators, like IndoPacific bottlenose dolphins (Tursiops aduncus) not observed taking tethered fish during the study.

Patterns of habitat use and abundance are central to understanding the potential impacts of herbivores on primary producer communities. In Chapter IV, I investigated the relative abundance of $P$. octolineatus, and another opportunistic herbivore (Monachanthus chinensis) in dense seagrass habitats found in the middle of banks (“interior" microhabitats) and along bank edges. Continuous underwater video surveillance data found that the number of $P$. octolineatus was relatively greater in interior areas of seagrass banks during the cold season, and that the mean length of $P$. octolineatus was greater for fish caught in interior compared to edge microhabitats. Dense seagrass likely provides a refuge from predators through reduced detectability and hiding places. In addition, dense seagrass sites may even provide increased food sources through increased surface area for epiphytic algae and invertebrates, which was not specifically investigated during my current studies.

Predictions regarding potential future changes to marine ecosystems in the face of overfishing and other stressors could be enhanced by gaining insights into the dynamics of communities with intact predator populations and grazer populations from multiple guilds. In chapter V, I used exclosure - transplant experiments to investigate the relative impacts of megagrazers (dugongs and sea turtles) and macrograzers (mainly fishes) in structuring an intact seagrass system. Results from these experiments suggested that both megagrazers and teleost fish grazing affected the establishment and persistence of three species of seagrasses. However, fish grazing had the largest impacts on seagrass species 
with the highest nutrient content, but primarily during warm months. These findings were consistent with predictions based on a behavior-mediated trophic cascade initiated by tiger sharks and transmitted through teleost grazers and their predators. Since both megagrazers and dolphins largely abandon the interior portions of banks during the warm months to minimize the risk of predation from tiger sharks (Heithaus and Dill 2006), this may allow herbivorous fishes to forage more freely. As a result, fish grazers should have larger impacts on fast-growing seagrasses than megagrazers during warm months. In contrast, during the cold months, fish are still present in the dense seagrass beds of the interior habitats but may not forage as freely in the more open areas that characterize locations on banks where fast-growing species are found and where exclosures were located. This is because teleost predators can forage more readily in interior seagrass banks because of reduced risk from tiger shark predators.

Overall, my studies provided critical first steps towards understanding the potential effects of abundant teleost grazers on seagrass ecosystems. Furthermore, I provided evidence that behavior-mediated trophic cascades involving teleost grazers likely are important in structuring communities, but food web structure may be important for determining the strength of these cascades. For pathways involving teleost grazers in seagrass ecosystems, further studies are required to obtain an understanding of food selection and gain a functional understanding of habitat use (e.g. effects of food abundance and quality, predation risk, reproductive considerations). In addition, specific studies investigating drivers of population regulation (e.g. recruitment limitation, food limitation, predation regulation) would also be beneficial. 


\section{References}

Cry, H., and M.L. Pace. 1993. Magnitude and patterns of herbivory in aquatic and terrestrial ecosystems. Nature 361: 148-150.

Davis, A.M., P.J. Unmack, B.J. Pusey, J.B. Johnson, and R.G. Pearson. 2012. Marinefreshwater transitions are associated with the evolution of dietary diversification in terapontid grunters (Teleostei: Terapontidae). J. Evol. Biol. 25: 1163-1179.

Harrold, C., and D.C. Reed. 1985. Food availability, sea urchin grazing, and kelp forest community structure. Ecology 66: 1160-1169.

Heithaus, M. R. 2005. Habitat use and group size of pied cormorants (Phalacrocorax varius) in a seagrass ecosystem: possible effects of food abundance and predation risk. Mar. Biol. 147: 27-35.

Hugie, D.M, and L.M. Dill. 1994. Fish and game - a game theoretic approach to habitat selection by predators and prey. J. Fish. Biol. 45: 151-169.

Kirsch, K.D., J.F. Valentine, and K.L.Jr. Heck. 2002. Parrotfish grazing on turtlegrass Thalassia testudinum: evidence for the importance of seagrass consumption in food web dynamics of the Florida Keys National Marine Sactuary. Mar. Ecol. Prog. Ser. 227: 7185.

Tomas, F., X. Turon, and J. Romero. 2005. Seasonal and small-scale spatial variability of herbivory pressure on the temperate seagrass Posidonia oceanica. Mar. Ecol. Prog.

Ser. 301: 95-107.

Vanderklift, M.A., PS. Lavery, and K.I. Waddington. 2009. Intensity of herbivory on kelp by fish and sea urchins differs between inshore and offshore reefs. Mar. Ecol. Prog. Ser. 376: 203-211. 
VITA

\section{CINDY BESSEY}

EDUCATION
$1996-1999$
B.Sc., Marine Biology
Simon Fraser University
$2000-2003$
M.Sc., Zoology
University of British Columbia Title: Reproductive performance of growth-enhanced transgenic coho salmon (Oncorhynchus kisutch).
2009 - Present
PhD Candidate, Biology Florida International University Title: The role of teleost grazers in a relatively pristine seagrass ecosystem.

\section{PUBLICATIONS}

Heithaus, M.R., J.J. Vaudo, S. Kreicker, M. Krützen, C.A. Layman, D.A. Burkholder, K. Gastrich, C. Bessey, R. Sarabia, K. Cameron, A. Wirsing, J. Thomson, M. M. DunphyDaly. 2013. Apparent resource partitioning and trophic structure of large-bodied marine predators in a relatively pristine seagrass ecosystem. Marine Ecology Progress Series. doi: $10.3354 / \operatorname{meps} 10235$

Norton,J.G., J.E. Mason, C. Bessey, and S.F. Herrick, Jr. 2011. Physical, biological and economic interconnections in the ecosystems and fisheries off California, 1877-2004. Quaternary International. doi: 10.1016〉j.quaint.2011.10.041

Watters G.M. and C. Bessey. 2008. Variation in the probability that male coho salmon (Oncorhynchus kisutch) will mature early: inferences from hierarchical models. Transactions of the American Fisheries Society. 137:70-95. doi: 10.1577/T06-101.1

Herrick, S.F.Jr., J.G. Norton, J.E. Mason, and C. Bessey. 2007. Management application of an empirical model of sardine-climate regime shifts. Marine Policy. 31(1):71-80. doi: 10.1016/j.marpol.2006.05.005

Bessey, C., R.H. Devlin, N.R., Liley, and C.A. Biagi. 2004. Reproductive performance of growth-enhanced transgenic coho salmon (Oncorhynchus kisutch). Transactions of the American Fisheries Society. 133(5):1205-1220. doi: 10.1577/T04-010.1

\section{MANUSCRIPTS IN REVISION}

Bessey, C., and M.R. Heithaus. 2013. Alarm call production and temporal variation in predator encounter rates for a facultative teleost grazer in a relatively pristine seagrass ecosystem. Journal of Experimental Marine Biology and Ecology. 
TEACHING

2000

Invertebrate Biology Laboratory Instructor

University of British Columbia

Vancouver, British Columbia

2013

Human Anatomy - Online Laboratory Instructor

Florida International University

Miami, Florida

AWARDS

2005

Robert L. Kendall Award, Best Paper

Transactions of the American Fisheries Society

2005

Stevan R. Phelps Award, Best Genetics Paper

Transactions of the American Fisheries Society

SERVICE

2003

$6^{\text {th }}$ Annual American Association of University Woman California State University of Monterey Bay Girls Science and Math Conference, California State University

2009

Sea Lion Bowl

Romberg Tiburon Center for Environmental Studies

San Francisco State University

San Francisco, California

2010-2012

Shark Bay Ecosystem Research Project

Monkey Mia, Western Australia

2010

Carmel Middle School

Carmel, California

2011

Undergraduate Career Day

Florida International University

North Miami, Florida

2011

Winchester Thurston School

Pittsburgh, Pennsylvania

2011

EcoEducation Shark Bay Professional Learning Department of Environment and Conservation

Shark Bay, Western Australia 